\title{
Von Kurkölns Beziehungen zu Frankreich und seiner wirtschaftlichen Lage im Siebenjährigen Kriege (1757-1761).
}

Von

Constantin Becker.

\section{Der Subsidienvertrag Kurkölns mit Frankreich. --} Der Vormarsch der Franzosen. - Kurkölns Neutralität.

Der Kölner Kurfïrst, Herzog Clemens August von Bayern, stand wie die meisten Fürsten der westleutschen Kleiustaaten im siebenjährigen Kriege auf Seiten des mit Österreich verbündeten Frankreicb. Man kann nicht sagen, dass er aus Überzeugung oder Begeisterung diese Stellung eingenommen hat ${ }^{1}$ ). Die Politik seiner langjährigen Freunde, der Franzosen, zwang ihn einfach da\%u. Nicht umsonst war seit langem anf Grund von Verträgen französisches Gold in die Kassen des vergnügungsfroben Fürsten geflossen.

Anscheinend will Huppertz ${ }^{2}$ ) an der bisher allgemein geltenden Annahme, es habe \%wischen Kurköln und Frankreich ein Subsidienvertrag bestanden ${ }^{3}$ ), rütteln. Genauere Mitteilungen über derartige

1) Becker, Constantin, Die Politik Kurkölns zu Beginn des 7jälır. Krieges. Diss. Bonn 1910.

2) Huppertz, Aeg. (Münster im 7jähr. Kriege; Münster 1908, S. 63 Anui, 5) nimmt au, Clemens August habe Subsidien bezogen, ohuc Truppen stellen zu müssen -- auf Grund welcher Akten sagt er nicht - bezweifelt aber, dass ein Vertrag geschlossen war.

3) Ranke, L. v., Zur Gesch. von Osterr. und Preussen. I,eipz 1875. Saintl. Werke Bd. XXX, S. 293, 307. - Erhard, H. A., Geschichte Münsters. Münster 1837, S. 585. - Stuhr, P. F., Forschungen und Eiläuterungen ïber Hauptpunkte des 7jähr. Krieges. Hamburg 1842. Teil I, S. 104.Schäfer, Gesehichte des 7 jähr. Krieges. Berlin 1870. Bd. I, S. 269. - 
Verträge macht nur Ennen "). Demuach verpflichtete sich der Kurfürst am 1. März 1751 gegen jährlich 270000 Florin (Flor.) im Falle eines Krieges 6000 Mann für Frankreich zu stellen. Dieser Vertrag, der am 26. Dezember 1753 ernenert worden war, galt beim Einmarsch der Franzosen in Deutschland nicht mehr. Es zeigt dies ein Brief des kurkölnischen Gesandten am Pariser Hofe, Adam Theodor von Rheen ${ }^{2}$ ), nach Bonn vom 7. Dezember $1758^{3}$ ). Demzufolge war ein Abkommen getroffen, das vom 1. März 1757 bis Ende Februar 1763 dauern sollte und dem Kurfürsten in den beiden ersten Jahren je 300000 Flor., in den vier folgenden je 240000 Flor. zusicherte. Unter welchem Datum der Vertrag getätigt wurde, ob man in Paris - Rheen war 1757 noch uicht Gesandter - oder in Bonn einig wurde, und was für eine Gegenleistung festgelegt war, darüber erfährt man aus dem Schreiben uichts. Im Verlaufe des Krieges wurde der Vertrag, wie wir noch sehen werden, geändert. Wenn weitere Einzelheiten bisher nicht bekannt geworden sind ${ }^{4}$ ), so darf man einen Grund dafür in ibrer wohlgelungeuen absichtlichen Geheimbaltung selien. Dass damit zu rechnen jst, zeigt ein Schreiben der Kaiserin Maria Theresia rom 26. Juli 1756 an ibren Vertreter Starhemberg zu Paris: er solle Genaueres über den Inhalt der von Frankreich geschlossenen Subsidienverträge mitteilen ${ }^{5}$ ). Ob es ihm gelungen ist, dein Wunsche seiner Horrin nachzukommen, ist nicht ersichtlich.

Ein andere Frage ist es nun, ob Clemens Augtist im 7jährigen

Hassell Ed. v., Die schlesischen Kriege und das Kurfürstentum Hannover. Hannover 1879, S. 301. - Bitteraul Th., Die Kurbayrische Politik im 7 jähr. Kriege. München 1901, S. 131. -- Grosser Generalstab, Die Kriege Friedrichs d. Gr. Teil 3, Bd.V, S. 12 f. - Brabant A., Das hl. röm. Reich deutsch. Nation im Kampfe mit Friedrich d. Gr. Berlin 1904. Bd I, S. 134.

1) Ennen, I., Frankreich und der Niederrhein. Köln 1855-56. Bd. II, S. 299 .

2) Der kurkölnische Hofkalender vom Jahre 1760, S. 51 schreibt so und setzt hinzu: „Churf. Hof-Rath, und Chargè d'Affaire“.

3) Königl. Staatsarchiv, Düsseldorf, Kurkölnische Kriegsakten: Fascikel $222^{2}$; zitiert von jetzt ab mit Fasc.

4) In der Recueil des traites de la France von de Clereq sowie der Histoire abregce des Tratis de: l'aix von Koch-Schoch, Paris 1817, Bd. II, III finden sich keine auf Kurköhn be»üglichen Verträge.

5) Publikationen aus den königl. preuss. Staatsarchiven, Bd. 74, S. 486 
Kriege wirklich Truppen an Frankreich gestellt hat. Darin kann ja die Gegenleistung an Frankreich für die gezahlten Geldsummen bestanden haben.

Es hiesse die französische Diplomatie gering einschätzen, wollte man annehmen, sie sei überzeugt gewesen, Clemens August habe die ihm gezablten Subsidienbeträge zum Unterhalt von Truppen verwandt. Der Vertraute des bayerischen Ministers Graf Hasslang, von Wrede, erklärte am 13. August 1750 in Hannover dem französischen Gesandten Valori bei einem Gespräch übcr die Subsidienverträge der deutschen Kleinfürsten: Bayern und Köln würden von dem Gelde Feste und Opern veranstalten, aber keine Soldaten unterhalten ${ }^{1}$ ).

Wie es 1750 war, so war es auch noch zur Zeit des 7 jährigen Krieges. Frankreich, das davon wusste, zahlte dennoch, nur un die Fürsten an sich zu fesseln. Auf ihre Truppen kam es ihm weniger an; dafür scbätzte es deren Leistungsfähigkeit zu gering: ein ${ }^{2}$ ). Zwar erging einer Mitteilung des österreichischen Gesandten Starhemberg aus Paris nach Wien zufolge bei Beginn des Krieges die Aufforderung an Kurköln, die Frankreich unter den obwaltenden Umständen vertraglich zustehenden 6000 Soldaten bereit zu balten ${ }^{3}$ ), doch ist die Nachricht mit Vorsicht aufzunehmen. Entsprach die Forderung dem Abkommen und hatte man sie in Bonn erhoben, so ist damit über die Stellung der Truppen noch gar nichts gesagt. Ebenso bedenklich wäre es, aus der Tatsache, dass in Paris Neigung vorhandeu war, bayerische und kurkölnische Truppen, zu denen man noch das meiste Vertrauen hegte, in französischen Dienst und Sold zu nehmen ${ }^{4}$ ), schliessen zu wollen, dies sei wic mit den bayerischen auch mit den kurkölnischen tatsächlich geschehen.

Woher hätte denn Clemens August diese Truppen nelimen sollen? Die Kriegsakten und Landtagsprotokolle des Erzstiftes wie des Bistums Münster ${ }^{5}$ ) wisseu nur von dem Reichssontingent, dessen Aufstellung und Unterhaltung den Ständen zur Last fiel ${ }^{6}$ ).

1) Mémoires des negociations du Marquis de Valori. Paris 1820, Bd. I, S. 442 .

2) Stuhr a. a. O. Teil I, S. 333.

3) Publikationen a. a. O. Bd, 74, S. 578.

4) Stuhr a. a. O. I, S. $333 . \quad$ 5) Huppert\% a. a. O. S. 63, Anm. 5.

6) Es ist durchaus abzulehnen, wenn Huppertz (S. 63, Anm. 5) 
Wäre es die Absicht des Kurfürsten gewesen, diese Truppen Frankreich zur Verfiigung zu stellen, dann hätte er sich zunächst mit den Ständen einigen müssen. Daran war aber bei deren Alncigung gegen den Krieg nicht zu denken. Erhoben sie ja doch sogar gegen eine Uherlassung kurkölnischer Truppen an Frankreich förmlich Einspruch ${ }^{1}$ ). Sie wussten eben von einem Vertrage und wollten, um allen Möglichkeiten vorzubeugen, ihr Mitverfïgungsrecht uber ibre Landeskinder ganz entschieden betonen. Weun somit keine Truppen in Frage kommen können, die die Landstände zu unterhalten hatten, so kann es sich nur um solche handeln, die Clemens August auf eigene Kosten unterhielt, also nm sogenannte Haustruppen. Deren besass er aber keine. Nirgendwo wird anch nur im geringsten eine Andeutung darüber gemacht. Ans alledem ergibt sich, dass man bisher irrtïmlich annahm ${ }^{2}$ ), Kurköln habe im 7jährigen Kriege Truppen an Frankreich gestellt. Zudem wissen Werke, die auf den Akten des französiscben Kriegsarchivs anfgebant sind, wie die ron Pajol und Waddington, nichts von solchen Truppen. Das Generalstabswerk nimmt allerdings an, die Lente - es kann sich dabei nur um kurkölnische Truppen handeln, nicht um solche Männer, die die Franzosen später selbst vielleicht aushoben - seien in französische Regimenter eingereilit worden ${ }^{3}$. Es ist indes schon sehr fraglich, ob Clemens August, der auf seinen Nanen, seine Würden und T'itel, seine vermeintlich machtvolle Stellung sowie deren Attribute sehr eitel war, nicht entschieden dagegen Verwahrung eiugelegt haben würde und damit auch gewiss ganz im Sinne seiner Untertanen, zumal der betreffenden MannscLaften gehandelt bätte. Nein! Kein einziger KurköIner ist offiziell vom Kurfürsten dem französischen Kommando unterstellt worden. Unbedingt kann man den klaren und deutlieben Worten des kurbraunschweigisch-hannoverschen Gesandten, Frhr.

schon daraus sthliesst, die Subsidien seien deshalb Unterhaltungsgelder der Truppen nicht gewesen. Rechtlich war der Kurfürst doch nicht verpflichtet, das Geld, das ihm als Souverain durch Verträge zufloss, für die Unterhaltung der von Reichswegen zu stellenden Truppen herzugeben, die verfassung'sgemäss von den Ständen zu unterhalten waren.

1) Becker, Diss. a. a. O. S. 24, Anm. 5.

2) Ennen a. a. O. Bd. II, 334. - Oncken W., Zeitalter Friedrichs d. Gr. Berlin 1880-82, Bd. II, S. 141.

3 Gross. Generalst. a. a. O. Bd. V, S. 13: Anlage 10. 
von Gemmingen, Glauben schenken, als er au 30 . Oktober 1758 zu Regensburg von den Verwtistungen der liranzosen im Jahre 1757 in den Landen seincr Gebieter sprach: „Des Churfursten zu Kölı und der Bischofs zu Luttich ') Durchl. Durchl. hatten keine Truppen, deren man bey der Französischeu Armee bedurfte. Für die geniessenden Subsidien öfueten sie ilı aber in ibren Landen Thür und Thor, und thaten derselben allen möglichen Vorschni" ${ }^{2}$ ).

Schon im Herbst des Jahres 1755 waren von Paris aus mit den Kurfürsteu von Köln und der Pfalz Verbandlungen wegen der Anlage von Magazinen im Westfälisehen und der Aufnahme französischer Truppen im Herzogtum Jülich angeknüpft worden ${ }^{3}$ ). Nachdem sich dann die Verhältnisse geklärt hatten, die Frankreich zuletzt an die Seite Osterreichs fesselten, trat man diesem in Versailles trotz des eigueu sehnlichen Wunsches, den englischen König in seiuen Stammlanden anzugreifen ${ }^{4}$ ), zurückhaltend gegenüber. Osterreich erhielt auf seine Frage, ob ein französisches Heer in Westfalen einrücken werde, um Hannover zu bedrohen, den Kurfürsten von Köln sowic Gleichgesinnte zu beruligen und andere Fursten an der Unterstlitzung Friedrichs d. Gr. zu hindern, die Antwort: es sei nötig, dass Ludwig XV. von Reichsfürsten, etwa lem Kurfürsten von Köln oder von der Pfalz „pour leur sûreté et defense" um Hülfe angegangen werde ${ }^{5}$ ). Dass man auf sie in Bonn baute, das zeigen die Erklärungen ${ }^{6}$ ), mit denen man die starke Aufregung bier zu beschwichtigen versuehte, als der preussische König in Sachsen einmarschierte. Zudem war jetzt Ludwig XV. durch dieses Vorgehen eine Handhabe geboten, als Garant des Westfälischen Friedens aufzutreten. Der Eiumarsch der Franzosen war uur noch eine Frage der Zeit.

Anfang 1757 reisten zur Überwachung der militärischen Interessen Frankreichs in Deutschland als Abgesandte Oberst

1) Johann Theodor, Fürstbischof von Lüttich und Bischof von Freisingen und Regensburg, war ein jüngerer Bruder von Clemens August. Ennen a. a. O. Bd. II, S. $383 \mathrm{f}$.

2) Teutsche Kriegskanzley. Frankfurt und I.eipzig 1758, Bd. III, S. 643.

3) Stuhr a. a. O. I, S. 23.

4) Am Niederrhein gingen zu Beginn des Jahres 1756 lebhafte Gerüchte, Frankreich rüste zuın Kriege. Stuhr a. a. O. I, S. 31.

5) I'ublikationen a. a. 0 . Bd. 74, S. 400, 524, 542.

6) Becker, Diss. a. a. O. S. 22. 
Ryhiner wach Münster und Ficker vach Paderborn 1). Clemens Augnst war diese Betriebsankeit der Franzosen wenig angenebm. Er gab sich der Selbsttäuschung hin, für sich und sein Land trotz der Annahme der Subsidiengelder nicht nur die aktive, nein auch die passive Teilnahme am Kriege wenn nicht ganz ablehnen, so docb auf das Mindestmass beschränkeu zu können ${ }^{2}$ ). Indes nahmen seine Freunde, für die das kurkölnische Gebiet bei dem beabsichtigten Feldzuge das war, was Sachsen fuir Friedrich bedeutete, bei ihrem entschiedenen Auftreten keine Rücksicht auf seinen kaum nennenswerten Widerstand. Wo sollte er auch die Kraft dazu hernehmen? Kenuzeichnend für seine Lage - mögen die Worte gefallen sein oder nicht - ist die Antwort des Kurfürsten, die el Mitte März 1757 dem englischen Gesandten Walmoden gegeben baben soll. ${ }_{n} \mathrm{Sr}$. Kurf. Durchl. ${ }^{\star}$ - so lautet sie nwürden eine genaue Neutralitait beobachten, und den fremden Truppen weder die Quartiere noch den Durchzug bewilligen; allein dero Macht wäre nicht hinreichend das eine oder andere zu verhindern, wenu die Französischen Truppen, unangesehen der Verweigerung des Durchizuges, dero Gebiet betreten sollten." Als Walmoden darauflin vorschlug, der Kurfürst möge seine Truppen zur Observationsarmee stossen lassen, erhielt er eine ablehnende Antwort ${ }^{3}$ ). Die Äusserung ist für den Kurfürsteu bezeichnend, selbst in ihrer Zweideutigkeit, ihrem Gemisch von Wahrheit und verschleierter Hinneigung zu Frankreicl. Eine Verweigerung des Durchzuges französischer Truppen war nicht elfolgt. Am 2. Mär\% 1757 bat ein nach Bonn geschicktes Scbreiben Lndwigs XV. in sehr höflichen, aber bestimmten Wendungen um freien Durchmarsch für die Truppen und die Gewährung von Lebensmitteln 'gegen pünktliche Bezahlung ${ }^{4}$ ). Am 20. März schloss der Kurfürst einen Vertrag mit der französischen Intendantur anf Lieferungen von Lebensmitteln durch das Erzstift ${ }^{5}$ ). Bereits 7 Tage später betraten die Spitzen der französischen Armee kurkölnischen Boden.

1) Stuhr a. a. O. 1, S. 103; Huppertz a. a. 0. S. 82.

2) Ennen a. a. O. Bd. II, S. $316 \mathrm{f}$.

3) Berlinische Nachrichten von Staats- und Gelehrten Sachen (Spenersche Zeitung) vom 22. III. 1757; Hildeshein, 15. III.

4.) Faber, Anton, Luropäische Staatskanzley. 115. 'Teil, \$. 139-142. Beyträge zur neueren Staats- und Kriegsgeschichte (Danziger-Beitr.). Bd. II, S. 547. - Huppertz, a. a. O. S. 547.

5) Gazette de Cologne vom 22. III. 1757; Düsseldorf, 21. III. 
Von Kurkölns Beziehungen zu Frankreich u. seiner wirtschaftl. Lage. 49

Alsbald machten sich die unangenehmen Wirkungen des dem Kurfürsten zugesagten ${ }_{n}$ Schutzes" ${ }^{*}$ bemerkbar. Fast ironisch mutet einen der Erlass des Kurfürsten vom 6. April 1757 an, der für die Verpflegungsfuhren der französischen Armee Wegegeldfreiheit an allen erzstiftischen Barrieren verkündete ${ }^{1}$ ). Als ob es obne diese Verfigung anders gewesen wäre! Die erzstiftische und westfälische Bevölkerung sah dem Anmarsch der Franzosen mit sehr geteilten Gefühlen, ja man kann wohl sagen mit Unmut und Angst entgegen; und die französische Intendantur traf, obwohl sie, von der herrschenden Stimmung durch ihre Abgesandten unterrichtet, teilweise vorbereitet sein konnte, bei der Verpflegung der Armee auf ungeahnte Schwierigkeiten ${ }^{2}$ ). Zu deren Regelung berief der Kurfürst nach Köln - in Münster geschah dasselbe - Ende April $175 \overline{7}$ Vertreter der vier Stände.

Mit regem Eifer nahmen sich diese der Sache des Erzstifts an. Den am 20. März 1757 mit dem französischen Kommissar Fum. de la Berlière geschlossenen Traktat erklïrten sie nur für verbindlich, wenn er die Kräfte des Landes nicht übersteige. Dies sei aber unbedingt der Fall, wie sich aus den Tabellen tiber den Fruchtvorrat des Erzstifts ersehen lasse ${ }^{3}$ ). Ein solches Auftreten war naturgemäss den mit dem französischen Hofe in engem Einvernehmen stehenden Kürfürsten höchst unangenehm. Kategorisch erklärte er am 21. April, wenn nicht innerhalb 14 Tagen betreffs der Lieferungen an die französische Armee ein entsprechender Entschluss gefasst sei, $n$ werde er gemüssigt sein, das Erforderliche nach einem von ihm dazu erwällenden modo selbst auszuschreiben $\left.{ }^{4}{ }^{4}\right)$. Trotzdem erbielt er als Antwort, dass bei ${ }_{n}$ Fortwäbrung der Lieferungen die Untertanen den Abgrund vor Augen sähen". Die Landeskasse sei "fast völlig erschöpft ${ }^{u}$; noch letzthin habe man beim Durchmarsch des Feldmarschalls Graf von Maillebois - er führte die Vortruppen der französischen Armee 40000 Reichstaler vorgeschossen ${ }^{5}$ ). Hof rat Joh. Bertram Frhr, von

1) Scotti J. J., Sammlung der Gesetze und Verordnungen für das vormalige Churfürstentum Cöln, Düsseldorf 1830 f. Bd. II, S. 779, Nr. 553.

2) Waddington, R., La guerre de sept ans. Paris $1899 \mathrm{ft}$. Bd. I, S. $386 \mathrm{f}$. - Stuhr a. a. O. I, S. 105 . - Huppertz a. a. O. S. 84 f.

3) Fasc. 198.

4) Fasc. 198.

5) „Die Einwohner im Cöllnischen, Jülischen und Bergischen fangen wegen der starken Lieferungen bereits sehr über den Mangel an Lebensmittel zu klagen an". I)anz.Beitr. Bd. II, S. 558. 
Francken, der als Vertreter des Kurfürsten an den Sitzungen teilnahm, begab sich am 24. April im Auftrage der Versammlung zum Kurfürsten und trug deren Wünsche vor: es möchten die Lieferungen für den Monat Mai alogelehnt werden, da sonst der arme Landmann durch Fouragierungen ,yauz und gar verdorben werde ${ }^{\star}$. Es sei unbedingt nötig, dass die Franzosen ejgne Magazine anlegten, und es werde vorteilhaft sein, den König von Frankreich und die kommandierenden Generale darum zu bitten ${ }^{1}$ ). So gut die Ratschläge gemeint waren, dem Hauptübel wurde damit kaum begegnet. Mit der stärkeren Nachfrage nach Lebensmitteln trat fast unvermeidlich eine von den Franzosen ebenso wie von Ständen gefürchtete Preissteigerung ein ${ }^{*}$ ). Sie wurde leider durch Selbstsücbrige noch künstlich vergrössert, indem diesc alle in ihrem IBesitz befindlichen Lebensmittel rom Markte olne Not zuruckhielten. Einem soleben verwerflichen Gebabren sucliten die Stände zu begegnen, indem sie am 25. April den Kurfürsten um Erlass ciner Frucht- und Fourage-Taxe baten, die zugleich mit der in der Stadt Köln von den Franzosen beabsichtigten ncon-

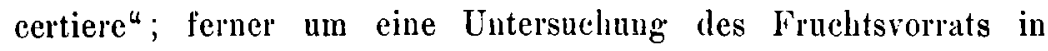
Gemeinschaft mit der französischen Generalität, die „der teutschen Sprach in etwa kündige Commissarii ${ }^{-3}$ bestimmen möge ${ }^{1}$ ). Dem letzten Wunsche entsprach der Kurfürst. Am 27. April wies er die erzstiftischen rheiniselen Lokalbehörden an, mit den französischen Kommissaren Visitationen zur Ermittlung des Vorrats aller Arten von Früchten abzulualten ${ }^{3}$ ). Dabei kam trotzdem längst nicht alles ans Tageslicht. So verkaufte die Abtei Deutz, die bei der Untersuchung durch die Behörde erklärt Latte, ${ }_{n}$ nur zur Befriedigung der Notdurft Korn zu besitzen", im folgenden Monat Korn das Malter für 20 Gulden ${ }^{4}$ ). Das war das Dreifache des üblichen Preises ${ }^{5}$ ). Ohne schwere Schädigung des wirtschaftlichen Lebens konnte dies nicht so weitergehen. Eindringlich legten die Ständevertreter Clemens August auseinander: der Landmann habe

1) Fase. $198 . \quad$ 2) Waddington a. a. O. Bd. I, S. 388.

3) Scotti a. a. O. Bd. II, S. 779, Nr. 551.

4) $1 \frac{1}{2}$ Gulden entsprachen 1 Reichstaler (Rtlr.). Vgl. Becker, Const., Uber die finanziellen Aufwendungen Kurkölns in $7 \mathrm{jähr}$. Kriege usw. in Annalen des hist. Ver. für den Niederrh. Heft 92, S. 72, Anm. 2.

5) Sitzung der Stäudevertreter vom 2. Juni 1757. Fasc. 198. 
mit Not nur noch für den Lebensunterhalt und die Aussaat ${ }^{1}$ ); auch fordere der Anmarsch der kaiserlichen Hülfsvölker ${ }^{2}$ ) Einstellung der französischen Fouragierungen, da sonst eine für das Stift wie für die kaiserliche Armee verlängnisvolle Unordnung einreissen könne ${ }^{3}$ ). Labei drängte man unablässig auf eine bebördliche Preisregulierung. Am 8. Mai baten die Ständevertreter Clemens August, die Preise

für das Malter Korm (kölnisches Mass) auf 4 Rtlr. 26 Albus

$\begin{array}{lllllllllll}n & n & n & \text { Weizen } & n & n & n & 5 & n & - & n \\ n & n & n & \text { Gerste } & n & n & n & 21 / 2 & n & - & n \\ n & n & n & \text { Hafer } & n & n & n & 2 & n & - & \end{array}$

fest/usetzen und sich dafür zu verwenden, dass in der Stadt ein Gleiches geschehe ${ }^{4}$ ).

Diese Besorguis um die Preise in Köln lässt auf ihre grössere Bedeutung für das rheinische Erzstift schliessen, als man auf den ersten Blick vermuten möchte. Verständlich wird sie, insofern niedrigere Preise in Köla für das Stift preisdrückend wirken konnten, während ungekehrt sich ein unliebsames, den Franzosen vielleicht angenelunes Zusammenfliessen der Lebens. mittel nach dorthin lemerkbar machen konnte. Wie dem in ein. zelnen nun auch sei, die Bedenken der Stände gegenïber Schädigungen seitens der Stadt und der in ihr herrschenden Franzosen war so stark, dass der kurkölnische Grosskanzler Frhr. von Raes. feld, dem ebenso wie seinem Herrn eine Fruchttaxe nicht zu behagen schien, sich veranlasst sah, jenen zu erlauben, „dass an die stadtkölnischen nach Mlülheim linleitende Pforten und die dazwischen befindliche Schlupfwinkel zu Verbütung deren in Verbringung der Frucht $z \mathfrak{u}$ besorgender Unterschleifen durch die französischen Truppen Schildwachen gestellt werden ${ }^{4}$ ). Die Fruchttaxe, die ja vielleicht nach dem Ermessen der Regierung auch scbädigend wirken konnte, liess noch auf sich warten, als sich das Erzstift Ende Mai 1757 von den Franzosen allmählich „evakuierte“. Die Preise für das Malter Korn waren um diese Zeit auf 7,8 und

1) Sitzung der Ständevertreter vom 26. April 1757. Fasc. 198.

2) Es waren dies die österreichisch-niederländischen Regimenter, die nach Böhmen ziehen soliten. Ygl. Becker, Diss. a. a. O. S. $46 \mathrm{f}$.

3) u. 4) Sitzung der Ständevertreter vom 27., 28. April, 8. Mai $175 \%$; Fasc. 198.

5) Raesfeld am 24. Mai an die Stände. Fasc. 198. 
9 Rtlr. gestiegen. Nochmals wiesen die Stände in einer erneuten Eingabe vom 2. Juni darauf hin und betonten, in den julichschen und bergischen Gebieten sei am 31. Mai folgende Fruchttaxe veröffentlicht worden ${ }^{1}$ ):

$\begin{array}{cclllllll}\text { Das Malter } & \text { Roggen } & 4 & \text { Rtlr. } & 41 & \text { Alb. } 8 & \text { Helle } \\ n & n & \text { Weizen } & 5 & n & 61 & n & - & n \\ n & n & \text { Gerste } & 3 & n & 20 & n & - & n \\ n & n & \text { Hafer } & 2 & n & 35 & n & - & n \\ n & n & \text { Malz } & 3 & n & 40 & n & - & n \\ " & n & \text { Erbsen } & 4 & n & 60 & n & - & n \\ n & n & \text { Buchweizen } & 2 & n & 40 & n & - & n\end{array}$

Die kurfurstliche Regierung blieb unerbittlich.

Der Durchzug der Franzosen war, wie vorhin erwähnt, seinem Ende nahe. Die in der Stadt Köln tagenden Ständevertreter des Erzstifts empfahlen schon dem Kurfürsten, den Brlickenmeister Mehlem aus Bonn mit seiner Brücke von Köln wegzurufen, da die Kölner Brücke für die übrigen wenigen Regimenter genüge, und beantragten am 25. Mai und 2. Juni die Auflösung der Versammlung. Darüber vergingen indes fast noch 2 Monate. Nicht nur war noch nhießiges Ert\%.Stiftisches Creiß-Kontingent in marchfertigen stand" zu setzen ${ }^{2}$ ), sondern auch eine Regelung der noch immer zahlreich einlaufenden Forderungen von Fuhrwerksstellungen für die französische Armee nötig. So sollte Eude Juni ein französischer Artilleriepark von Köln über Wipperfürth nach Arusberg geschafft werden. Vom Erzstift verlangte man 200 Wagen $^{3}$ ). Trotz des Einspruchs mit der Begründung, es seien bereits 1800 \%weispäunige Karren gestellt worden, war man schliesslich genötigt, den Franzosen zu Willen zu sein. Einige Wochen später, etwa Mitte August, wurden vom Kurfürsten anfs neue zu einem Mehltransport von 10000 Sack von Wesel nach Dülmen 400 Fuhren gefordert $\left.{ }^{4}\right)$. Diese Dienstleistungen, die sehr oft den Verlust von Fuhrwerk und Pferden bedeuteten, wurden der Bevölkerung sebr

1) Sitzung der Ständevertr. vom 2, Juni. Fasc. 198.

2) Sitzungen vom 26. Mai und 2. Juni. Fasc. 189. - Becker, Diss. a. a, O. S. 48 .

3) Der frz. Intendant Fum. de la Berlière am 17. Juni nach Kölıs. Fasc. 198.

4) Sitzungen rom 18., 24., 28. Juni; 17., 18. Aug. Fase. 198. 
schwer und vom Landmann zur Zeit der Ernte doppelt bitter empfunden.

Der Kurfürst stand diesem Auftreten der Franzosen in seinen Gebieten machtlos gegenüber. Ganz sicher hat er auf Grund seiner Erfahrungen in früheren Jahren die Folgen eines Durchzuges der französischen Armee vorausgesehen. Doch was nützte ihm, der in dem beginnenden Kriege melr als je auf französisehes Wohlwollen und Gold angewiesen war, die Erkenntnis, dass es „Grundsatz der französischen Verwaltung war, die Truppen so lange sie wenigstens in den Staaten der deutschen Bundesgenossen lagen, möglichst gut, aber auch möglichst billig leben zu lassen", und dass „man zu diesem Zwecke möglichst viele Dienstleistungen unentgeltlich beanspruchte $^{4}$ ). In Paris beschwerte er sich zwar über das rucksichtslose Vorgehen der zügellosen Soldateska, vergass auch nicht, um Schonung seiner ausgedehnten Jagden durch die französischen Offiziere zu bitten, doch kümmerte er sich nach einer vorübergehenden Besserung vorläufig nicht mehr darum ${ }^{2}$ ). Seine leichtlebige, Eindrücke des Elends verabscheuende Natur konnte bei dem spärlichsten Lichtblick alles Unglück vergessen.

Langsam, aber unaufhaltsam waren seine Beschutzer uber Köln, Jülich, Dtisseldorf, Wesel und von dort zu beiden Seiten der Lippe ostwärts vorgedrungen ${ }^{9}$ ). Das nördlich gelegene Münster, dessen Regierung mit der französischen Intendantur ebenfalls einen Verpflegungstraktat geschlossen batte, wurde ein Hauptstitzpunkt für die kriegerischen Unternehmungen ${ }^{4}$ ). Wie im Erzstift benahmen sich die Franzosen auch hier nicht wie geduldete Gäste, sondern wie unumschränkte Herren. Lebensmittel aller Art sowie Fuhren und Karren mussten in grosser Zahl beschafft werden. Jetzt erst, als die französische Armee hart an den Grenzen Hannovers stand, dachte der Fuhrer der Observationsarmee, Herzog von Cumberland, unter dem Eindrucke von Friedrichs II. Sieg bei Prag an Gegenmassregeln ${ }^{5}$ ). Der Mitteilung an die Regierungen zu Müster,

1) Eicken, H. v., Die Reichsarmee im 7 jähr. Kriege in Preussische Jahrbücher Bd. 41, S. 123. - Spen. Zeitg. vom 31. Mai 1757; Köln, 24. Mai.

2) Ennen a. a. O. Bd. II, S. 321 f. - Spen. Zeitg. 14. Juni 1757; Köln, 2. Juni.

3) Gross. Gstb. a. a. O. Bd. V, S. 75 f. - Schäfer a. a. O. Bd, I, S. 356 f.

4) Huppertz a. a. O. S. 85.

5) Koser, R., Friedrich der Grosse. Stuttgart 1893 und 1903 Bd. II 1 , S. 88. 
Paderborn, Osnabrück und Arnsberg: die in kurkölnischem Gebiet vorrückende französische Armee könne nur eine Bedrohung Hannovers bedeuten ${ }^{1}$ ), folgte erst am 20. Mai der seit dem 21. April angekündigte Einmarsch des Generals Zastrow in Paderborn. Das Bistum war von den oben genannten Gebieten das einzige den Alliierten noch offen stehende Land. Die Aufregung der kurfürstlichen Regierung beruhigte man mit dem Hinweis, man werde Stadt und Bistum nicht feindlich behandeln, strenge Mannszucht halten, alles bar bezahlen und die Truppen des Bistums - hier war man ja wie in Münster und Bonn mit der Aufstellung des Reichskontingents beschäftigt - unbehelligt lassen ${ }^{2}$ ).

An dieser Stelle sei auf etwas hingewiesen, was für die Haltung des Kurfürsten gegenüber den spätern Feldyïgen Ferdiuands von Braunschweig ausserordentlich wichtig ist. Es muss auffallen, dass Cumberland die zum Kampfe gegen Friedrich II., den Bundesgenossen seines Vaters, bestimmten 'Truppen in Paderborn nicht entwaffnet hat. Es war dies ja ein lebhaft geäusserter Wunsch des preussischen Königs ${ }^{3}$ ). Unzweifellaft liegt bier ein Einfluss des hannoverschen Ministeriums vor, das ebenso wie Clemens August in der Neutralität die vorteillafteste Stellung sah. Darin liegt auch die Erklärung für die Stoffers ${ }^{4}$ ) merkwürdig erscheinende Tatsache, dass die Hannoveraner die Kurkölner Truppen und diese jene rubig gewähren liessen. Immer noch versuchten beide Regierungen ibre Stellung zu wahren, die jetzt fast widersinnig geworden war. So waren doch die Hannoveraner trotz der beabsichtigten neutralen Defensivstellung ${ }^{5}$ ) tatsächlich in Feindesland, sie enthielten sich aber möglichst jeder Gewalttat gegenüber den Reichsfürsten und nahmen durchweg nur gegen Bezahlung die Naturalien der berührten Landstriche weg. Änderte

1) Cumberland forderte zugleich die Zurücknahme der vom Kurfürsten erlassenen Getreideausfuhrverbote. Hassell a. a. O. S. 301.

2) Cumberland gestattete den Aufenthalt von $100 \mathrm{Mann}$ in der Stadt, die übrigen konnten "aller Orten frey und ohngehindert" ziehen, mussten sich aber „zuvorderist anheischig machen, nicht wider die Observationsarmee, solange die jetzigen Umstände währen, zu dienen". Faber a. a. 0. 115. Teil, S. 172 f. - Stoffers, Alb., Das Hochstift Paderborn zur Zeit des 7jährigen Krieg'es. Diss. Münster 1910, S. 31 ff.

3) Becker, Diss. a. a. O. S. 29.4 4) Stoffers, Diss. a. a. O. S. 34.

5) Gross. Gstb. a. a. O. Bd. V, S. 78 f. - Hassell a. a. O. S. 302. 
sich diese Haltung Hannovers zumal nach der Ubernahme des Oberbefehls über die Observationsarmee dureh Herzog Ferdinand von Braunschweig, so bleibt die des Kölner Kurfürsten wäbrend der ganzen Zeit des 7jäbrigen Krieges fast dieselbe. Immer und immer betonte er bei jeder sich bietenden Gelegenheit, seine Lande seien neutrales Gebiet und beklagte sich bitter "sur la manière dure, dont on traite des gens Nentres". Er war offenbar der Ansicht oder stellte sich wenigstens so, als ob die Teilnahme seines Kontingents ${ }^{1}$ ) am Reichskriege ihn nicht zum Feinde Preussens und Englands mache, und glaubte, man dürfe ihn als Souverain nicht entgelten lassen, was er als Reichsfürst zu tun verpflichtet war. Diese Sophistik richtet sich schon, wenn man nur an die Unterstützung denkt, die er der französischen Armee zuteil werden liess, und sehr eingehend wies sie Ammon, der preussische Vertreter zu Köln, in einem Briefe an Ferdinand zurück. Er kommt zu dem Schlusse, nes werde unmöglich sein, dass man jemals diese Länder als neutral betrachten könne ${ }^{62}$ ).

Cumberland zog Zastrow, der in reger Unternehmungslust, auf das Neutralitätsprinzip wenig achtend, Klöster und Magazine grïndlich untersucht batte ${ }^{3}$ ), schon Anfang Juni über Bielefeld an sich. Kurze Zeit später marschierten die Franzosen durch den nordöstlichen Teil des Bistums Paderborn und gingen bei Höxter über die Weser. Nachdem sie sich am 26. Juli durch die Schlacht bei Hastenbeck den Weg nach Braunschweig und Hannover freigemacht hatten, stand auch das am weitesten nach Osten liegende kurkölnische Gebiet, das Bistum Hildesheim, ibrem Einzug offen. Sofort verlangten sie anch hier Lebensmittel und Fubren für die nach Norden ziehende Armee ${ }^{4}$ ). Bis jetzt batte verhältnismässig

1) Becker, Const., Die Erlebnisse der kurkölnischen Truppen im Verb. der Reichsarmee während des 7 jähr. Krieges. Annal. d. hist. Ver. f. d. Nied. Heft 91, S. 63 ff.

2) Am 2. April 1760 aus Münster; siche Westphalen, Ph. von, Geschichte der Feldzüge des Herzogs Ferdinand von Braunschweig. Berlin 1859-72. Bd. IV, S. $265 \mathrm{f}$.

3) Danz.-Beitr. Bd. III, S. $98 \mathrm{f}$ - Reden, Feldzüge der alliierten Armee 1757-62; wach dessen Tagebuch herausgegeb. durch v. d. Osten. Hamburg 1806, Bd. I, S. 38.

4) Die Spren. Zeitg. meldete am 6. Sept. 1757 aus Hildesheim unter dem 26. Aug.: Die Durchmärsche der französischen Truppen hielten an : 
am wenigsten von kurkölnischen Landen das Bistum Osnabrück ${ }^{1}$ ) und das Herzogtum Westfalen (Westfälisches Erzstift) durch die Franzosen gelitten.

Clemens August war über das Glück der französischen Waffen bocherfreut. Mit rauschenden Festlichkeiten beging er den Sieg seiner Freunde bei Hastenbeck; dann reiste er ihrem Heere, das nicht mehr Marschall d'Estrées, sondern der räuberische Herzog von Richelieu führte, nach. Am 6. Augnst traf der Kurfurst in Paderborn ein ${ }^{2}$ ) und begab sich nach 14tägigem Aufenthalt nach Hannover. Von hier aus machte er sich das recht eigentümlich anmutende Vergnügen, Briefe und Erlasse an Bekannte und Behörden abzusenden ${ }^{8}$ ), während er es ängstlich mied, mit der in seinen Landen berrschenden Not in allzu nale Berührung zu kommen ${ }^{4}$ ). Viel angenehmer war ihm ein "déjeuner de porcelaine ${ }^{4}$ und ein „portefeuille magnifique " im Werte von $5-6000$ Livres, Geschenke, die ihm Madame de Pompadour zum Dank für "das grosse Interesse, das der Kurfürst an den Erfolgen" der französischen Armee nehme, hatte zugehen lassen.

Die augenblickliche Lage auf dem westlichen Kriegsschauplatz benutzten die Kurfürsten von Kölı und der Pfalz, um den westfälischen Kreistag auf den 18. August nach Köln zusammenzuberufen ${ }^{5}$ ). Trotz des Protestes, den der preussische Gesandte Ammon am 22. August dagegen einlegte ${ }^{6}$ ), nahmen die versammelten westfälischen Stände Stellung zu den Reicbstagsbeschlusse vom 17. Januar, durch den der Reichskrieg gegen Friedrich d. Gr. beschlossen worden war. Sie bewilligten nachträglich als Beitrag

die französische Generalintendantur verlangte 1200 Fuhren, um 12000 Sack Mehl von Einbeck nach Hannover zu schaffen.

1) „Quoique nous soions entourés de diverses Armées ancunes Troupes n'a encore mis le pied dans nôtre Evêché." Gaz. de Col. vom 24. Mai 1757; Osnabrück, 19. Mai. - „Noch hat kein Feind unsere Grentzen entweyhet", man fordert aber von allen Seiten "Korn und Fourage". Spen. Zeitg. vom 7. Juni; Osnabrück, 28. Mai.

2) Gaz. vom 26. Aug.; Paderborn, 20. Aug.

3) Luynes, Duc de, Mẻmoires sur la cour de Louis XV. Paris 1864. Bd. XVI, S. 164.

4) Huppertz a. a. O. S. 99.

5) Becker, Diss. a. a. O. S. 58. - Gaz. vom 26. Aug. Köln, 26. Aug.

6) Teutsche Kriegskanzley (T.-Krgk.). Frankf. und Leipzig 1757, Bd. III, S. 834. - Oertel, Chr., Reichs-Tag's-Diarium. Regensburg 1759, Bd. III, S. 572. 
Von Kurkölns Beziehungen zu Frankreich w. seiner wirtschaftl. Lage. $\quad 57$

zu der vom Reiche beschlossenen armatura ad triplum ${ }^{1}$ ) für Münster 1026, für Paderborn 387 Mann $^{2}$ ). Dem Protest Ammons setzten sie am 19. Norember einen Reprotest entgegen, in dem erklärt wurde, nach dem bekannten Reichsbeschluss sei eine Convocation des westfälischen Kreises mit Ausschluss von Brandenburg nichts Rechtswidriges ${ }^{3}$ ). In ähnlicher Weise verteidigte der kurköInische Gesandte in Regensburg, Karg von Bebenburg, der sich auch über den "völkerrechtswiđrigen Einfall" in Münster und Paderborn beschwerte ${ }^{4}$ ), das Vorgeben am 13. Dezember mit den Worten: „Die zu verfügen gewesene Beratschlagung habe das Kondirektorium selbst in einer eigenen Angelegenheit betroffen" ${ }^{\text {" }) \text {. }}$ Trotzdem legten Ammon am 20. Januar 1758 und Plotho, der preussische Vertreter in Regensburg, am 3. Februar gegen die erneute Berufung des westfälischen Kreises anf den 10. Januar nach Köln wiederum Protest ein ${ }^{6}$ ). In Regensburg selbst war es in den Wintermonaten im ubrigen ziemlich ruhig. Auch in dem Achtsverfahren gegen Friedrich $d$. Gr. spielte Kurköln keine hervortretende Rolle; mit Pfalz und Bayern handelte es $n$ wieder in bausunionsmässigem Einverständnis ${ }^{4}$ ) and damit in kaiserfreundlichem Sinne.

\section{Wirtschaftliche Kriegsleistungen der westfälischen Be- sitzungen des Kölner Kurfürsten (1758).}

Mit den völlig neuen Verhältnissen, die der neue Oberkommandierende der Alliierten, Herzog Ferdinand zu BraunschweigLüneburg, auf dem westlichen Kriegsschauplatz schuf, wurde die

1) Becker, Annalen, Heft 92, S. 71.

2) Da die Bistümer mehr Truppen, ins Feld gestellt hatten, als diese Zahlen zur Pflicht machten, sah Ammon darin einen Beweis, wie feindselig Clemens August gesinnt sei, und wie sehr er alles Anrecht auf Neutralität verwirkt habe. Westfalen a. a. O. Bd. IV, S. 265. - Becker, Diss. a. a. O. S. 58 .

3) T.-Krgk. 1757 Bd. III, S. 965 f. $\quad$ 4) Brabant a. a. O. S. 356.

5) Oertel a. a. O. Bd. III, S. 591.

6) T.-Krgk. 1758, Bd. I, S. 17. - Oertel a. a. O. Bd. III, S. 617. Helden-, Staats- und Lebensgeschichte Friedrichs des Anderen. Frankf. und Leipz. 1756-63, Bd. V, S. 714.

7) Bitterauf, Th., Die kurbayrische Politik im 7jähr. Kriege, München 1901 S. 104. 
Lage der kurkölnischen Gebiete eine ganz andere. Schon Ende 1757 hatte Richelieu empfunden, dass er jetzt einem gefährlicheren Gegner gegenüberstand. Die Operationen des neven Jahres sollte er nicht mebr leiten. Anfang Februar wurde er durch Marschall Clermont ersetzt. Um diese Zeit begann Ferdinand seinen Feldzug. Sein Plan war mit Unterstützung des Prinzen Heinrich, der von Halberstadt anf Hildesheim vorrücken sollte, die Franzosen durch einen Angriff auf ihre linke Flanke bei Bremen und Verden übcr die Aller und Weser soweit wic möglich nach Westen zu werfen ${ }^{1}$ ).

Was er sich vorgenommen batte, glückte ihm. Unaufhaltsam rückte er nach Südwesten und näherte sich den Ländern des Kölner Kurfürsten. Vor ihm betrat jedoch Prinz Heinrich, dem Wunsche des Königs wie Ferdinands entsprechend, kurkölnisches Gebiet ${ }^{2}$ ). Schon Mitte Februar batte er durch ein Korps unter Henckel von Donnersmarck die östlichen zu Hildesheim gehörenden Ämter Wiedelah und Schladen heimsuchen und auch Geiseln von dort wegführen lassen ${ }^{3}$ ). Einige von ihnen wurden mit der Aufforderung nach Hildesheim gescbickt, in 8 Tagen eine Kontribution von 200000 Rtlr. und in 3 Wochen 100000 Rationen beizubringen ${ }^{4}$ ), andernfalls würden die übrigen nach Magdeburg geschafft und gegen das Land "mit Plïnderung, Feuer und Scbwert verfahren". Am 19. Februar veröffentlichte Prinz Heinrich einen Erlass an die Regierung zu Hildesbeim, in dem es

1) Tempelhoff, G. F. von, Geschichte des 7jähr. Krieges (Fortsetzung der Geschichte des General Lloyd). Berlin 1787. Bd. II, S. $14 \mathrm{f}$. - Osten-Redeu a. a. O. Bd. I, S. 105 f. - Schäfer a. a. O. Bd. III, S. 37 f. - Renouard, C., Geschichte des Krieges in Hannover, Hessen und Westfalen. Kassel 1863-64, Bd. I, S. 434. - Gross. Gstb. a. a. O. Bd. VII, S. $132 \mathrm{f}$.

2) Schmitt, R., Prinz Heinrich im 7jähr. Kriege. Greifswald 1885 bis $1897 \mathrm{Bd}$. I, S. $50 \mathrm{f}$.

3) T.-Krgk. 1759, Bd. III, S. 51 ff. Die Darstellung der Bedrückungen kurkölnischer Gebiete durch die Allierten in Jahre 1758 im folgenden stützt sich meist auf das Memorial der kurkölnischen Gesandtschaft zu Regensburg, das diese auf Grund amtlicher Erkundigungen am 24. Juli 1759 dein Reichstige vorlegte. Zur Diktatur kam es am 13. Aug. 1759 und ist abgedruckt in der 'T.-Krgk. 1759 Bd. III, S. 9-292, sowie gekürat in Faber's "Europäische Staatskanzley" Neue Folge (Continuation) 4. Teil, S. $204-433 ; 5$. Teil, S. $103-130$.

4) Gaz. vom 3. März 1758; Hildesheim, 24. Febr 
hiess ${ }^{1}$ ): „Des Churfürsten von Cölln Lbd. dero Landes Herr stehen mit denen Feinden des Hauses Preussen in gar zu genaner Verblindniss und unterstützen dieselben nach allen Kräften und allem Vermögen: Es ist also nach denen Kriegsgesetzen allem Recht und Billigkeit gemäss, dass, da das hiesige Fürstenthum, insbesondere die arme Stadt Halberstadt von denen Feinden ausfouragiret und durch die ibr auferlegte Kontribution sehr hart mitgenommen worden ${ }^{2}$ ), Se. Königl. Hoheit per Repressalien dasjenige aus denen ihnen am convenablesten liegenden Provinzen der Aliierten mit denen Feinden ihres Hauses wieder einzuziehen suchen ...." Hildesheim leitete sofort mit den Preussen Verhandlungen ein. Am 1. März vereinbarte Syndikus Tils mit dem Kriegs- und Domänenkammerdirektor Dietrich, in etwa 6 Wochen 125000 Rtlr. zu zablen, und die Armee „von diesem Stifte, solange als solche darinn stehet, frey und ohnentgeltlich nach KriegsGebrauch, und soweit die Unterthanen solches mit ihrer Conservation zu prästieren im Stande", zu verpflegen. Dafür sollten Ausschreitungen vermieden und bei pünktlicher Bezablung die Geiseln freigelassen werden ${ }^{3}$ ). Am 3. März wurde die Stadt Hildesheim besetzt ${ }^{4}$ ). Einige Tage später (8.) liess Heinrich die

1) T.-Krgk, 1759, Bd. III, S. $53 \mathrm{f}$.

2) Was die Hannoversch-Braunschweigischen Länder vom Monat Juli 1757 bis zun März 1758 durch die Franzosen unter Richelieu gelitten hatten (Tempelhoff a. a. O. Bd. II, S. $11 \mathrm{f}$ ), zeigt die durch den Gesandten in Regensburg am 30. Okt. 1758 cingereichte Beschwerde. In ihr ist der Schaden auf $4935325 \mathrm{Rtl}$. $12 \mathrm{Gr}$. $4 \mathrm{Pfg}$. berechnet. Beteiligt sind daran:

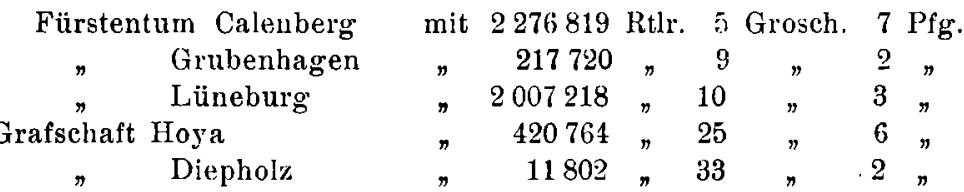

T.-Krgk. 1758 Bd. III, S. 646 f. - Faber a. a. O. Neue Folge 3. Teil, S. 295. - Gaz. vom 5. Jan. 1759; Hannover, 28. Dez. 1758.

Mitchell, der englische Gesandte in Berlin, schrieb am 1. Febr. 1758 an Holdernesse, den englischen Staatssekretär, $\ldots \ldots$ the real intention of the French is to spread ruin and desolation over Germany". Mitchel, Memoirs and papers of Sir M. London 1850 Bd. I, S. 388.

3) T. Krgk. 1759 Bd. III, S. 55 f. - Gross. Gst, a. a. O. Bd. VII, S. 142.

4) Tempelhoff a. a. O. Bd. II, S. 17 f. - Gaz rom 7. Mär 1758; Supl. Hildesbeim, 3. Mär\%. 
kurfurstlichen Kassen mit Beschlag belegen. Dem Hofkammerrendanten Oppenheimer verbot man, sich weiterhin um Einnahmen und Ausgaben des Stifts «u kümmern und vor allem, irgend etwas nach Bonn zu senden. 34000 Rtlr. an ruckständiger Pacht und Gefällen verlangte man sofort ausbezablt zu erhalten, andernfalls würden Kammerpräsident Gottlob Frbr. von Hörde und der Drost Jobst Edmund von Brabeck nach Halberstadt gefulhrt. Durch Verhandlungen wurde erreicht, dass die Preussen sich am 20. März mit 24000 Rtlr. zufrieden erklärten und versprachen, im Falle der Zahlung während des weiteren Verlaufs des Krieges die Einkünfte des Kurfürsten unangetastet zu lassen ${ }^{1}$ ).

Trotzdem währte es nicht lange, so begann sich eine immer stärker drückende Not im Bistum geltend zu machen. Besonders schädigend war der Mangel jeder genauen Bestimmung über den Umfang der zu leistenden Verpflegung. T'äglich wurden 10600 Portionen - jede bestand aus einem 2 Pfund schweren Brot -5175 Pfund Fleisch und 3000 Rationen gefordert; ausserdem für jeden Gemeinen 2, für jeden Unteroffizier 4 Groschen und für die Offiziere 2-10 Rtlr. Auch für die in Wolfenbuittel und Goslar stehenden Truppen war zu sorgen, und ein neues Korps von Halberstadt war angekündigt ${ }^{2}$ ). Die Bevölkerung sträubte sich gegen diese unerhörten Leistungen. Die Preussen sahen auch wobl ihre übertriebenen Forderungen ein und mässigten sie. Mitte März einigte ${ }^{3}$ ) man sich auf 4875 Portionen und 1484 Rationen für 6 Bataillone und 3 Eskadronen im Hildesheimischen; ausserdem waren 96 Rationen nach Goslar zu liefern. Von der Verpflegung der in Wolfenbüttel stehenden Truppen wurde man befreit.

1) T.Krgk. 1759, Bd. III, S. $59 \mathrm{f} ., 173,209 \mathrm{f}$.

2) T.-Krgk. 1759, Bd. III, S. $64 \mathrm{f}$.

3) T.-Krgk. 1759, Bd. III, S. 70.

Die Portion bestand aus $21 / 2$ Pfund Brot, $1 / 2$ Pfd. Fleisch, 2 Quart Bier, sowie Zugemüse wie Erbsen, Linsen, Kohl, Rüben usw.

Die Ration setzte sich zusammen für die Infanterie aus:

$1 / 4$ (Hildesh.) Mass Gerste, $21 / 2$ Metzen Gerste oder 3 Metzen Hafer (Berliner Mass), $8 \mathrm{Pfd}$. Heu und 6 Metzen Häcksel; für die Kavallerie aus: 1/4 (Braunschw.) Mass Gerste, 3 Metzen Gerste oder 4 Metzen Hafer (Berl. Mass), 10 Pfd. Heu und 6 Metzen Häcksel.

Am 28. März 1758 schreibt die Gaz. im Supl. unter Hildesheim, 21. März: „Les Prussiens traitent actuellement cet Evêché avec beaucoup plus de douceur, qu'ils n'ont fait dans les premiers jours de leur 
Während dieser Vorgänge im Bistum Hildesheim war Ferdinand von Verden aus in schnellem Marsche die Weser hinaufgezogen und batte nach der am 14. Mär"z erfolgten Einnahme von Minden am 19. März sein Hauptquartier zu Melle, fast in der Mitte zwischen Minden und Osnabrück aufgeschlagen. Noch an demselben Tage sandte er nach Osnabrück, "um dort im voraus für Brod und Fourage sorgen zu lassen; sowohl das Capitel als die Regierung bot gern und willig dazu die Hände ${ }^{\mu}{ }^{1}$ ). Verlangt wurden 83000 Portionen und 31000 Rationen gegen bare Bezahlung sowie 1000 bespannte Wagen. Obgleich die Aufträge nach der Ansicht der kurkölnischen Gesandten Bebenburg ${ }_{n}$ vielleicht in Rücksicht der dem Hauss Braunschweig - Lüneburg darinnen ${ }^{2}$ ) durch den Ossnabrückischen Friedens-Schluss festgestellter alternativer Succession" noch nleidentlich" zu nennen waren, machte sich doch recht bald auch hier die Kriegsnot bemerkbar ${ }^{3}$ ). Zwar ,hatte die Stadt Osuabriick und ihre Regierung seit dem 20 sten März alles mögliche getban, der Armee Liefrungen $z \mathfrak{u}$ verschaffen, und diese Betriebsamkeit in unserer Verpflegung hatte es auch dem Herzoge nur möglich gemacht", so schreibt dessen Generaladjutant Reden, nbis an die Lippe vorzudringen, was ausser dem gar nicht zu wagen gewesen wäre" Allein Osnabriick, wo Ferdinand ein Magazin anlegte, befand sich in ,einer durchaus armen und zudem rom Feinde sehr ausfouragierten Gegend", so dass sogar geringe Kontributionen die Be-

entrée...... Malgré... notre situation est toûjours des plus douloureuses". Mitchell a. a. O. Bd. I, S. 405.

1) Osten-Reden a. a. O. Bd. I, S. 133.

Dieses Entgegenkommen wird leichter verständlich, wenn man an die eigenartigen Bestimmungen denkt, die bei Abschluss des Westfälischen Friedens über die Besetzung des Bistums Osnabrück getroffen worden waren. Demnach führte abwechselnd ein Oberhirt katholisehen und protestantischen Bekenntnisses hier den Krummstab, und zwar mussten die protestantischen Bischöfe aus dem Hause BraunscbweigLüneburg, aus dem ja auch Ferdinand stammte, genommen werden. Alsdann leitete der Erzbischof von Köln die Seelsorge der Katholiken. Nacbfolger von Clemens August wurde Anfang 1764 der halbjährige Sohn Georgs III., Friedrich, Herzog von York. Stüve, C., Geschichte des Hocbstifts Osnabrück, Jena 1882, Bd. III S. 317 f. Uber die Leiden Osnabrücks im 7 jähr. Krieg vgl. von demselben: Geschichte der Stadt Osnabrück 1826, Bd. III, S. $306 \mathrm{ff}$.

2) Im Bistum Osnabrück.

3) T.-Krgk. 1759, Bd. IIl, S. $71 \mathrm{f}$. 
völkerung sehr hart trafen ${ }^{1}$ ). Die Lage des Heeres hätte indessen Ferdinand nicht gestattet, selbst Freundesland weniger in Anspruch zu nebmen.

Viel empfindlicher jedoch als Hildesheim und Osnabrück mussten die Bistüner Paderborn und Münster die Macht der Feinde ihres Herrn verspüren ${ }^{2}$ ).

In Paderborn wird die Bevölkerung selbst teilweise die Strenge, mit der vorgegangen wurde, verschuldet haben. Anstatt sich dem Recht des Stärkeren zu beugen, leistete sie manchmal Widerstand. So kam am 25. März es beim Einzug des Obersten W. v. Freytag in der Stadt zu Ausschreitungen. Ferdiuand befahl daraufhin abgesehen von der geforderten Angabe des Fruchtvorrats die Auslieferung der Gewehre und untersagte jeden Briefwechsel mit den Franzosen. Freytag, der seinerseits auch sehr riicksichtslos "ohne höhere Ordre" ${ }^{3}$ ) aufgetreten sein muss, duldete, dass in der umfangreichsten Weise, durch cinzelne Streifkorps Kontributionen eingezogen wurden. Trotz einer Verordnung Ferdinands vom 24. März 1758, in der er Religionsfreiheit, Sicherheit und Schutz für Personen und Eigentum zusicherte, litten die Einwohner ungemein. Besonders schonungslos hanste man wie im Jahre 1757 bei der Geistlichkeit in Klöstern und Stiftern. Doch am 28. März schon verbot Freytag - wabrscheinlich weil er sah, dass die Übergriffe sich erschreckend mehrten - die Einziehung der Kontributionen durch einzelne Korps, verlangte aber gleichzeitig zur neuen Bekleidung seiner hannoverschen Jäger 17000 Rtlr. ${ }^{4}$ ), wobei er darauf hinwies, Frankfurt habe als neutrale Stadt das französische Freikorps Fischer neu kleiden müssen. Als die Paderborner bei Ferdinand darüber Beschwerde führten, erklärte dieser die Forderung für nichtig. Gewonnen war darum doch nichts, denn am 1. April

1) Osten-Reden a. a. O. Bu. I, S 136, $139 \mathrm{f}$.

2) ${ }_{n}$ Les Prussiens exigent des contributions immenses des Evêchés de Hildesheim et d'Osnabrugg' et cet Evêché doit s'attendre à subir le même sort" Gaz voin 24. März 1758; Paderborn 18. März.

3) Greve, J. B., Der 7 jähr. Krieg und seine Drangsale im Hochstift Paderborn. Nach Malberg's Tagebuche. Erschienen in Blätter zur näheren Kunde Westfalens 1872, Nr. 7, S. 82.

4) Das Domkapitel solite 6000 , Kloster Abdinghof 6000 und die Jesuiten 5000 Rtlr. beitragen. 
Von Kurkölns Beziehungen zu Fankreich u.seiner wirtschaftl.Lage. 63

forderte Freytag von dem Bistum für die langst den Lippe Fluss bis Hamm, Soest und Erwitte kantonnierende 6 Bat. nnd 19 Esk." die Lieferung von täglich 9200 Portionen und 5120 Rationen, sowie das alliierte Feldkriegskommissariat an 5. April 50000 Scheffel Roggen und 200000 Rationen $^{1}$ ) Fourage für das münstersche Magazin ${ }^{2}$ ). Noch nicht genug damit, beanspruclite der Ingenieuroberst J. P. Isenbart am 12. April für den Festungsbau in Lippstadt, das für die Verbindung der jetzt bei Münster stehenden Alliierten nach Osten und Stiden gleich wiclitig war, wöchentlich 100 Arbeiter, 6 Zimmerleute, 6 Ordonnanzwagen mit je 4 Pferden, 20 angeschirrte Zugpferde, 30 Schiebkarren, 20 „Schlagen“, 10000 Pallisaden, 1000 Faschinen, 5000 Pfähle, 100 Eichbäume, 250 Stück trockene Dielen, 80 Stïck Boblen und 10000 Fuss Latten ${ }^{3}$ ). LebLafte Einsprüche der Regierung veranlassten Ferdinand am 14. April seinen Generaladjutanten Reden nit dem Auftrag um Erleichterungen nach Paderborn zu senden, „damit die Zufuhr des Getraydes nicht gehemmet und schwehr gemacht würde"4). Daraufhin brauchten nur 60 Arbeiter, 2 Ordonnanzwagen, 20 angeschirrte Zugpferde, 5000 Pallisaden, 600 Faschinen und 3000 Pfähle geliefert zu werden ${ }^{5}$ ).

Die Heimsuchung des Hochstifts Münster war, so begann der kurkölnische Gesandte in seinem Bericht von diesem Bistum zu reden, "noch weit schreckbarer" ${ }^{6}$ ). Am 26. März betraten dic ersten Alliierten Münster selbst, und nach einigen Tagen befand sich der weitaus grösste Teil von Ferdinands Heer im Bistum.

1) Jede Ration sollte aus $1 / 4$ Scheffel Hafer (Berl. Mass), 10 Pfd. gebundenem Heu und 5 Pfd. Stroh bestehen.

2-4) T.-Krgk. 1759, Bd. III, S. 23-26; 79-91.

5) Hinsichtlich der Anforderungen an das Bistum konnte hier wie an den übrigen Stellen des Aufsatzes mit Rücksicht auf das Thema, den Raum und auch wohl die mir zugänglichen Quellen nur das Wichtigste angeführt werden. Die Einzelheiten dürften der Lokalforschung als dankbares Gebiet zu überlassen sein. Für Paderborn hat sie in umfassender Weise in Fortsetzung seiner Dissertation a. a. O. A. Stoffers in der Zeitschrift für vaterländische Geschichte und Altertumskunde, Münster 1912, Bd. 70, Abt. 2, S. 68-184 dargelegt. Allerdings will mir scheinen, als ob das hier verwertete, umfangreiche Material - zumal das handschriftliche - nicht immer so bemeistert ist, dass sich die wünschenswerte klare Cbersicht ergibt. Vgl. vorl. Aufsatz S. 67, Anm. 4.

6) T.-Krgk. 1759, Bd. III, S. 29 f. 
Es galt eben den fluchtartigen Rück»ug der Franzosen zum Rheine nicht zum Stillstand kommen zu lassen.

Ferdinand batte mit der münsterschen Regierung eine Konvention geschlossen, die in ibren Grundzügen darauf hinauslief, Einrichtungen von Kirche, Staat und Gesellschaft zu achten, sowie Freiheit von Personen und Eigentum zu gewährleisten, falls die Kräfte des Bistums gegen Bezahlung den Alliierten zur Verfügung ständen 1). Verlangt wurden täglich 60000 Portionen und 24000 Rationen; Es lässt sich mit Huppertz wohl kaum dariu eine milde Gesinnung der alliierten Heeresleitung sehen. Das Gegenteil war die Ansicht Bebenburgs, der davon spricht, beim Abschluss des Vertrags habe sich ${ }_{n}$ die feindselige Beliandlung gegen Ihro Churfürstliche Durchlaucht zu Cöllen genugsam veroffenbaret" ${ }^{2}$ ). Ferdinand war unstreitig über die wahre Gesinnung des Kölner Kurfürsten Clemens August ebenso gut unterrichtet wie Prinz Heinrich. Obgleich jener die Forderungen in eine weniger schroffe Form kleidete, so steckten die Härten für jeden, der tiefer sal, doch darin. Was den Leuten an Freibeit noch verblieb, war alles andere als eine Folge von Versöhnlichkeit und persönlichem Mitgefühl. Weshalb sollten auch die Alliierten nicht mit wohluberlegter Berechnung um das bitten, was sie mit Macht jederzeit nehmen konnten? Aber auch diese damit zusanmenbängenden Vorteile gingen der Bevölkerung und Regierung teils durch ihre eigne Ungefälligkeit, teils in der Verkettung der Umstände durch Übergriffe und die drängenden Bedürfnisse des Heeres verloren. Ein treffendes Stimmungsbild für diese Verbältnisse gibt Reden in seinem Tagebuch ${ }^{3}$ ). Es beisst dort: n.... als wir uns in den ersten Tagen des Aprils in dem Bisthum Münster mehr zusammenzogen, das erst wenige Tage ja Stunden vor uns von dem Feinde geräumt war, fanden wir in der Regierung jetzt wohl mehr Personen wider als für unser Interesse gestimmet. Bereits am 28 sten März war dieselbe avertiert, Vorrichtungen für die Armee zu treffen; aber man betrieb hier alles mit einer solchen Nachlässigkeit, dass ein Tag nach dem

1) Huppertz a. a. O. S. $104 \mathrm{f}$. - Den von Ferdinand bei seinem Einzug in Münster veröffentlichten Erlass brachte die Gaz. am 18. April 1758; Supl. Münster, 12. April.

2) T.-Krgk. 1759, Bd. III, S. 30.

3) Osten-Reden a. a. O. Bd. I, S. 140. 
anderen verstrich, olne anch nur etwas beschickt zu haben. Dies latte denn die schr natiulichen lolgen, dass vor\%üglich auf dem platten Lande mancherlei Unordnungen einrissen, dass man fouragierte, wo man etwas fand und den Banern das wenige, was sie zu ilırer eigenen Subsistenz bedurften, mit aufzehrte".

So kamen allenthalben Plïnderungen und Úberfälle vor. Abt Bermard von Marienfeld schätzte den Schaden, den sein Kloster um diese Zeit erlitt, am 4. April auf $7903 \mathrm{Rtlr}$. Älnnlich erging es den Klöstern ${ }^{1}$ ) Rengering und Vinenberg sowie dem „u Osnabriick gehörenden Orte Schepsdorf ${ }^{*}$ ). Der Pfarrer Joh. Heiur. Sprencker zu Lette wandte sich unmittelbar an den Kurfirrsten mit ler Klage, er sei in \%wei aufeinander folgenden Nächten von Husaren überfallen und ausgeplündert worden. Das Tabernakel habe man sogar nicht geschont und die Hostien umhergestreut ${ }^{3}$ ).

Natürlich daif man alle derartigen Ausschreitungen der Heeresleitung nicht zur Last legen wollen, indes zeigen sie doch, wie es mit der Freiheit und Sicherheit bestellt war.

Von Beschwerden blieb infolgedessen Ferdinand nicht verschont; und er linderte auch die Not, wo es sich mit dem ungestörten Fortgang seiner Pläne vereinen liess. So wurde auf seinen Befehl die Exekution aufgehoben, die am 8. April in Münster über den Vizeprüisidenten der münsterschen Hofkammer H. K. v. Hauxleden und den Domkantor Gosw. Ant. Spiegel zu Diesenburg verhängt worden war, weil weder die geforderten Lebensmittel noch das Entsprechende an Geld im Betrage von 211989 Rtlr. 24 Grosch. 91/3 Pfg. beschafft worden war. Erst als auch jetzt noch keine Anderung eintrat, wurden die Genannten wiederum und ferner Geheimnat Adrian Wilh. von Nagel zu Ittlingen mit Exekution belegt und den Bewohnern, die in grosser Zahl auch zu Wegearbeiten und Ansbesserungen sowic Verstärkungen der Stadtbefestigung herangezogen wurden, ihre Vorrate bis auf einen zweimonatlichen Bedarf weggenommen ${ }^{4}$ ).

1) T.-Krgk. 1759, Bd. III, S. 29 f., 98 f., 162 f. - Die Klöster bildeu heute Teile dus Dorfes Milte nordwestl. von Warendorf.

2) An der Ems südwestl, von Lingen.

3) T.-Krgk, 1759, Bd. III, S. 157. -- Ahnliches ereignete sich im Bistum Paderborn im Jahre 1760. Vgl. vorl. Arb. S. 110.

4) T.-Krgk. 1759, Bd. III, S. 110 f. - Osten-Reden a. a. O. Bd. I, S. 142,145 . - Huppertz a. a. O. S. $108 \mathrm{f}$. 
In diesen ersten Monaten des Jahres 1758 kam verbältnismässig am glimpflichsten infolge seiner Lage noch der westfälische Teil des Erzstifts davon.

Das Herzogtum Westfalen luatte an 31. Mär\% 500 vierspännige Wagen zum Lebensmitteltransport von Soest nach Hamm zu stellen. In kluger Weise begannen die Stände sogar mit der Lieferung von 12000 Scheffel Roggen, 12000 Scheffel Hafer (Berl. Mass) und 5000 Zentner Heu, deren Beschaffung man freiwillig angeboten hatte, und die man in 3 Terminen $z u$ besorgen versprach. Dessen ungeachtet forderte Isenbart am 13. April fuir den Festungsban in Lippstadt dasselbe, was er vou Paderborn beansprucht hatte. Dem Vest Recklinghausen wurden in 2 Terminen 15000 Scheffel Hafer, 5000 Scheffel Roggen und 7000 Zentner Heu abverlangt ${ }^{1}$ ).

Friedrich der Grosse war mit dieser Behandlung der kurkölnischen Gebiete durchaus einverstanden. Jetzt war die Zeit gekonmen, wo Clemens August „die Zeche bezallen" ") musste. Am 1. April 1758 sandte der König an Ferdinand einen Brief mit der Bitte, in die Gebiete der Kurfüsten von der Pfal\% und Köln, die „im ganzen Verlaufe des gegenwärtigen Krieges eine unverniuftige und sehr iubel angebrachte Leidenschaftlichkeit" grezeigt lä̈ten, Husaren und Dragoner abuaschicken, „um in diesen Ländern zu plündern und so diese Fiirsten ein wenig für das iible Betragen zu ziichtigen"3). Drei Tage später empfahl er nochmals aufs angelegentlichste seine $W$ unsche. Wenn Ferdinand in das Bergische, Westfälische und Münstersche sowie die andern Länder der Kurfürsten vou der Pfalz und Köhn komme, müssten sie unbedingt fül die Undankbarkeit der Fürsten durch starke Kontributionen und eine gute Anzahl Rekruten biissen 4).

Entsprechende umfassende Massnalimen Ferdinands liessen nicht lange auf sich warten. Sie stellten alles bis jetzt Erlitiene

1) T.-Krgk. 1759, Bd. III, S. 44, 149, 151, 155.

2) Becker, Diss. a. a. O. S. 29.

3) Politische Correspondenz Friedrichs d. Gr. Berlin 1879 f. Bd. XVI. Friedrich am 1. April 1758 an Frerd. Nr. 9880.

4) Friedr. am 4 April 1758 an Ferd. Pol Corr. Bd. XVI, Nr. 9893. -- Tempelhoff a. a. O. Bd. II, S. 385 . - Knesebeck E, v. d, Ferdinand, Her\%. von Braunschweig und Lüneburg, wihrend des 7jähr. Krieges. Hannover $1857-58$, Bd. I, S. 68. 
Von Kurkölns Beziehungen zu Frankreich u. seiner wirtschaftl. Lage. is7

in den Schatten. Waren sie alleh in erster Linie durch den allgemeinen Kriegstranch veranlasst, in Feindesland das eigne Heer auf Kosten der Bevölkerung zu uutcrhalten und das Land nach Möglichkeit wirtschaftlich zu schädigen, so wird doch die drillgende Aufforlerung Friedrichs nicht olne Wirkung gewesen sein. An 6. Mai erliess Ferdinand für den Bereich der von ihm besetzten Bistimer Osnabrick, Paderborn und Münster Kontributionsforderungen, die in ihrer Höhe fast unerhört zu nennen sind ${ }^{1}$ ). Für das Her\%ogtum (Westfälisches Er/stift) erfolgten sie am 12. Juni ${ }^{2}$ ). Sie hatten folgenden Umfang:

\begin{tabular}{c|r|r|r|r}
\hline \hline Art der Lieferung & Osnabrück & Parlerborn & Münster & Westfalen \\
\hline Portionen & 562800 & 586300 & 2230100 & 1115100 \\
Rationen & 241200 & 251200 & 955800 & 477900 \\
Centner Lägerstroh & 21900 & 22900 & 86900 & 43500 \\
Drillsäcke & 838 & 874 & 3326 & 1663 \\
Leinensäcke & 1675 & 1745 & 6638 & 3319
\end{tabular}

Da diese Mengen unmöglich in der gewünschten Zeit ge. liefert werden kounten, galen die Alliierten zugleich die entsprechende Summe in Geld an, wobei sie die Portion zu 2, die Ration zu 24, den Zentner Stroh zu 20, einen Drillsack жu 24 und einen Leinensack zu 18 Mariengroschen berechneten. Die Beträge mussten in 3 Terminen mit je $1 / \mathrm{s}$ der Gesamtsumme erlegt werden. Folgende Tabelle gibt eine Übersicht ${ }^{3}$ ).

\begin{tabular}{|c|c|c|c|c|}
\hline & Osuabrück & ('aderborn $\left.{ }^{4}\right)$ & Münster & Westfalen \\
\hline Gesamtsumme & $\underset{205629}{\mathbf{R t | r}} \mathbf{M g r}$. & $\begin{array}{l}\text { Rtlr. Mgr. } \\
214216 \quad 10\end{array}$ & $\underset{814908}{\text { Rtll }} \underset{20}{\text { Morr. }}$ & $\begin{array}{l}\text { Rtlr. Mgre } \\
40748+\underset{30}{30}\end{array}$ \\
\hline $1 / 9$ der $n$ & $68543 \quad 6$ & $71405 \quad 151 / 3$ & $217636 \quad 62 /$ & 13582810 \\
\hline 1. Termin & 3. Juni & 9. Juni & 31. Mai & 26. Juni \\
\hline 2. $\quad n$ & $24 . \quad n$ & 1. Juli & 21. Juni & 24. Juli \\
\hline 3. & 12. Juli & 22. & i2. Juli & 21. August \\
\hline
\end{tabular}

1-2) T.-Krgk. 1759, Bd. III, S. 73 f., 92 f., 122 f., 152 f. - Huppertz a. a. O., S. 110 .

3) Addiert man die Gesamtsummen von Osnabrück, Paderborn und Münster, so erhält man die Summe (1 234753 Rtlr.), die Ennen Bd. II, S. 3:8 als Linnahme der Allierten aus don westfälischen Besit\%ungen des Kurfürsten angibt.

4) Stoffers führt in der Zeitschrift f. vat. Gesch. u. Altkd. Bd 70, 
${ }_{n}$ Wie ein Aufachrei der Empörunga ging es durch die betroffenen Gegenden. Beschwerden, Klage- und Bittsehriften sandte man an alle, die irgendwic einen Einfluss auf den Gang der Dinge auszuaiben vermochten, sei es num der Landesherr, Ferdinand von Braunsehweig, der König von England oder eine Mittelsperson ${ }^{1}$ ). Ferdinand war unerbittlich. $\mathrm{Er}$ bestand anf seinen Anspriichen. Man fügte sich also ins Unvermeidliche. Aber kein Territorium lieferte anch nur annühernd pünktlich die ansgeschriebenen Geldsummen. Naturallieferungen sah man schon nicht melir gern und wurden kaum mehr angenommen. Dic natïliche Folge war Beschlagnahme der Landeskassen und Exekutionen bei den reichsten und vornehmsten Einwohnern, wemn nicht gar deren Gefangennahme. So wurden z. B. in Paderborn Domdechant Wilh. Jos. Frhr. von und $z$ Weichs, vom weltlichen Adel Frhr. von Westfalen und als Bürgerlicher der Bürgermeister von Paderborn mit Exekution belegt. Zahlreiche Personen wurden als Geiseln weggeführt. Dem Regierungspräsidenten Domprobst Joh. Friedr. Bernh. Graf von Schaesberg gelang es, sich rechtzeitig in Sicherheit zu bringen. Den Schaden dieser Exekutionen berechneten die Paderborner auf 156000 Rtlr., also mehr als das Doppelte der ersten Rate" ${ }^{2}$.

Auf diese Weise wurde aus den Ländern weit mehr als die vorhin angefuihten Summen gerogen. So hatte der Wert der Leistungen bezw. Erpressungen im Bistum Osnabritck, das, wie gesagt, am ehesten auf Schonung hätte rechuen dürfen, An.

S. 74 ebenfalls die genamnten Summen für l'aderborn an, weist aber nicht auf ihren Zusammenhang mit den auf $\mathrm{S}$. 73 stehenden Portionen usw. hin. Der dritte Teil von der Gesamtsumme ist nicht gan\% genau, wie man leicht nachprüfen kann. Die Termine zur Hinterlegung des Goldes sind jedenfalis unzutreffend. Die Allierten werden doch nicht Anfang und Eude $17 \vdots 9$ (15. II. -- 15. IV. -- 15. IX.) verlangen, was sie im Sommer 1758 ausschreiben. Aus der in vorliegendem Aufsat\% mitgeteilten Tabelle ergibt sich, dass bei $W$ estfalen die 'Termine in Sommer 1758 je 4 Wochell, hei den übrigen 3 Wochen auseinanderlagen. S. 74, Zeile 20 gibt Stoffers auffallend in ganz anderem Zusammenhange den Dritteil dor Gesantsumme tatsächlich als im Sommer 1758 goliefert an. Vgl. vorl. Arbeit S. 90, Anm. 5.

1) Huppertz a. a. O. S. 111.

9) Tir.irk. 1759, Bd. III, S. $28 \mathrm{f}$. 
Vou Kurkölns Bezichungen zu Frankreich u. seiner wirtschaftl. Lage. 69

fang Au "ust insgresamt eine Höhe von uber 231000 Rtlr. erreicht ${ }^{1}$ ) Dabeit stand die 2. und 3. Rate noch ans. Im Bistum Mïnster betrugen die Ausgaben zu gleicher Zeit insgesamt 951701 Rtlr. 21 Schilling 10\% Pfg. ${ }^{2}$ ), nämlich an Naturalien 680065 Rtlr. 11 Schill. 4\% ${ }_{3}$ Pfg., in bar 271636 Rtlr. 10 Schill. 6 Pfg. Hier war $^{3}$ ) ebenfalls dic zweite und dritte Rate noch nicht bezahlt.

Der Kurfürst stand diesen Kriegsschrecken wehrlos gegeniiber. Kann ihm dies auch kaum jemand zum Vorwurf machen, so doch die Art, wie er den schwer leidenden Einwohnern gegen. iibertrat. Leicht erkennt man, dass die Teilnahme, die cr für seine Gebiete hegte und die Schritte, die er für die Linderung der Not unternahm, in erster Linie der Sorge nu die Abnalume seiner Einkünfte entsplang. „Alle Kassen gehen niemanden als uns allein an". Diese Worte wagte der Kurfürst den Ständen noch zu schreiben, als die Alliierten bereits unbestrittene Herren seiner Bistümer waren. Er war empört, wem seine Regierungen im Drange der Not Massnahmen obne seju Vol'wissen trafen ${ }^{4}$ ).

Frei von den Feinden und noch nicht in Bereiche ihrer Macht war bis Mitte Mai nur noch das rheinische Erzstift. Deslıalb war aber des Kurfürsten und der Bevölkerung Lage hier um nichts besser. Die ganze Masse der Franzosen, die bisher auf las Gebiet von der Aller bis zum Rheine verteilt gewesen war, liatte sich seit Ende März auf das linke Rheinufer hinïberzuziehen begonnen und stand nun dort, iiber 60000 Mann-stark, ron der holländischen Grenze bis Bonu ${ }^{5}$ ). Schon am 4. Mär latten die Franzosen den erzstiftischen Landständen einen Auftràg zur Lieferung von 670000 Fourage-Portionen zugehen lassen. Diese bescliwerten sich heim Kurfürsten und beantragten seine Verwendung für die Untertanen sowie seine Fürsprache bei den französischen Befehlshabern zur Verhinderung der häufig vorkommenden Gewalttätigkeiten $\left.{ }^{6}\right)$. Als nichtsdestoweniger die frau-

1-2) T.-Krgk. 1759 Bd. III, S. 77, 145, 215. - Oertel a. a. O. Bd. JII, S. 799. - Huppertz a. a. O. S. 118, Anm. 2; S. 120.

3) In einem Schreibon des kurkibln. Grosskanzlers Ratesteld an den Gesandten von theen in Paris vom 16. Aug. 1758 wirl der in Münster ungerichtete Schaden ebenfalls mit 951701 Rtlr. angegeben. Fasc. 222.

4) Huppertz a. a. O. S. 111, 113.

5) Gross. Gstb. a. a. O. Bd. VII, S. $151 \mathrm{f}$.

6) Landtagsprotoliolle des Kölner Erzstifts vom Jahre 1758 (L,-Pr.). 
zösische Generalintendantur in Nenss Mitte April von Erzstift die Licferung von Fourage und Holz für 19 Infantericregimenter verlangt und in Weigerungsfalle mit Zwangsmassregeln drohte, überreichten sic Klemens August nochmals eine Bittschrift. Vor allem drängten die Stände darauf, cs möchte sowohl ins französische Hauptquartier wie an den französischen Hof ein Gesandter geschickt werden. Am 20. April erfuhren sie, dass der Kurfurst ihrer Bitte zuvorgekommen war. Er liatte den Hofrat von Kempis ins französische Lager und den Hofrat Adam Theodor von Rheen nach Paris gehen lassen ${ }^{1}$ ).

\section{Dio erste Tätigkeit des kurkölnischen Gesandten ron Rheon am Pariser Hofe. - Verstinmung in Bonn und Hin- neigung zn Österreich.}

Mit fast unwiderstehlicher Gewalt schoben sich die Alliierten in die Gebiete des Kurfürsten und nahmen ihm den grössten Teil seiner Einkünfte; nicht weniger bedrohlicb traten die Franzosen auf, da sie alle Kräfte der kurkölniscben Untertanen für ihre Heere beansprnchten, mithin ebenfalls zur Plage für Fürst und Volk wurden. Und doch konnte man nur von Frankreich, an das man sich ja gekettet hatte, Rettung aus der Not erhoffen. Vor allem galt dies flir den Kurfürsten. Woher sollte er das Geld zur Bestreitung seines umfangreichen Hofhaltes nehmen, wenn seine Freunde sein Land wie seine Feinde aussaugten, wenn sie lässig Krieg fiulhrten und so der Feind im Lande blieb, wenn gar dazu noch die Subsidien aus Paris auf sich warten liessen?") All das veranlasste den Kurfürsten zur Absendung der Hofräte Kempis und Rheen, bevor die Landstände den oben angefühten Wunsch geäussert hatten.

1) L.-Pr. 1758.

2) Nach den Angaben des sogenannten "Livre rouge" soll Clemens August im Jahre 1757 von Frankreich die beträchtliche Summe von 937500 Livres bezogen haben; also weit mehr, als ihm vertraglich zukam. Auszug aus dem Registre des depenses de la cour connu sous

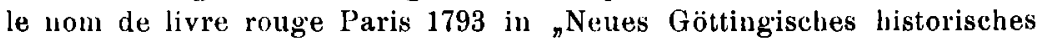
Magazin" von Meiners u. Spittler, Hannover 1794, Bd. III, S. 336 f. 
Hofrat Adam Theodor von Rheen ${ }^{1}$ ) ging in Friihjalr 170 nach Paris. Seine Berichte nach Bonn geben uns manche bemerkenswerten Aufschlüsse über die Beziehungen Kurkölns zı Frankreich wälurend des Krieges "). Am 16. April kam der Bevollnächtigte in Frankreichs Hauptstadt an. Seine Aufgabe war, wic seine Instruktion zeigt ${ }^{3}$ ), ebenso umfangreich wie schwierig. Gleich in zweiten Punkt -- der erste schreibt ihm vor, sich über die Absichten des französischen Hofes auf dem Laufenden zu halten - wird ihm zur Pflicht gemacht, auf dic pünktliche Bezahlung der Subsiedienbeträge zu drängen, jedoch wegen der Münzsorten und der Unwechslung vorsichtig zu sein. Die weiteren fünf Punkte handeln von den Beziehungen der französischen Armee zu Kurköln: es miisse eine Bezahlung der durch die Bistimer Münster, Paderborn und Osnabrück geleisteten Dienste in bar beantragt und erreicht werden; auf hannoverschem und braunschweigischem Gebiet könne sich das französische Heer schadlos halten. Zum Schluss wird dem Gesandten befohlen, „bei nächstkünftigem Friedensschluss" auf Indemnisationen für den Kurfürsten hinzuwirken; ïber die "höchstilıro auf ein und andere Örter deren Churbrandenburgischen und Hal:norerschen Landen babende gerechteste Pretension" wiirde ihm "bei ruigeren Zciten die ausführliche Nachricht zugehen". Ein beigefügtes Schreiben trägt Rheen noch auf, dic Unfähigkeit des Kurfürsten zu betonen, weiterhin seine Reichstruppen zu unterhalten, wie es schon nach Wien gemeldet sei, sowie "für etwaige mittel und, wodurch besagte fernere Unterhaltung füglich geschehen könnte", tätig zu sein. Über die Schwierigkeit sich dieser Hauptaufträge zu entledigen, schrieb Rheen, als er kaum acht Tage in Paris war ${ }^{4}$ ), man habe ihm bedeutet: der Mangel an Bargeld mache seine Sendung nicht nur „difficile ${ }^{u}$, sondern sogar "odieuse".

Um die volle Bedeutung dieser Worte zu ermessen, ist es angebracht, in einigen Strichen zu zeigen, dass Kurköln sich an

1) Er unterschreibt nach französischem Geschmack seine Berichte: "de Rèen." vergl. vorlieg. Aufsatz S. 44, Anm. 2.

2) Vergl. vorl. Aufsatz S. $1 \mathrm{ff}$

3) Instruktion Rheens vom 8. April 1758. K.-K a. a. O. Fasc. 22!'.

4) Kheen am 22. April nach Bonn. Die Worte teilt er als Ausserung: der französischen Financiers Paris du Montmartel und seines Bruders Duvernay mit. Fasc, 2:21. 
eiuen Stalat gebunden hatte, der mit Riesenschritten scinem wirtsehaftlichen Untergang entgegeneilte. Es kann sich an dieser Stelle allerdings nicbt darum handeln, ein genaues Bild der frau. zösischen Zustände zu geben. Es soll nur angedentet werden, wie der kurkölnische Gesandte die Verlıältnisse, die er vorfand, auflasste und dem Bonner Hofe schilderte.

Ausschlaggebender Faktor der französischen Politik war damals nicht mehr wie unter dem „Roi Soleil“ der König und scin Ministerium. Den König Ludwig XV. kemnzeichnet Rheen unit den Worten ${ }^{1}$ ): "wollte Gott, dass dieser liebreichste Fiurst das höchst argerliche Leib und Seel verderbende Luder-Leben ${ }^{2}$ ) gänzlich verlassen könnte. Ohue dieses und die Jagdt zu Pferd ist er melancholisch und fällt ihm die Zeit lang. Er ist (!) und trinkt stark. Die Champagnerweine und Liqueure schmecken ibm am besten". Dass eine solche Persönlichkeit - wie bekaunut - unter den vollständigen Einfluss der Madame de Pompadour, seiner Maitresse, geraten konnte, ist verstandlich. Sie war die Seele der hohen Politik und ${ }_{n}$ den wienerisch Hof mit Leib und Seel wegen kostbaren von der Kaiserin empfangenen Juweleu (welche auch ihr öfters schreibt) zugetan" ${ }^{3}$ ). Täglich besuchten die Minister sie, „um Sie von allen wichtigen Vorfallenheiten genan zu benachrichtigen ${ }^{4}{ }^{4}$ ). Rheen nennt sie meist ${ }_{n}$ die bewusste herrschende Frau" oder "la dame en question".

Über die am Hofe herrschende Günstlingswirtschaft von Unehrlichkeit und Habsuclit meldet er: „Sr. Majestät werden erschröeklich bedrogen und bestohlen " von Kommissaren, Eutreprenneuren und Lieferanten an Hofe und bei der Armee ${ }^{5}$ ). Wic

1) Rheen am 31. Mai 1759 nach Bonu; Fasc. 2223.

2) Der Ausdruck findet seine besondere Erklärung im ersten Teile des Bricfes. Er kann wegbleiben, da er hier in seinen Einzelheiten über sinnliche Aussehweifungen des Königs zwecklos ist.

3) Rheen arn 25. Dez. 1758 nach Boun; Fasc. 222\%.

4) " 17. Jan. $1759 n " \pi 222^{3}$.

Am 1. Febr. 1759 schreibt Rheen von der Pompadour: „Sie ligt aujetzo kranli an die rote Masern, welche oft nach sich ziehen die: Rinderblattern. Diese Unpässlichkeit ist ein grosses Geheimnis und wird ausgegeben für einen neuen Schnupfen," weil sie sonst vom Hofe weg' in ihr Haus müsse. Fasc. $222^{3}$.

5) Rheen am 21. Jan. 1759 wach Boun; Fasc. $222^{3}$. 
Von Kurkölns Beziehungen zu Frankreich u. seiner wirtschaftl. Lage. 73

in unbeschreiblicher Verselıwendung die Fonds und Zuflüsse der Schatzkammer auf eine "nicht zu sagen dörfende weise distrahirt ${ }^{4}{ }^{1}$; wurden, verriet er am 15. Februar 17592). Demnach beliefen sich die Ausgaben des Staates fiil

Hofstaat und Plaisirs . . . . . . auf 300 Mill. Livres

Subsidien (eingeschränkte Zahlungen) " $82 \pi \pi$

Pensionen ... . . . . . . . . n $200 \pi n$

Minister und Enissäre . . . . . . " 6 , 6 n

Im Jahre 1758 seien 1200 Milliouen Livres ausgegeluen worden. Was hatten diesen Summen gegeniber neue Einnahmen von etwa 80 Millionen Livres zu sagen, die Rheen erwähnte ${ }^{3}$ ), um dem Kurfürsten Iloffnung auf Zahlungen zu machen. Bei dieser Misswirtschaft durfte Rheen mit Recht melden: ${ }_{n}$ Es gelit hier doll und verwirret $z u^{\prime \prime}{ }^{4}$ ), und ${ }_{n}$ das hiesige Ministerium weiss endlich nicht mehr, wo Ihnen der Kopf steht. Guter Rat wird recht tener wegen Abgang des Credits bei so fatalen als verwirrten Umständen "5). Das Schreiben schliesst: „Diese Herren seind und bleiben nichtsdestoweniger selur stolz, wollen durch ihre vermeintliche gute haltende Contenentz ihre grosse Verlegeuheit dem Publico bergen " ${ }^{5}$ ).

Die Untertanen empfanden jedoch längst am eigenen Leibe, welche Verhältnisse im Staate herrschten. ${ }^{2}$ Das Volk klayt und seufzt, da es weiss, dass neue Steuern der verschiedensten Art" in Aussicht stehen $\left.{ }^{6}\right)$. Handel und Gewerbe lagen schwer darnieder. Die unerhörten Lasten, die Hof und Krieg za tragen zwangen, liessen den Kaufmann an jeder aussichtsreichen Tätigkeit veræweifeln. Der König verlangte „viel Geld“, ohne dass das Volk "durch den Haudel, sein Gewerbe und seine gewöhn-

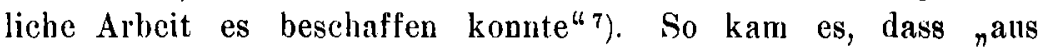
Mangel an Flandel und Kredit die Aktien täglich mehr und meh!" tielen. Die grossen Banken waren für die Anleihen des Königs

1) Rheen am 4. Juli 1758 nach Boun; Fasc. 2221.

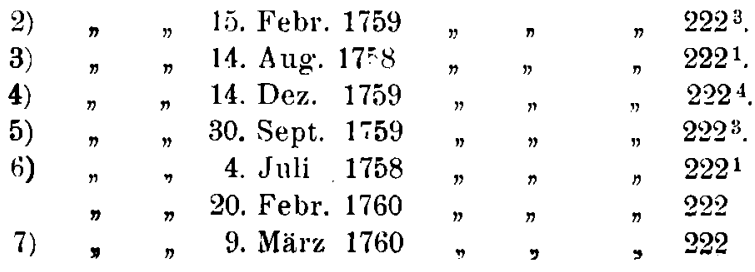


geschlossen ${ }^{1}$ ). Da zudem Ludwig XV. alle Staatskassen ihre Zahlungen einstellen liess, waren die nattirlichen Folgen, nentsetzlichste Unordnung, Bankrotts und Betrügereien " $=$ ).

Nach Frieden sehnte sich ganz Frankreich; es war ndie Stimme des Volkes, die leidenschaftlich deu Frieden ${ }^{4}$ wiüsehte ${ }^{3}$ ). Wie nötig er für das schwer um seine Existeuz ringende Land war, sagte Rheen Ende 1759 mit den Worten: würden nicht ein. wandfreie Rettungsmittel angewandt und wïrde nicht durch eine glückliche Kriegführung in nächsten Jahre ein guter Friecle erzielt, $n^{\mathrm{s} 0}$ gehet gewis zugrunde diesse monarchey in gegenwärtigem Krieg" ${ }^{4}$ ).

Ob nun wohl der Eriede Frankreich vor dem Untergange gerettet hätte? Nagrte nicht ein schlimmerer Feind, von der Pbilosoplie der Aufklärung genährt, am Mark des Volkes; bestand nicht überall eine unbeschreibliche Glaubens-, Zucht- und sittenlosigkeit in sämtlichen Ständen? Nur die ärnısten unter den Gedrlickten suchten teilweise vorläufig noch in ihrem Glauben Halt, bis anch sie namenlose Wut und Erbitterung ïber ihr endloses Elend zum ärssten trieb.

Als der Erzbischof von Paris, Christoph von Beaumont auf den Wunsch des Königs durch ein Rundschreiben vom 29. Mai 1760 öffentliche Gebete anordnete ${ }^{5}$ ), um für die französischen Waffen den Sieg zu erflehen, schlrieb Rheen darüber nach Bonn' ${ }^{6}$ ): „Aber ach! Man sieht nur die Bürger, die armen Handwerker und die Bauern in Menge zu den Tempeln des Herrn des Himmels und der Erde eilen, um sich in Demut vor der göttlichen Majestät verborgen im heiligen Altarssakrament niederznwerfen, und um sein Erbarmen und seinen Segen anzuflehen; denn die Mebr\%ahl

1) Rheen am 17. Juni 1758 nach Bonn; Fasc. $222^{1}$.

" $" 14$. Okt. 1759 ", $222^{4}$.

2) $"$ 28. Okt. $1759, ", \quad 222^{4}$.

In dem Briefe schrieb der Gesandte: „Le roi vient de suspendre tous les paiements des lettres de Change et des rescriptions des $\mathrm{Co}_{0}$ lonies. Les caisses des annuités des capitaux et interêts, celle de l'in. terêt des billets de la lotterie roiale et celle des fermiers généraux sont. fermées."

3) Rheen ain 9. März 1760 nach Bonn; Fasc. $222^{5}$.

4) " 21. Nov. $1759 \quad, \quad, \quad$ " 2224.

5) T. Krgk. 1760, Bd. II, S. $16 \mathrm{f}$.

6) Rheen am 5. Juni 1760 nach Bonn; Fasc. $222^{5}$. 
der gemächlich von ibren Reuten Lebenden denken nur darau, ilı Leben in einem Taumel von weltlichen Vergnügungen uud Freuden aller Art zuzubringen und zu beenden. Diese deuken nur oberflächlich an Gott, wenu der Tod kommt und sie weg. rafft. Er ruft sie oft ab, ohne dass der göttliche Heiland, dem zu dienen sie vergessen haben, ihneu die Gnade gewährt, vollständig zur Selbsterkenntnis zu kommen und in dem Augenblick zu beichten, da er sic vor seimen Richterstuhl ruft". Dass all diese Zustände ein Ende wit Schrecken vorbereiteten, hatte Rheen schon nach zweimonatlichem Aufenthalt in Paris erkannt. Er sagt damals: ${ }_{n}$ Fürwahr, weilen dahier besonders bey gross und reich Leuthen fast keine spuhr dess wahren catholisch glaubens melr anzutreffen ist, so ist zu befiurchten, dass Gott labe seinen fluch ausgegossen auf dieses zum untergang und Verderben sich neigendes Künigreich" "1).

Das waren die Verbaltnisse des Reiches, auf das Klemens August seine ganze Hoffuung geset/t hatte.

Den kurkölnischen Gesandten hatte der Vertreter Bayerns au französischen Hofe ${ }^{2}$ ), Max. Enmanuel Graf van Eyck, bei Hofe eingeführt. Dabei überreichte Rheen dem französischen Minister des Auswärtigeu, Abbé Bernis, sein Beglaubigungsschreiben fur den König. Ihm und seiner Familie wurde der Gesandte am 25. April vorgestellt. Bei dieser Gelegenheit gelang es diesem, mit Bernis uber die äble Lage des "zahlreichen" Bonner Hofes zn sprechen. Der französische Minister, der seit der Schlacht bei Rossbach unablässig bemüht war, Frankreich der Teilnalıme des für das Land gefährlichen Krieges zu entziehen, machte wahrscheinlich aus dem Gedankenkreise seiner eifrigen Friedensbestrebungen heraus ${ }^{3}$ ) jenem danit Hoffnung: ${ }_{n}$ dass man in der Folge

1) Rheen am 24. Juni 1758 nach Bonn; Fasc. $222^{1}$.

1) Bitterauf Th., a. a. O. S. 19, 26, 28, 36.

2) In seinen Memoiren (Mémoires et lettres du Cardinal Bernis. Puris 1878. Bd. II, S. 44) schreibt Bernis, nachdem er die ungünstige Lage auf den Kriegsschauplätzen Ende 1757 und die der Finanzen berührt hat: dans cet état il y aurait de la folie a continuer une guerre ruineuse." Am 6. Jan. 1758 schreibt er dein frz. Gesandten Stainville nach Wien: "Mon avis serait donc de faire la paix et de commencer par une trêve sur terre et sur mer" (Il, 161). Diese Friedensbestrebungen nahm er im April 1758 beim Vordringen Ferdinands ron neuem auf. 
Sr. kurfürstlichen Durchlauch Entschädigungen und Kompensationen für die entstandenen Nachteile und Schäden sowie für die Nebenunkosten verschaffen könne". Jan sei ja nit dom Kururfirsten zutrieden und nur ungehalten uber gewisse Kavaliere - es waren vornehmulich westfälische gemeint - die mit Hannover und Brandenburg konspirierten ${ }^{1}$ ). Über diese ersten Berichte wall Klemens August wenig erbaut. Er wünschte nicht, dass scin Gesandter weiterhin van Eyck in Anspruch nahm, und wies ihn an, dem bisherigen französischen Gesandten in Bonn, Monteuil, der damals in Paris war ${ }^{2}$ ), recht höflich zu begegnen. Auch geficl es ihm nicht, wie Rheen den Bomner Hof geschildert hatte; es batte einen $z u$ ärnlichen Eindruck gemacht. Vor allem aber seien die Namen der verdächtigten Kavaliere bczw. Jaandständc zn erkunden und mitzuteilen $\left.{ }^{3}\right)$. Der franzüsische Kricgsminister Belleïsle jedoch, an den sich Rheen deshalb wanlte, wcigerte sich, dies zu tun ${ }^{4}$ ).

Endlich am 9. Mai konnte Rheen nach Boun eine Nacbricht gehen lassen, die für seinen Hof ail Wichtigkeit alles andere in den Schatten stellte. Ein Kurier, so lantetc die Mittcilung, sei abgeschickt, um dem Kurfürsten durch den französischen Inten.

Am 22. April berichtet Rheen nach Bonn: „L'arrive de Nonsieur l'Abbé le Maire intrigue tous les ministres Etrangers, qui le supposent venu pour proposer à sa cour une Trêve acceptable avec les Hamnoveriens. tempus docebit." Fasc. 2221. - Schaefer a. ^. O. Bd II 1, S. 21, :11.

1) Rheen am 26. April 1758 nach Bonn; Fasc. 2221.

2) Monteuil war am 27. Jan 1758 nach Paris gereist (Gaz. v. 27. Jan. Köln, 27. Jan.). Als Ersatz wollte man von dort aus in Sommer einen gewissen Graf von Corsac schicken, den der Kurtürst aber Hblehnen liess (Raesfeld am 17. Juni an Rheen; Fasc. 2221). Dalauf wurde am 25. Juni Baron de Breteuil zurn Nachfolger Monteuils, der nach Warschau an den polnisch-sächsischen Hof ging, ernanot (Rheen am 21. u. 26. Juni nach Ponn; Fasc. 2221), Er kam am 23. August in Boun an (Giz vom 29. Aug. Bonn, 27. Aug.).

3) Racsfeld am 4. Mai 1758 an Rheen; Fasc. 2221.

4) Rheen am 17. Mai 1758 nach Bonn; Fasc. 222'. - Mit Belleïsle sprach Rheen auch über den Wunsch seines Herrn, es möchle das frz. Lazarett und das Pesthaus nicht dem Antray des stalitkölniselıen Rats entsprechend aus der Stadt ins Erzstift verlegt werden (Raesf. am 4. Mai an Rheen) Belleisle neigte aber dor Ansicht der Stalt Köln $z$, , überliess jedoch die Entscheidung darüber dem frz. Marschall Broglio (Rheen am 17. Mai nach Bonn). Vermutlich ist der Antrag (les Kölner Stadt. rats nicht durchgedrungen. 
danten de (kayot 800000 Livres $^{1}$ ) auszahlen zu lassen. Zugleich bemerkte Rheen, er habe Madame la Maréchale de Mirepoix ${ }^{2}$, die Frenudin der Pompadour, der er bereits mehrfach seine Aufwartung gemacht hatte, gebeten, sich bei dieser für iln zu verwenden ${ }^{3}$ ). Gross war indes das Erstaunen in Bonn, als der Intendant, für den Rheen einen Zahlungsbefehl von $800000 \mathrm{I}$. ervirken sollte ${ }^{4}$ ), unter keinen Umständen melır als $100000 \mathrm{~L}$. hergehen wollte. Man musste sich endlich damit begnügen. Dem Gesaudten hatte man in Paris auf seine Vorstellung erwidert, man würde ${ }_{n}$ successive $^{u}$ die Millionen abtragen $\left.{ }^{5}\right)$. Dem Kurfürsten war damit wenig gedient, da seine Fimnahmen infolge des Vormarsches der Alliierten langsam zu versiegen begannen. Rheen schilderte eingehend in einem Bericht an den Kriegsminister Belleisle die Lage der kurfürstlichen Lande und teilte ihm die ungeheuren Forderungen Ferdinands vom 6. Mai bezw. 12. Juni mit $\left.^{6}\right)$. In Bonn empfahl er ein kurfurstliches Handschreiben an Georg II., in dem mit dem Hinweis, es ständen keine kurfürstlichen Truppen gegen Hannover zu Felde ${ }^{7}$ ), Schonung von Land und Leuten beantragt würde ${ }^{8}$ ). Der Kurfürst befolgte den Rat, erhielt jedoch als Antwort nur „duukle, zweideutig und boshafte, wiewobl glimpfliche Vorwilrfe" ${ }^{49}$ ). Nach der Lage der Dinge

1) Möglicherweise sind diese 800000 Livres der von Huppertz a. a. O. S. 100 Anw. 2 erwähnte Tresor von $800000 \mathrm{~L}$.

2) Sie war die Gattin des Ende Olst. 1757 verstorbenen Marschalls Mirepoix (Duc de Luynes, Mémoires sur la cour de Louis XV. Paris 1864. Bd. XVI, S. 194). Luyues sagt in Bd. XVI, S. 302: „Il est dit que Mme de Mirepoix avoit beaucoup contribué à la fortune rapide de son mari. Toutes ces graces elle les doit a $\mathrm{Mme}$ de Pompadour, avec qui alle s' étoit liée de l'amitié la plus intime."

3) Theen nach Bonn am 9. Mai 1758; Fasc. $222^{\prime}$.

4) Raesfeld ann 15. Mai 1758 an Rheen: Fasc. 222 ${ }^{1}$. - Die Auszahlung erfolgrte Ende Mai. Es war also un die Zeit, da de Gagot durch Duvernay ersetzt wurde. Waddington, a. a O. Bd. II, S. $64 \mathrm{f}$.

5) Rheen an 27. Mai 1758 nach Bonn; Fasc. 222 ${ }^{1}$. Wenn hier von Million'n gresprochen wird, so sind gewiss auch die der franz. Armee goleisteten Dicuste und Lieferungen gemeint. Arb S. 67 .

6) Rheen an 19. Juni nach Bonn; Fase. 2221. - Vergl. vorl.

7) Auch (in Beweis für die S. 44 ff. in vorl. Arbeit verfochtene Ansicht.

8) Rhcen am 25 Mai 1758 nach Bonn; Fase. 2221.

9) Diese Kritik übte Rheen an der ihm von Raesfeld mitgeteilten 
lätte er kaum eine anderc erwarten können Eben erst hatte der glänzende Vormarsch Ferdinands bis auf das linke Rheinufer durch den Sieg bei Krefeld seinen Höhepunkt erreicht. Friedrich (ler (Grosse feierte in einer begeisterten Ode 1) den glücklichen Verlauf der Ereignisse und riet, wie bekannt, in grimmigem Scher\%, den Franzosen die Anfangsbuchstaben des Westfälischen Friedens auf den Rücken einzubrennen ${ }^{2}$ ). Doch nicht nur die Antwort des englischen Königs, auch die französischen Finauzen zeigten die Wirkungen dieses Sieges. Hatte Rheen noch am 17. Juni gehofft, dass „der erloschene Kredit des Königs" durch siegreiche Schlachten wieder belebt werde ${ }^{3}$ ), so musste er jetzt melden, die Niederlage würde die vom Kurfürsten ersehnten Zahlungen noch mehr hinausschieben ${ }^{4}$ ). Der üble Eindruck dieser Nachricht in Bonn wurde noch verstärkt durch die beginnende rucksichtslose Ausbeutung der kurfürstlichen Gebiete seitens der Franzosen. Es begann sich am Kurkölner Hofe ein Stimmmingswechsel geltend zn machen, der durch die Verleihung des „Privilège du papier timbré ${ }^{\text {(5) }}$ ), das Klemens August auf Verwendung des französischen Gesandten zu Wien, Stainville, vom Kaiser Ende Juli verliehen worden war, eher gefördert als gehemmt wurde. Das Privileg selbst war von recht zweifelhaftem Werte. Während der Kurfürst sich in Paris darüber beklagte, dass man die Lieferungen seiner Untertanen mit sog. „reçus ${ }^{\star}$, wertlosen Empfangsbescheinigungen, bezahlte ${ }^{6}$ ), wollte er jetzt durch ähnliche Massnahmen seine gesunkenen Einktinfte aufbessern. Die beginnende wirkliche Hinneigung des Kurfirsten zı Österreich erregte bei der französischen Diplomatie, deren Politik mit Ruick. sicht auf die Verhältnisse zum Reich trot\% des Bündnisses in

Antwort des Königs Georg II. aus Kensington vom 27. Juni 1758. Rheen an 23. Juli 1758 nach Bonn; Fase. 2221.

1) Oeuvres de Fredéric le Grand. Berlin $1846 \mathrm{f}$. Bd. XII, S. $8 \mathrm{f}$.

2) Knesebeck a. a. O. Bd. I, S. 63.

3) Rheen am 17. Juni 1758 nach Bonn; Fasc. $222^{1}$.

4) " 28 . " 1758, , ,2221.

5) Rheen gibt den Ausdruck im Deutschen mit „Privileg des Stempel-Papiers" wieder, Er berichtet über die Angelegenheit am 28. ı. 29. Juni und meldet arn 2. Aug. die Verleihung. Fasc. 2221.

6) Zahlreiche Briefe Raesfeld an Rheen im Monat August 1758. Fasc. 222\%. 
einem fortwährenden Gegensatz zu der Österreichs stand ${ }^{1}$ ), grösstes Unbebagen und bei dem kurkölnischen Gesandten unwillige Verwunderung. Dieser hatte noch am 19. September von Paris aus, wo sich damals der Ministerwechsel Bernis Clıoiscul vorbereitete, folgenden beachtenswerten Brief nach Bonn gesandt ${ }^{2}$ ). Er lautete:

"Es ist mir zur Fürderung des wirklichen Vorteils für Ew. kurfürstliche Durchlaucht äusserst erwünscht, wenn erwähnter Kardinal [Bernis] immer den Beratungen mit Sr. Majestät beiwohnt und mit dem Herzog von Choisenl, alias Marquis de Stainville, arbeitet; denn wenn er alles genannten Herzog machen lässt, befürchte ich, Monseigueur, man möchte beim Friedenschluss die Behandlung Ew. kurfürstlichen Durchlaucht, so einrichten, wie es dem Wiener Hof gefallen wird, sie vorzuschreiben und weniger vorteilhaft festzusetzen. Kaiser und Kaiserin gedenken nichts zu tun, was den Einfluss der Kurfürsten und geistlichen Fürsten vergrössern und sie mächtiger machen kïnnte, als sie schon sind, folglich die Lage Ew. kurfürstlichen Durchlaucht verbessern könnte, indem man den Kurfürsten von Hannover und Brandenburg (ausser der Bezahlung dessen, was seine Untertanen den Truppen der beiden Fürsten und ibren Verbuindeten in natura und in Geld haben liefern müssen) zur Entschädigung und Genugtuung fiur die erlittenen Verluste, Schäden und Nachteile irgend ein ertragreiches Lehen oder Besitztum wegnähme, zumal dem Kurfürsten von Brandenburg einige der schönen Balleien, die dem Deutschorden durch seine Vorgänger entrissen und geraubt worden siud, und deren Zuruickerstattung jch bei Gelegenbeit für den Deutschorden beantragen werde, obschon man nicht gern davon sprechen hört ${ }^{3}$ ). Man wird sehen, wie der Kaiser für sich und seine Nachkommen Lehen des kurfürstlichen Hauses Brandenburg sichert, sobald man den König von Preussen vernichtet hat. Es wird indessen noch viel Blut vergossen werden müssen, bevor man

1) Stuhr a. a. O. Bd. II, S. 289

2) Rheen am 19. Sept. 1758 nach Bonn. Fasc. 222\%.

3) Es handelte sich um Gebiete Preussens, Livlands. Kurlands und Semigalliens, auf die der Kurfürst Clemens August in seiner Eigenschaft als Deutschordensmeinter Anspruch erhob. Sein Gesandter in Regensburg brachte Mitte Juli 1760 einen dahin lautenden Antrag beim Reichstag ein. Faber a. a. O. Nene Folge 2. Teil S. 73; 5. Teil S. 219. 
dieses Ziel erreichen kann. Anch werden die französischeu Heere zu diesem Zwecke in nächsten Feldzuge gut opericren miissen".

Scharf stellt Rheen in diesen Zeilen den Siandpunkt Österreichs und Frankreichs.wegen Gebietserwciterungen der geistlichen Kurfürsten gegeniuber. Er will offenbar damit zeigen, dass Kurköln unbedingt an die Seite Frankreichs gehöre, unterlässt es aber nicht, seinen Argwolın gegen den isterreichisch gesinnten Choiseul und seinen wachsenden Einfluss zu äussern. Und nun wollte sein Herr sugar ganz zur Partei Österreichs iibergehen! In Paris deutete man Rheen an, „überrascht zu sein, dass Sr. kurfürstlichen Durchlaucht sich zu dem Scbritt verstanden habe, die Verwendung der Dienste des Wiener Hofes neben den Ihrigen "u suchen" "). Dieser bemühte sich eifrig, Verstimmungen iu Paris zu beseitigen, muss aber anscheinend von Bonn aus nicht so unterrichtet worden sein, um mit Erfolg arbeiteu zu können. Schon Ende April 1758 hatte er den Kurfürsten um grösseres Vertrauen gebeten, weil ihm uichts von dem zum Reichskontingent gesandten Rekrutentransport ${ }^{2}$ ) mitgeteilt worden sei ${ }^{3}$ ). Diesmal wissen die Berichte Rheens nichts von Verhandlungen, die damals in Herbst 1758 zwischen Kurköln und Österreich über eine Militärkonvention schwebten. In ihnen wird ein wicbtiger Anlass für die Hinneigung des Kurfürsten zu Österreich zu suchen sein.

Ans zwei Klemens August unterstehenden Bistünern, Osnabrück und Hildesheim, waren zum Reiclssheere keine Truppen gesandt worden. Der Kaiser drängte nun damals jenen nicht auf Einhaltung dieser reichsrechtlichen Verpflichtuugen. Er suchte ibn vielmehr zu veranlassen, die Aufstellung der Truppen für die säumigen westfälischen Stände selbst in die Hand zu nelımen und die Kosten, wie dies die Reichsverfassung zuliess, jenen einfach aufzuerlegen. Weiterhin war es ein sebnlicher Wunsch des Kaisers, das kurkölnische Kontingent über die matrikelmässige Stärke hinans verstarkt $z$ sehen ${ }^{4}$ ). Uber beide Punkte fanden nun bis Ende 1758 zwischen denı Grosskanzler Raesfeld und dem Vertreter des Kaisers zu Frankfurt, Graf von Pergen - an ihn

1) Kheen am 19. Okt. 1758 wach Bonn; Fasc. 222\%

2) Becker a. a. O. Annalen, Heit 91, S. 76.

3) Rheen am 26. April 1758 nach Bonn; Fasc. $222^{1}$.

4) Schreiben vom 22. Aug. 1758; Fasc. 199. 
Von Kurkölns Beziehungen zu Frankreich u. seiner wirtschaitl.Lage. 81

hatte man von Wien aus jenen gewiesen - Verhandlungen statt, die sich schwierig gestalteten. Man sehickte sich gegenseitig Vertragscntwürfe zu, obne sich einigen zu künnen. So ging ein au 4. Oktober von Pergen gesandter Entwurf am 10. Oktober geändert nach Frankfurt zurück ${ }^{1}$ ). Dennacb war Klemens Anfstellung von $1433^{3} / 4$ Mann Infanterie in 1 Regiment zu 3 Bataillonen und 285 Mann Kavallerie in 2 Eskadronen für die säunigen westfälischen Stände bereit. Dafür sollten diese aber „durch hinlängliche Exekutionsmittel ${ }^{"}$ das Geld für 3 Monate im voraus beibringen. Im zweiten Teile des Entwurfs verpflichtete sich der Kurfürst, seine Truppen auf 4800 Mann zu Fuss und 1200 Mann zu Pferd zu erböhen, wenn der Kaiser zwei Drittel der Unkosten trage. Docb aucb diese Bereitwilligkeit hatte ein ${ }_{n} \mathrm{Abcr}{ }^{*}$. Überall und so auch hier, we es für den Kurfürsten galt, Verpflichtungen einzugehen, finden sicb einschränkende Wendungen wie: noweit sich die Möglichkeit dazu vorfinden wird ${ }^{4}$.

Ennen ${ }^{2}$ ) und Huppertz ${ }^{3}$ ) bericbten beide über diese Verhandlungen. Jener ist indes im Irrtum, wenn er annimmt, ler Kurfürst babe „sein Kontingent" wicht zur Reicbsarmee geschickt ${ }^{4}$ ), betrachtet aber mit Recht, wie sich zeigen wird, eine Verpflichtung zur. Stellung von Truppen und damit die Militärkonvention als bestehend an. Dies bestreitet nun Huppert\% mit den Worten: $\eta$ um schliesslich von beiden Seiten aufgegeben zu werden", zumal sie nim Widerspruch zu seinen geäusserten friedfertigen Absichten" gestanden babe. Ohne diese Friedfertigkeit im geringsten be-

1) Fasc. 199 .

2) Clem. August weigerte sich sein Kontingent zor Reichsarmee zu stellen. Mit 4800 Mann war er noch im Rückstande und der Kaiser wollte ihm alle Ansprüche an die kleinen Fürsten des westrïlischen Kreises, die noch 1500 Fusssoldaten und 200 Reiter an die hrichsarmee zu liefern hatten, abtreten, wenn er ungesäumt seiner Reichspflicht nachkommen werde." Ennen a. a. O. Bd. II, S. 334.

3) „Bereits am 10. Okt. 1788 (!) kam es zu einem förmlichen Entwurf einer Militärkonvention, in welcher der Kurfürst 4800 Infanteristen und 1200 Reiter stellte, wenn der Kaiser zwei Drittel der Kosten übernahm ...... In November aber wurde diese Konvention schon wieder ahgeändert, um schliesslich von beiden Seiton aufgegeben zu werden." Huppert\% a. a. O. S. 105 Anm. 4.

4) Becker a. a. O. Annalen Heft 91, S. $63 \mathrm{ff}$. 
zweifeln zu wollen "), wird man doch mit Ennen ${ }^{2}$ ) an den vollzogenen Abschluss einer Militärkonvention festhalten müssen. Noch im August 1759 erkundigte sich Graf P'ergen in ungehaltenem Tone, wie es mit der Stellung der Kontingente für die saumseligen westfälischen Stände sei, da "sich annoch keine Würkung zeiget" "3). Und 3 Monate später schreibt derselbe: Der Kaiser wolle in Beherzigung der Unterredung - es hatte eine solche zwischen Raesfeld und Pergen in Spa stattgefunden - nicht „lhro Churfürstliche Durchlaucht mit dem wirklichen Vollzng sothaner Convention beschwehren", doch müssten die Kontingente der westfälischen Stände ${ }_{n}$ executive ${ }^{4}$ beigebracht werden ${ }^{4}$.

Welcher Art die beherzigenswerten Worte Raesfelds gewesen waren, lässt sich leicht erraten. Die traurige Lage des Kurfïrsten und seiner Lande erlaubte es nicht, den Verbindlichkeiten nachzukommen. Doch, und damit kommt man der Erklärung für die bei der Kriegsscheu des Kurfürsten auffälligen Verträge nälıer. hatte dieser denn überhaupt die Absicht, ja die Möglichkeit seinem Versprechen nachzukommen? Es kann dies mit Recht stark in Frage gestellt werden. Bei der Übernahme der Ver. pflichtung waren die Militärverhältnisse und die allgemeine Lage Kurkölns so, dass sie • unmöglich eine Gewähr für entsprechende Durchführung boten. Nicht um die Stellung von Truppen, sondern um die Erlangung von Geld war es Klemens August zu tun. Ehen deshalb forderte er in dem erwähnten Vertragsentwurf Geld fiir drei Monate im voraus und fügte seinen Verpflichtungen immer

1) Wenn der Kurfürst dem münsterschen Landtag auf seine Bitte, die münst. Miliz wieder von Bonn nach Münster yehen zu lassen, am 1. April 1758 erwiderte, er habe nie die Absicht gehabt, seine Truppen $z u$ den königl.franz. stossen $z u$ lassen, vielmehr geien sie für seine Residenz nötig, so ist dem $m$. Er. unbedingt Glauben zu schenkon (vergl. auch vorl. Arb. S. $44 \mathrm{ff}$ ) und darin keine Ausrede zu sehen, die ,den wahren $Z$ weck" dieser Truppenentfernung verhüllen sollte (Huppertz a. a. O.S. 105 Anm. 3). Damals war es um die Zahl kurköln. Truppen in Bonn schlecht bestellt. Man denke an den Rekrutentransport zur Reichsarmee (Vorl. Arb. S. 80). Es handelt sich also nicht um eint : $u f^{-}$ keimende Kriegslust.

2) Ennens Mitteilung Bd. II, S. 334 stützt sich auf Arch. dn min. des aff. étrang. \%u Paris. Col. reg. 96.

3) Pergen an 1. Aug. 1759 aus Spa nach Bonn; Fase. 199.

4) Pergen am 14. Okt. 1759 aus Frankf. nach Bonn; Fasc. 199. 
einen abschwächenden Zusat\% hinzu. Wenn er sein Ziel nicht erreichte, so lag das vor allem an der vorsichtigen österreichischen Diplomatie, die sich in richtiger Einschätrung des Bonner Hofes niemals $z u$ Geld $\%$ ahlungen herbeigelassen lätte, ohne eine sichere Gewähr für entsprechende Gegenleistungen in Händen zu haben. Rheen, der kurkölnische Gesandte in Paris, war von diesen Beziehungen zu Österreich seinen Briefen nach nicht unterrichtet. Trotzdem bemülıte er sich, wie erwähnt, das räitselhafte Verhalten seines Herrn zu entschuldigen Auch Frankreich, das wohl tiefer als Rheen salı, glaubte dem Kurfürsten Beweise seines Wolıwollens geben zu mïssen und fand, da dieser in Wien eben nichts erreicht hatte, bald wieder Gegenliebe. Als Klemens August Mitte Oktober Ludwig XV. bat, seine Untertanen durch Quartierlasten nicht in Verzweiflung, zur Auswanderung und zum Hungertod zu treiben, liess dieser in Bonn ein Handschreiben ïberreichen, in dem die Erfüllung aller Wünsche und die entsprechende Instruktion des Oberkommandierenden Contades versprochen wurde. Der französische Gesandte Breteuil unterstittte in Bonn dieses königliche Eingreifen leblaft und war vor allem bemiiht, unter Betonung des religiösen Moments Versuche der englisch-preussischen Partei, die günstige Gelegenheit zur Gewinnung des Kurfürsten zu nutzen, zu vereiteln ${ }^{1}$ ). Als nun nach Constades am 8. Dezember in Brühl unter Schmeicheleien und Versprechungen seine Aufwartung machte und Klemens August ein wirksames Zugeständnis an seine Eitelkeit gemacht wurde ${ }^{2}$ ), waren die letzten Wölkchen einer Verstimmung verschwunden. Ferdinand, der in Bonn die Neutralität anbot, falls man den Franzosen den Aufenthalt im Kurstaat während des Winters verweigere, wurde abgewiesen. Was indes von der Sinnesänderung der Franzosen zu halten war,

1) Enneri a. a. O. Bd. II, S. $333 \mathrm{f}$. Die Möglichkeit eines Erfolges der engl.-preuss. Partei ist nicht zu stark zu unterstreichen. Diese nie granz aussetzenden Bemühungen der Gegner werden damals höchsteris nachhaltiger als sonst gewesen sein Ein "völliger Ubertritt" (Siehe, Ennen) lag aber ganz ausser dem Bereiche der Möglichkeit - man denke an die Militärkonvention. Praktisch wäre der Anschluss an England-Preussen nur ein ohnmächtiger, wirkungsloser Protest gegen die Vergewaltigung her kurf. Lande gewesen.

2) Dem Kurfürsten wurden die militärischen Ehren eines Prinzen von königlichem Geblüt erwiesen. Ennen a. a. O. Bd. II, S. 336. 
lässt ein Brief des Kriegsminister's Belleisle an Contades vom 7. Dezember erkenneu '). Es war die Antwort auf ein Schreiben des französischen Generalissimus, man künue während des Winters in den besetzten Gebieten von Lüttich, der Pfalz und Köln dem Bülger kein Bett gönnen, bevor die Soldaten untergebracht seien. Belleisle entgegnete, man habe den richtigen Ton angeschlagen. Dieser sei in Umgang mit den Deulschen nötig, und Constades werde gut tun, „sich dessen im Verkehr mit den Regierungen des Kölner Kurfürsten und noch melır des Pfälzers zu bedienen ${ }^{42}$ ).

\section{Kurköln von Mitte 1758 bis Ende 1759.}

Wie schon erwähnt, war das rheinische Erzstift bis um die Mitte des Jahres 1758 noch nicht vom Feinde betreten worden ${ }^{3}$ ). Als Ferdinand von Braunschweig gegen Ende Mai seine Vorbereitungen beendet hatte, änderte sich auch auf dem linken Rhein. ufer manches. Bei Emmerich ging er über den Strom, fasste mit den Spitzen seiner Truppen am 1. Juni dort festen Fuss und drängte die Franzosen, die keinen Widerstand leisteten, inmer mehr nach Siden. Überall trieben die Alliierten nach Kriegsbrauch Kontributionen ein, von denen besonders hart das im Norden des rheinischen Erzstifts liegende Städtchen Uerdingen betroffeu wurde.

Da nach Angabe der Alliierten von Bürgern dieses Orts auf die Soldaten geschossen worden war, verlangte General Wangenheim am 16. Juni die Ablieferung sämtlicher Gewehre, in 12 Stunden 2000 Pistolen in bar und für den folgenden Tag 6 Ubr 15000 Rationen Heu und Hafer; andernfalls würden Planderung und Brandschatzung folgen. Die Ratsmitglieder wurden als Geiseln weggeführt und mussten dem preussischen Hofrat Voss zu Duisburg, der dem Ort 1000 Pistolen nebst 10000 Rtlr. anstatt der 15000 Rationen vorschoss, den Betrag garantieren ${ }^{4}$.

1) Schaefer a. a. O. Bd. II', S. 181.

2) E. v. d. Knesebeck, Zur Charakteristik der ersten Hälfte des $7 \mathrm{j}$ ahr. Krieges im nordwestlichen Deutschland. Archiv des hist. Vereins für Niedersachsen. Jahrg. 1845. S. 334.

3) Vergl. vorl. Arbeit S. $69 \mathrm{f}$.

4) T.-Krgk.; 1759, Bd. III, S. 284 f. - Der kurk, Grosskanzler Raes- 
Clemens August befand sich in der grössten Aufregung. Sie stieg noch, als Ferdinand am 23. Juni bei Krefeld iiber die Franzosen siegte. Streifkorps zeigten sich schon in der Umgebung von Bonn ${ }^{1}$ ). Der Kurfürst bat in seiner Angst und Sorge den Kurfursten von Trier, ilın mit seiner Garnison ${ }^{2}$ ) in die Festung Ehrenbreitstein auf $/$ unehmen $^{3}$ ); so wenig vertraute er mebr der Kriegskunst der Franzosen. Er liess sich jedoch von seinen Vertrauten und dem französischen Befehlshaber Clermont beruhigen ${ }^{3}$ ). Diesem war nach der Niederlage die strenge Weisung Belleisles zugegangen, sich auf kcinen Fall weiter auf Köln zu zurüickzuziehen, da die Preisgabe der pfälzischen und kurkölniscben Gebiete die Bestürzung aller mit Frankreich verbündeten Reichsfürsten auf das Höchstc treiben werde ${ }^{4}$ ). Mit Befriedigung erfullte es so auch Clemens August, als es dem Nachfolger Clermonts, Contades, gelang, Ferdinand vom linken Rheinufer wegzumanöverieren, weniger durch seine überlegene Kriegführung als infolge der Bedrohnng des Rückzuges Ferdinands durch Soubise, der von Hessen aus vordrang und in rücksichtsloser Weise das Land ausfouragierte und brandschatzte ${ }^{5}$ ). Ferdinand, der, wie wi' wissen, zwar auch die Lande seiner Gegner zu starken Leistungen heranzog - so berechnete das rheinische Erzslift den durch den Aufenthalt der Alliierten im Sommer 1758 verursachten Schaden auf iiber 400000 Reichstaler 6; -- war itber ein solches Vorgehen empört. Um eine Änderung herbeizuführen, richtete er am 9. August einen Brief an Clemens August, in dem er diesem erklärte, er

feld teilte die Behandlung Uerdingens an 23. Juni unmittelbar detn frz. Krieg'sminister Belleisle mit. Fasc. 22: 2.

1) Eunen a. a. O. Bd. II, S. 331 .

2) Was dem Kurfürsten an eigenen Truppen zur Verfügung stand, kain für den Widerstand nicht in Betracht. Es sollten zwar nach don Landtagsprotokollen die $\% u$ Hause Gebliebenen 600 Mann betragen, diese waren auch durch die münstersche Miliz, die der Kurfürst beim Annarsche Ferdinands hatte nach Bom kommen lassen, verstairt ivorden; trotzdem waren es insgesamt kaum melir als 1000 Mnun, die wiederuın böchstens nur zu zwei Drittel marschbereit waren. Huppertz a. a. O. S. 102, 105. Gaz. vom 4 April 1758; Köln, 4. April.

3) Ennen a. a. O. Bd. II, S. $331 . \quad$ 4) Stuhr a. a. O. Bd. II, S. 102.

5) Schäfer a. a. O. Bd. II 1, S. 169.

6) T.-Krgk., 1759; Bd. III, S. 282. - Faber a. a. O. Neueste Folge 4. Teil S. 412, 432. - Oertel a. a. O. Bd. IIl, S. 799. 
müsse die Behandlung der kurfürstlichen Lande von dem Auftreten Soubises in Hesseu abhängig machen ${ }^{1}$ ). Rheen, der kurkölnische Gesandte in Paris, wurde angewiesen, die Sache dort zur Sprache $z u$ bringen. Er erhielt indes von den französischen Ministern Bernis und Belleïsle zur Antwort, die Franzosen könnten auf das Recht des Krieges nicht verzichten, docb bitte man deu Kurfursten fest zu bleiben ${ }^{2}$ ). Diese Entgegnung wäre für Clemens August noch erträglich gewesen, wenn wenigstens der die Lippe aufwärts vorstossende Marschall Contades seine Gebiete glimpflich bebandelt bätte. Doch weit davon entfernt, machte er es ebenso wie Soubise. Sofort wies Ratesfeld den Gesandten in Paris an, Schritte zu tun; er schricb, der Kurfürst sei bestiirıt über das französische Beitreiben von Lebensmitteln aller Art ${ }^{3}$ ). Rheen erlielt auf die dem Kriegsminister überreichten Mémoires, in denen über die Gewalttätigkeiten der französischen Armee geklagt und um Geld gebeten wurde ${ }^{4}$, von diesem die Antwort: ${ }_{n}$ Wir liaben kein Geld; sobald wir welches haben, werde ich Sorge tragen, Sr. kurf. Durchl. zu Köln vor den andern Bundesgenossen des Königs solches äberweisen $z u$ lassen. " Mit dieser scheinbar nur den zweiten Punkt berührenden Erwiderung hatte der französiscbe Minister auch den ersten, vielleicht wider Willen zu ehrlich, beantwortet. Mehr als je begann der Krieg den Krieg zu ernähren. Doch nicht nur dies. Durch planmässige Verwüstung der von ihnen durchzogenen Gegenden glaubten die Franzosen, den Krieg rascher seinem Ende zuzufübren. Zwischen Rhein und Weser sollte nach einem Befehle

1) Knesebeck, Archiv; a. a. O. S. 330.

2) Raesf. am 24. Aug. 1758 an Rheen. Fasc. $222^{2}$. Rheen am 29. Aug. 1758 an Raesf. Fasc. $222^{2}$. Rheen bezeichnet in seinem Brief das Gebiet des Kurf. als "Etat neutre de l'Empire." -- Am 2. Sept. teilt Rheen unit, auch Kurpfaly habe von Ferdinand einen Brief erhalten. Fasc. 222 .

3) Raesfeld teilt Rheen bei dieser Gelegenheit mit, die Geldabgaben an die hannoverschen Truppen betrügen 71000 Rtlr., die Naturalleistungen 40000 Rtlr., der Wert der vom Jahre vorher an die Hannoveraner erfolgten Leistungen 45000 Rtlr., an die Franzosen 800000 Rtlr. Dazu kämen der Unterhalt des Hochstiftischen Regiments mit 60000 Rtlr. und die Landpensionen mit 29000 Rtlr. Die fehlende genauere Angabe, für welche Gebiete diese Summen gelten - von Paderborn ist nur beiläufig die Rede - beeinträchtigt den Wert dieser Angaben. Fasc. 2222.

4) Eins ist vom 28. Aug., cin anderes rom 5. Sept. datiert Fasc. 2222. 
Bellcïsles alles vernichtet werden, was nicht aufgebraucht werden könne ${ }^{1}$ ). Dabei blieb es trotz aller von Clemens August geführten Klagen. „Sie werden, so lautete die erneute Weisung. Belleïsles an Contades am 28. September, alles, was Sie nicht aufbrauchen, vervichten, um ganz Westfalen von Lippstadt und Münster bis zum Rheine einerseits und von der Lippe und Paderborn bis nach Kassel andrerseits zu einer Wïste zu machen" 2). Bei der kaum nennenswerten Beachtung, die Ferdinand somit seinen Forderungen entgegengebracht sah, konnte er unmöglich auf die kurfürstlicheu Gebiete melır Rücksicht nehmen, als es ihm die unbedingt nötige Ruicksicht auf die Bewohner und die Vorsorge auf die Verpflegung seines Heeres geboten. Er hatte sich entschlossen, deu vordringenden Franzosen gegentiber, wenn eben möglich, Westfalen zu behaupten, und die Stellung bei Koesfeld Dülmen nur vorübergehend, über Münster nach Osten ausweichend, aufgegeben.

Überall trieb er auf Bezahlung der im Frühjahr ausgeschriebenen Kontributionen ${ }^{3}$ ). Mit Not wurden im August 1758 die ersten Raten beglichen. Viele Verzögerungen, gleichgültig ob aus Unvermögen oder Widersetzlichkeit, wurden durch Exekutioneu gealındet ${ }^{4}$ ). Dazu lud man den Bistümern noch Leistungen der mannigfachsten Art auf. So musste Osnabrück Ende August täglich 150 Fuhren zum Transport von Lebensmitteln aus dem dort befindlichen Magazin nach Münster und zur Armee stellen ${ }^{5}$ ). Das Herrogtum Westfalen erhielt am 20. August eine Aufforderung, 70 Stück Eichenbäume, 300 Stäck Eichenbohlen, 3000 Faschinen, 5000 Pallisaden, 9000 Faschinenpfähle und 16 Fuder grïne Weiden

1) Knesebeck, Archiv a. a. O. S. 335 .

2) Knesebeck, Archir a. a. O. S. 336. Uber die Behandlung der Einwohner schreibt Marquis de Chevert, einer der rücksichtslosesten frz. Untergenerale, am 31. Okt. 1758 an Contades - es handelt sich um die Einwohner von Soest - ,Je n'ai épargné ni menaces de coups de Butôn, ni celle de la Démolition des maisons". Knesebeck, Archiv a. a. O. S, 332 .

3) Vergl. vorl. Arbeit. S. 67. 230,261 .

4) Huppertz a. a. O. S. 120. - T.-Krgk. 1759, Bd. IlI, S. 194, 215, 226,

5) T.-Krgk, 1759; Bd̀. III, S. 216. Man schätzte die Gesamtzahl der von diesem Stift bis dahin greleisteten Fuhren auf 4300. T.-Krgk. 1759; Bd. III, S. 176 . 
nach Lippstadt zu liefern $\left.{ }^{1}\right)$. Dazu kamen für die Ämter Erwitte, Oestinghausen, Geseke und Ruthen an 5. September 6000 Berliner Scheffel Roggen und 50000 Rationen ").

Bedeutend schärfer litten wieder Paderborn und Münster.

Von jenem forderten die Alliierten am 9. September in 8 Tagen 80000 Rationen für Lippstadt. 5 Tage später begann der Durchmarsch der Truppen des Generals Oberg, den Ferdinand gegen den Hannover bedrohenden Soubise gesandt hatte. Sofort wurden 9000 Stück Brote à $8 \mathrm{Pfd}$., $3000 \mathrm{Kav}$. und $1000 \mathrm{Inf}$. Rationen, 24 Fuder Holz, 1500 Bund Lagerstroh und für die Folge täglich 8000 Portionen und 3-6000 Rationen sowie 10 Klafter Holz verlangt.

Kaum war Oberg abgezogen, da drängte die Intendantur der Alliierten auf Beschaffung der vorlin erwälnten 80000 Rationen. Klagen und Bitten halfen wenig. Erleichterungen fanden kanm statt. Eben hatte man bis zur Mlitte des folgenden Monats einen Teil abgetragen, da lief vom Erbprinzen von Braunschweig eine neue Forderung für den 18. Oktober ein: 30000 Bund Stroh a 8 Pfd., 16000 Rationen und 80 Klafter Holz; 2 Tage später von General Hardenberg aus Lippstadt 500 Fuder Holz und 100 mit Schüppen, Hacken und Spaten ausgerüstete Leute. Die am 21. Oktober zur Überfülırung des Bielefeldschen Magazins nach Lippstadt befohlene Stellung von täglich 100 Fuhren wurde auf zweimal in der Woche je 60 ermässigt. Der kleine Vorteil ging indes wierler verloren, als am 24. Oktober $1000 \mathrm{Klafter} \mathrm{Holz}$ gefordert sowie befollen wurde, 10000 Brote, die Oberg in Paderborn gelassen hatte, in 48 Stunden nach Lippstadt $z u$ schaffen ${ }^{2}$ ).

Nicht besser erging es Münster. Als Mitte August Ferdinand seine Truppen bei Koesfeld konzentrierte, verlangte er am 17. August von den Ämtern: Wolbeck 50000, Werne 20000, Lassenberg 20000 sowie Dübnen 20000 Rationen und schon am folgenden Tage innerhalb 5 Tagen vom gesamten Bistum 500000 Rationen und ebenso viele Portionen.

An dieser Stelle möge etwas zu der sich bier sehr lejcht aufdrängenden Frage gesagt werden, wozu Ferdinand die fort-

1) T.-Krgk. 1759; Bd. III, S. 154, 287.

2) T.Krgk. 1759; Bd. III, S. 179 f., 186, 221 f., 227 , 237 f., 244 f. Näheres bei Stoffers a. a. O. in d. Ztschr. f. vat. Gesch. u. Alt. Bd. 70, 2, Abt. S. 75 f. 
Von Kurkölns Beziehungen zu Frankreich u. seiner wirtschaftl. Lage. 89

während geforderten Lebensmittel, die in ibren Umfange doch wcit über die Stärke seines Heeres hinausgingen, verwertete. In recht eingehender Weise klärt er selbst uns in einem Briefe vom 23. Dezember 1762 an Lord Halifax zol London auf ${ }^{1}$ ). Demnach war Ferdinand nicht nur von Friedrich II. sondern auch vou Georg II. seit Anfang des Jahres 1758 aufgefordert worden, in den besct\%ten Provinzen und Bistumern Kontributionen zu erheben. Das Geld kam aber nur knapp ein, und man morkte damals schon, ndass man sich an die Lebensnittel und Bodener\%eugnisse dieser Provinzen halten müsse, welche an Korn und Fourage mehr Uberfluss als an harem Geld besitzen". So mussten denn dic Länder die Winterquartiere tragen, Festungsmaterial beschaffen und mehrere 1000 Rekruten stellen. Da die Lieferungen zu reichlich waren, ü̈tigte man die Bevölkerung dic gesparten Rationen und Portionen zurückzunelmen. Die Gelderträgnisse der Gebiete, die jährlich mebrere 100000 Taler betrugen, flossen in die sogenannte Kontributionskasse, in die so während der Jahre 1759-1762 an 2 Millionen Taler kamen. Davon verteilte Ferdinand Gratifikationen, befestigte wichtige Pläłze, warb ein Korps von 6000 Mann und unterhielt es.

Ausser den vorhin erwähnten Lebensmitte!n musste Münster am 18. August 300 Spannfulıren und einige Tage später täglich 150 Fuhren beschaffen. Für jede fehlende wurden 50 Rtlr. Strafe erhoben. Ferner waren zur Ausbesserung der Strassen nach Koesfeld und Dülmen 20000 Fascbinen und eine Menge Arbeitskrätte bereitzustellen. In Münster wurden aus dem Zeughaus zalireiche Kanonen und viele Zentner Pulver, Blei und Kugeln den Wert berechnete man his zum 18. September auf 16000 Rtlr. weggenommen. Auf dic Einspriuche liess Ferdinand erwidern, es würde alles \%urïckerstattet ${ }^{2}$ ).

Am wenigsten wurde in der zweiten Hälfte des Jahres 1758 anscheinend das Bistum Hildesheim belästigt. Abgesehen von fortwährenden Fubrdiensten - die Zahl der gestellten Wagen schätyte man für die Zeit vom Juli bis November auf etwa 2000 - blieb es bis zum Anbruch des Winters leidlich verschont ${ }^{3}$ ).

1) Knesebeck a. a. O. Bd. II, S. $565 \mathrm{f}$.

2) Huppertz a. a. O. S. 121. T.-Krgk. 1759; Bd. III, S. 247, 250 f., 270 f.

3) T. Krgk. 1759 ; Bd. III, S. 174 f. 
Schmerzlicher als all dies Elend seiner Landeskinder traf den Kurfürsten die Mitte Oktober erfolgte gänzliche Sperrung seiner Eink ünfte in den von Ferdinand besetzten Gebieten ${ }^{1}$ ). Man batte zwar schon im April, bevor die grossen Kontributionen ausgeschrieben worden waren, die kurfürstlichen Gefülle beschlagnahmen wollen und auch bei Gelegenheit, wenn die Bistïmer mit ihren Leistungen gar zu saumselig waren, die kurfürstlichen Kassen geleert; indessen hatte man im Interesse der Lieferungen - sie zu bezahlen, wurden von den Ständen auch die kurf. Gelder herangezogen - immer wieder davon abgesehen, Clemens August auch diese Einnahmequellen zu scbliessen ${ }^{2}$ ). Wenn man diese Massnahme jetzt traf, geschab es weniger in der Überzeagung, dass der Kurfürst zuviel wegnahm - er kann unmöglicb viel erhalten haben - als vielmehr in der Absicht, selbst das Wenige im Lande »u halten und so alle Kräfte der Gebiete für die Winter quartiere $z u$ sammeln.

Zur selben Zeit, da Ferdinand seine Truppen auf die kurkölnischen Länder zum Winteraufentlalt vcrteilte, liess seine Intendantur - es war am 8. November -- Deputierte nach Münster zur Entgegennahme von Armeeforderungen rufen ${ }^{9}$ ). Im ganzen wurden von den beset»ten kurkölnischen Gebieten vom 1. De\%ember 1758 bis Ende Mai 1759 täglich 106128 Portionen und 62483 Rationen verlangt ${ }^{4}$ ). Die Bistümer waren einzeln in folgender Weise berange ${ }^{2}$ gen worden.

$\begin{array}{lcrc} & & & \text { Rationen } \\ \text { Münster } & \text { mit } & 19525 & 33165 \\ \text { Osnabrück } & n & 7810 & 13266 \\ \text { Paderbobn nebst Rittberg } & n & 7810 & 13266 \\ \text { Herzogtum Westfalen } & n & 15620 & 26532 \\ \text { Hildesbeim } & n & 11715 & 19899\end{array}$

Alles, was nicht in natura geliefert wurde, musste in Geld bezahlt werden. Zahlungstermine waren: 15. Dezember 1758, 15. Februar und 15. April $1759^{5}$ ). Da nach einem Überschlag

1) T.-Krgk. 1759; Bd. III, S. $195,212,217 \mathrm{f}$., 246, $266 \mathrm{f}$.

2) Osten-Reden a. a. O. Bd. I, S. 143. - Huppertz a. a. O. S. 112.

3) T.Krgk. 1759; Bd. III, S. 207, 288 f.

4) Die Portion sollte bestehen aus 2 Pfund Brot, $1 / 2$ Pfund Fleisch nebst Gemüse und 1 Mass Bier; die Ration aus 8 Pfund Haler, 10 Pfund Heu und 6 Pfund Stroh.

5) Stoffers gibt in seiner Abhandlung (Ztschr. a. a. O.S. 76) statt 
der durch die Winterquartiere entstehendeu Unkosten die Ration mit 17 Maricugroschen und die Portion wit $1 / 24$ Rth. berechnet wurde "), und die Länder diese Mengen von Lebensmitteln cbensowenig liefern konnten, wie die Alliierten auf der Beschaffung in natura bestanden ${ }^{2}$ ), so beliefen sich die Ansprüche an die Gebiete für die 6 Winternonate (Dezember bis Mai) in Geld umgerechnet

fïr Mïnster

"Osnabrick

$\pi$ Paderborn nebst Rittberg

" das Herzogtum Westfalen

$r$ Hildesheim

$$
\text { Rationen Portionen }
$$

anf 1659625 Rtlr. $2487371 / 2$ Rtlr.

$\begin{array}{rrrrr}n & 663850 & n & 99495 & n \\ " & 663850 & n & 99495 & " \\ n & 1327700 & n & 198990 & n \\ n & 995775 & n & 1492421 / 2 & n\end{array}$

$\mathrm{Zu}$ schildern, unter welch unsäglicher Mühe Teile dieser Suumen von der Bevölkerung beigebracht oder durch Exekutionen mit ihren ganzen Gefolge von Not und Elend während des Winters eingetrieben wurden, darf der besonderen Lokalforschung iberlassen bleiben ${ }^{3}$ ). Hier mögen zwei Stimmungsbilder genügen : das eine aus dem bisher am schwersten betroffenen Bistum Munster, das andere aus dem bisher verhältnismässig am wenigsten heimgesuchten Bistum Hildesheim.

Die Gazette de Cologne schrieb am 22. Dezember 17584): Munster, 17. Dezember. „Zu der Zeit, da wir etwas in Ruhe

des 15. Dez 1758 den 15. Jan. 1759 an. Die Vermutung eines Irrtums liegt nahe, da die andern von ihm angegebenen Termine mit den auf S. 74 genannten übereinstimmen. Vergl. auch vorl. Arbeit S. 67, Anm. 4.

1) Ferdinand zog Geldzahlungen sogar vor, wie denn überhaupt die Aussehreibung dieser Lebensmittel in der Regel auf Zahlungen hinauslief, also eine verkappte Steuer war. Den Unterhalt des Heeres musste die Bevölkerung noch dazu tragen. Vergl. vorl. Arbeit S. 88.

Stoffers gibt in sein. Abh. (Zeitschr. a a. O. S. 76) als Preis für die nicht gelieferte Ration und Portion 6 und 21/2 Rtlr. an. Das würde dem ebenfalls dort mitgeteilten Geldanschlag eines Termins in Höhe von 291236 Rilr. nicht entsprechen, sondern ergäbe für die 6 Monate zu je 30 Tagen 14404500 Rtlr. ( $1 / 3=4801500$ Rtlr.). Die Preise köunen auch nicht, un die Lebensmittellicferuug zu erzwingen, nur scheinbar so hoch angesetat worden sein, denn Ferdinand wollte und konnte gar nicht die Naturaiien in dem Umfange fordern. 2) T.Krgk. 1759; Bd. III, S. 292.

3) Vergl. Huppertz a. a. O. für Münster und Stoffers a. a. O. für Paderborn.

4) Eine gleiche Schilderung: Gaz. de Col voin 26. Jan. 1759; Münster, 20. Jan. 
gelassen zu werden uns schmeichelten, sehen wir uns aus Mangel an Fourage am Vorabend des gänzlichen Ruins. Unsere Regierung befindet sich in einer unglaublichen Verlegenheit. Die von uns angenommeneu Entrepreneure ${ }^{1}$ ) haben iluren Kontrakt nicht halten können wegen des grossen Mangels und des beklagenswerten $\mathrm{Zu}$ standes, in denı sich ganz Westfalen durch die ungeheneren wälırend des vergangenen Jahres gelieferten Fouragemassen befindet. ${ }^{\text {" }}$

Alnnlich lautet der Bericht am 16. Januar 1759 aus

Hildesheim, 7. Januar: „Dies kleine Bistum, umgeben von Lannoverscliem Gebiet, verspürt das ganze Gewicht eines Krieges, an dem es nie den geringsten Anteil genommen hat. Trotz des Unvermögens seiner Eiwwobner, die auferlegten Sumwen zu beschaffen, drängt man sie fort und fort und verweigert dic Annahme von Wechseln. Man will bares Geld. Woher nehmen? Unserer Erschöpfung ungeachtet müssen wir nichts destowcniger für den 15. dieses Monats 81000 bare Taler, den Rest rom 1. Termin, bei Strafe militärischer Exekution aufbringen. Doch man begutigt sich nicht mit diesem erschüpfenden Aderlass. Es haudelt sich noch um einen zweiten und dritten Termin von melreren 100000 Talern. Wann es möglich sein wird, sie zu beschaffen, vermögen wir nicht abzusehen, und so bleibt uns nur die traurige Aussicht übrig, eines Tages von der Exekution betroffen zu werden, deren Vorstellung uns scbon im voraus zugruude richtet."

Von der bei diesen Umstïnden äusserst gercizten Stimmung des Volkes kann man sich dengemäss ein Bild macheu. Ferdinand suchte deshalb auch durch Vorsichtsmassregein revolutionären Ausschreitungen vorzubeugen. So liess er am 22. De\%ember 1758 bekannt machen, er nüusse nmissfälligst wahrnehmen, dass in denen jetzo in Besitz labenden Hochstiften und Landen und vornehmlich in Münster und Paderborn [den] gemachiten Verordnungen und Reglements nicht nachgelebt und dasjenige, was zu ohnumgänglich nöthiger Sustentation der Armee gefordert ist, nicht fourniret und bezahlt werde". Er warne vor Aufrührern, die bebaupteten, "dass nicht allein eliestens eine völlige Veränderung derer Umstände in hiesigen Landen sich ereignen und deren Befreyung erfolgen würde,

1) Es waren dies Händler, meist Juden, die einen Vertrag mít der Regierung abgeschlossen hatten, durch den sie sich zur Lieferung von Lebensmitteln verpflichteten. 
sondern auch, dass innerhalb kurzer Zeit eine grosse Anzahl junger Mannschaft zu Recruten mit ausgenommen und die Hälfte davon zu Completirung und Augmentation der combinirten Armen gebrauchet, die andere Halbscheid aber unter die Kriegs-Völker Sr. Königl. Majestät in Preussen geschickt werden wiilde ${ }^{4}$ ). Mit der Androbung "hartel Alındung" gegen die Ausbreiter "dergleichen Erdichtungen" schliesst der Erlass. Wie ernst die Lage war, erkennt man an dem am 29. Dezember ausgegehenen Befehl, der Bevölkerung der Bistümer Münster, Paderborn und Osnabrück die Gewehre wegzunehmen ${ }^{*}$ ).

Zum Gluck für die Bevölkerung war Herzog Ferdinand nicht genötigt, einen allgemeinen Aufrubr bewaffnet niederzuwerfen.

So brach denn das Jahr 1759 an. Die pekuniäre Lage des Kurfürsten war schlechter denn $\mathrm{je}^{3}$ ). Vergebens bemühte er sich in Wien und bei venetianischen Kauflenten eine grössere Anleihe aufzunehmen $\left.{ }^{4}\right)$. Die Beträge, die er aus Paris und seinen Gebieten erbielt, waren zu gering, um den Hofhalt, in dessen verschwenderiscbe Festlichkeiten ${ }^{5}$ ) nur zu Anfang des Jabres der erfolgreiche Vormarsch Ferdinands störend eingegriffen batte ${ }^{6}$ ), zn bestreiten. Wenn aus Paris das Geld reichlicher als im Jahre $1758 \mathrm{kam}$, sn war dies neben der Fürsprache des österreichischen Gesandten Starbemberg, den man von Wien aus entsprechend unterrichtet hatte, eine Folge der eigentïmlichen Stellung des Versailler

1) Herz. Ferdinand wollte offenbar betonen, dass die jungen Leute nicht "mit Gewalt" genommen würden, denn Rekruten sind sehr zahl. reich in den kurkölnischen Gebieten ausyehoben worden. Schreib. Ferd. vou 24. Jan. u 23. Dez. 1762. Knesebeck a. a. O. Bd II, S. 565.

2) T.-Krgk. 1758; Bd. III, S. 866, - Gaz. de Col. vom 19. Jan. 1759 Hanunver, 10. Jan.

3) Im Jahre 1758 hatte er angeblich von Frankreich im ganzen 562500 Livjes erhalten. Spittlers Neues hist. Magazin, Bd. III, S. 337. Vergi. vorl Arb. S. 70.

4) Enuen a. a. O. Bd. II, S. 336.

5) Gaz. de Col. vom 27. Febr., Supl. Bonn 27. Febr.; vom 30. März, Bonn 29. März; vom 31. Juli, Spa, 27. Juli; vom 9. Nov. Supl. Bonn 7. Nov.; rom 13. Nov., Köln 12. Nov.; vom 21. Aug., Bonn 20. Aug. Der Bericht vom 20. Aug. enthält die Ernennung des Generalmajors Baron v. Nagrel, des Führers des kurf. Reichskontingents, zum Generalleutnant anlässlich der Geburtstagsfeier des Kurfürsten (16. Aug.).

6) Clemens August glaubte, Ferdinand beabsichtige einen Hand. streich auf Köln und wollte deshalb nach Spa, Tönnisstein oder Frankfurt fliehen. Ennen a. a O. Bd. II, S. 338. 
Kabinetts zum Bonner Hofe. Rheen meldete nämlich Ende Dezember $1758^{1}$ ), in Paris beabsichtige man dic Snbsidiengelder für Wien, Petersburg, Stockholm und Kopenhagen zu beschneiden und die an Bayern, Wïrttemberg und die Pfalz, deren Truppen man entlassen werde, zu unterdrücken, nur die an Kurköln sollten weiter gezahlt werden ${ }^{2}$ ). Diese Begünstigung war wahrscheinlich auf die erst Anfang Dezember neu gefestigte Freundschaft zuriickz.ufübren ${ }^{3}$ ). Raesfeld batte Rheen schon am 17. Dezember, obne vorber durch diesen von einer in Aussicht stehenden Geldsendung benachrichtigt zu sein, angewiesen, das vom französischen Hof zu erwartende Geld unmittelbar den Kurfürsten zu übermitteln ${ }^{4}$ ). Dennoch wollte es Rheen nicht gelingen, "durch die bewusste Frau eine dergleichen Zahlung zu erpressen ". Die französischen Minister, ungehalten iber das Eingreifen der Pompadour und des österreichischen Gesandten Starhemberg, wussten die Zahlung bis Anfang Februar hinauszuschieben. Ihr folgte am 19. April eine weitere $^{5}$ ) gerade zu der Zeit, da auch für Rheen in Paris die Gefangennahme der Kurkölner bei Meiningen und Wasungen das wichtigste Ereignis war und von ihm mit Starhemberg eifrig besprochen wurde ${ }^{6}$ ).

Noch etwas anderes zog damals im Er\%bistum Köln die Anf.

1) Rheen am 25. u. 28. Dez. 1758 nach Boni. Fasc. 222\%.

2) Schaefer a. a. O. Bd. II, 1; S. 265. Die gänzliche Unterdrückung der Subsidiengelder bei den drei genannten Staaten fand tatsächlich nicht statt. Die Bevorzugung Kölns macht es aber begreiflich, weshalb „sich von den drei wittelsbachischen Fürsten Clem. Aug. von Cöln am ersten über die Reduktion der frz. Hülfsgelder beruhigte. “ Bitterauf

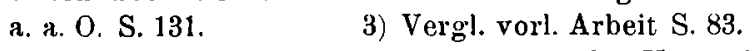

4) Es ist leicht möglich, dass bei der Umwerbung des Kurf. Ende 1758 eine pünktlichere Bezahlung der Subsidiengelder versprochen wurde. So wären der Brief Raesfelds vom 17. Dez. und der Umstand verständlich, dass der Grosskanzler auf einen Vorschlag Rheens nicht eingeht, die vertragsmässige Forderung von je 300000 Flor. für die Jahre 1757-59 auf die Jahre 1761-63 zu verschieben. Fasc. 222\%. Vergl. vdrl. Arb. S. $1 \mathrm{ff}$.

5) Rheen am 17., 21, 25. Jan, 1, 7., 21. Febr.; 8. Mär\% u. 19. April nach Bonn. Fasc. 2223. Die Zahlung vom 1. Febr. - es waren 62500 Livres - liess Rheen durch den Kölner Banquier Meinerzhagen dem Kurfürsten, die vom 19. April dem Finanzdirektor Falkenberg über. weisen.

6) Becker in den Annalen d. h. Ver, f. d. N. Heft 91, S. 82 ff. 
merksamkeit der beteiligten Kreise auf sich. In Berlin und London war man bis Anfang 1758 von allen Vorgängeu in den niederrheinischen Gebieten durch die in Köln wohnenden Gesandten Ammon und Cressener unterrichtet worden. So wusste Friedrich der Grosse durch Ammon ganz genau, dass im April 1758 aus den westf:̈lischen Bistümern nach Regensburg Geld in die Reichsoperationskriegskasse geflossen war. Er schrieb deshalb an Ferdinand, man möge verhindern, dass in Zukunft so ndas Geld zum Fenster hinausgeworfen würde ${ }^{u}{ }^{1}$ ). Ein solche Spionage war natürlich den Gegnern des Königs unangenelım, und die Verhältnisse wurden für die beiden Gesandten, auf die der in Köln kommandierende französische General Torcy ein wachsames Auge hatte, immer schwicriger. Bereits im August 1758 erlaubte daher Friedrich der Grosse Ammon, er könne „zur grösseren Sicherheit ${ }^{4}$ von Düsseldorf aus ihm und Ferdinand "alles, was sich in den dortigen Gegenden zutrage", mitteilen ${ }^{2}$ ). Er blieb indes noch. Wahrscheinlich muss nun Anfang 1759 auf Befehl des Kurfürsten an seine Gebiete, das fur den Reichskrieg bestimmte Geld ihm $\%$ verabfolgen ${ }^{3}$ ), solches nach Bonn gekommen sein; kurz, Ferdinand hatte hierüber wie über Truppensammlungen ${ }^{4}$ ) des Kurfuirsten durch Ammon Nachricht erlalten und glaubte, Clemens Angust habe Grund, etwas zu verbergen ${ }^{5}$ ). Jedenfalls werden Unzuträglichkeiten, die sich aus diesen und ähnlichen Vorfällen entwickelten, mitgewirkt haben, dass der französische Kriegsminister am 7. März 1759 Torcy den Befehl erteilte - Clemens August war durch den von Choiseul' ${ }^{6}$ ) benachrichtigten Breteuil,

1) Friedr. an 17. Mai 1758 an Ferd. Pol. Corr. Bd. XVII, Nr. 4997.

2) Friedr. am 2. Aug. an seine Minister Podewils u. Finkenstein. Pol. Corr. Bd. XVII, Nr. 10182.

3) Raesfeld teilte am 31. Dez. 1758 Rheen diese Verfügung mit und setzte hinzu, in den Stiftern müsse man sich in Frankreich dafür bedanken. Fasc. $222^{2}$.

4) Es waren das die Truppen, die Clem. Aug. als Ersatz für die Verluste seiner im Felde stehenden Regimeuter sammelte.

5) Ferdinaud am 12. Febr. 1759 an seinen Sekretär Westphaleu. Westphalen a. a. O Bd. III, S. 160.

6) Er befand sich seit Ende Oktober 1758 an der Spitze des franz. Ministeriums. Vou seinem Vorgänger Bernis meldete Rheen am 15. 1)ez. 1758, er sei durch einen "lettre de cachet" verbannt worden, weil er der "bewussten Frau" missfallen habe. Fasc. 2222. 
den französischen Gesandten in Boun, verständigt worden - Ammon und Cressener als Köln auszuweiseu. Trotz ihres Einspruchs verlangte Torcy, sie sollten an 16. März abreisen. Da sie der Aufforderung nicht nachkawen, erfolgte zwangsweise die Ausweisung, der sie sich unter Protest beim städtischen Magistrat fügten. A mmon nahm später seinen Sit/ in Münster. Plotho, der preussische Vertreter in Regensburg, legte an 19. April am Reiclistag gegen diese Behandlung des Gesandten Verwabrung ein ${ }^{1}$.

Von einer Tätigkeit des kurkölnischen Gesandten zu Paris in dieser Angelegenheit vernimmt man nichts; wohl aber nahm Clemens August ihn in Anspruch, als es sich Anfang Juli um eine Sache handelte, die mehr das Haus Wittelsbach als Kurköln anging.

Die Vertretung von Pfalz-Zweibrücken-Birkenfeld am Reiclsstag musste neu vergeben werden. Nun war der in Zweibrücken herrschende Christian IV. im Jahre 1758 in aller Stille zum katholischen Glauben übergetreten. Es war dies weniger Herzensl,edürfnis als Erbschaftspolitik, da er bei dem Tode des kinderlosen Karl Theodor von der Pfalz, der katbolisch war, als nächster Erbberechtigter in Frage $\mathrm{kam}^{2}$ ). Als Rheen nun Anfang Juli 1759 meldete, der Herzog von Pfalz-Zweibrücken wolle seine Vertretung ail Reichstag nicht dem katholischen Baron de Karg (v. Bebenburg), sondern trotz seines Ubertritts einem Lutheraner, genanut. werde ein Baron de Teuffel ${ }^{3}$ ), übertragen, bekam er den Auftrag, mit dem kurpfälzischen und dem österreichischen Gesandten in Paris Gegenschritte zu tun. Choiseul stand der Sache ziemlich teilnahmlos gegenüber $\left.{ }^{4}\right)$. Ihn schien der protestantische Vertreter ein Vorteil zu sein, denn er wirke nnter seinen meist ja auf Friedrichs Seite stehenden Glaubensgenossen werbend, während ein katholischer insofern „überflüssig“ wäre, als „die Mehrheit par la bonne cause entschieden sei". Zudem könne die Anstellung

1) T.-Krgk. 1759 , Bd. Il, S. $153,161,166$. Faber a. a. O. Neue Folge 4. Teil S. 272-290.

2) J. G Lehmann, Geschichte des Herzog'tums Zweibrücken; München 1867. S. 494.

3) Es ist höchstwahrscheinlich der Vertreter des auf österpreichischer Seite stehenden Mecklenbury, Baron 'Teuffel von Birckensce, gemeint. Brabant a. a. O. B I, S. 18, 77.

4) Faber a. a. O. Neue Folge. 4. Teil S. $238 \mathrm{f}$. 
Von Kurkölns Beziehungen zu Frankreich u. seiner wirtschattl Lage. 9r

eines Katholiken die Protestanten verstimnen. Alle Mühe, Choiseul von dieser Ansicht abzubringen, hatte wenig Erfolg. Er liess sich nur zu dem Versprechen bewegen: es solle Sorge getragen werden, dass die Stimme für die Daner des Krieges nicht besetzt wer(le ${ }^{1}$ ).

Auf dem Kriegsschauplatz in Westeu war im Frühjahr das Kriegsgliick Ferdinand v. Braunschweig untren geworden. Nach seinem Zug nach Thiringen hatte er den Marsch gegen Frankfurt gerichtet und bei Bergen durch den Marschall Brog'lio eine Schlappe erlitten; die ilun zum Rückzug veranlasste ${ }^{2}$ ). Dabei gelang es den Franzosen, Ferdinand vom Main und von der Lahn aus - am Niederrhein bei Disseldorf stand Armentières - aus allen kurkölnischen Gebieten mit Ausnahnie von Hildesheim zu verdrängen. Das wohlbefestigte Lippstadt, das wichtige Müuster, das Hauptmagazin Osuabrück, selbst Minden fiel ilınen in die Hüude.

Clemens August bielt nun den Augenblick fïı gekommen, die hannoverschen und braunschweigischen Länder für die hohen Kontributionsforderungen in kölnischem Gebiet, die der kurkölnisehe Gesandte, längst iiber die Leiden der Bistümer unterrichtet ${ }^{3}$ ), am Ł. April 1759 dem französischen Kriegsminister in einem ausfülırlichen Mémoire darlegte ${ }^{4}$ ), büssen zu lassen. Da Armentières anı Niederrhein sich seiner Bitte, die durch Detachements nach Hessen geschwächten Allierten anzugreifen, nicht willfährig zeigte ${ }^{51}$ ), musste Rheen in Paris darauf hiilarbeiten. Als er dam seinen Wunsch erfüllt sah, drangen dieselbeu Klagen wie im Jahre 1758 an sein Ohr. Raub, Plünderung und Gewalttat gehörten zu den tagtäglichen Erscheinungen. Wie im vergangenen Jahre war dies wieder die Folge eines von verantwortlicher Stelle aus teils durch den $Z$ wang der Verhältnisse ergangenen Befehls. Belleïsle schrieb am 15). Juli

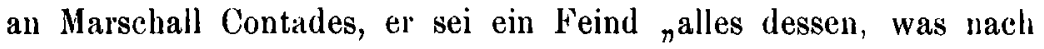
Raub und Pliinderung aussehe ${ }^{4}$, aber es müsse eine Ausmahme gemacht werden $\left.{ }^{(i}\right)$. Er sehe nämlich „für die drängendsten Aus-

1) Raesfeld am 23. Juli an Rheell. Fasc. $222^{3}$.

Kheen am 5., 12., 29. Juli 1759 nach Bonn. Fasc. $222^{3}$.

$$
\text { " 1. August } 1759 \quad " \quad, \quad, 222^{4} \text {. }
$$

2) Renouard a. a. O. Bd. II, S. 94f. - Schaefer a. a. O. Bd. $I^{1}$, S. $351 \mathrm{f}$.

3) Raesfeld an Rheen an 2\&. Dez. 170̄8. Fasc. 2222. 4 4) Fasc. $222^{3}$.

5) Am 13. April wurde Rheen dies mitgeteilt und hinzugefiugt, Armentières habe erklärt, er müsse die Weisungen seines Holes befolgeu. Fasc. 22:23.

6) Kuesebeck a. a. O. Archiv S. 338. 
gaben und die Instandsetzung der Truppen " nirgendwo eine Quelle als in den Mittehn, die die feindlichen Gebieten darböten; von dort "wïrden, abgesehen von Geld, Unterhaltungsmittel jeglicher Art wie Hen, Stroh, Hafer für den Winter, Getreide, Vieh, Pferde selbst Menschen zum Ersatz für die fremden Truppen bezogen werden müssen ${ }^{4}{ }^{1}$ ). Selbstverständlich konnten sich die Franzosen dessen, was sie in Hessen demnach notgedrungen taten, anch auf dem Marsche durch kurkölnisches Gebiet nicht enthalten. Rheen führte darüber in Paris entriistete Klagen, erbielt aher von Belleïsle die dreiste und rücksichtslose Antwort: er muisse sich über die üble Gesinnung der westfälischen Bcvölkerung beschweren ${ }^{2}$ ). Auch Choiseul äusserte sich dem Gesanlten gegenüber in ähnlicher Weise. Trotzdem dieser ganz richtig crwiderte, für diese unliebsame Erscheinung seien weder der Kurfïrst noch die Einwohner verantwortlich zu machen, vielmebr sei sie bei dem C̈bermass des erduldeten Kriegselends begreiflich ${ }^{3}$ ), musste er bei einer erneut von ihm gefuhrten Beschwerde die Bemerkung himnehmen, an eine Entschädignng für seinen Herren könne nicht gedacht werden, wenn die Einwohner sich weiterhin weigerten, die französische Armee zu unterstützen ${ }^{4}$ ). So war man denn, ganz von dem Wohlwollen der Frauzosen abhängig, gezwungen zn schweigen.

Wie man sieht, macbten die Franzosen kaum einen Unterschied zwischen Freundes- und Feindesland. Und dass selbst die von Clemens August bei jeder Gelegenheit in Paris beantragten iepressalien in feindlichem Gebiet ${ }^{5}$ ) ein zweischneidiges Schwert waren, so lange die Alliierten nicht alle Gebiete der mit Frankreich-

1) Belleïsle am 23. Juli 1759 an Contades. -- Knesebeck a. a. O. Archiv S. 340 2) Rheen am 15. Juli 1759 nach Bonn. Fasc. 2223.

3) Rheen am 26. Juli 1759 nach Bonn. Fasc. $222^{3}$.

4) " 26. u. 30. Aug. 1759 nach Bonu. Fasc. $222^{3}$.

Die französische Intendantur war ungehalten, dass die Bevöllerung aus den von den Alliierter hinterlassenen Magazinen Lebensmittel wougenommen und Vorräte in ihren Kellern verborgen hatte.

5) Am Tage der Schlacht bei Minden (1. Aug. 1759) hatte Rheen noch davon an Belleisle geschrieben und die Hofinung durchblicken lassen, sein Herr werde dann nicht leor ausgehen. In dem Briefe wird huch der Austausch eines Barous v. Spiegel und des Sekretäs Ficker ... beide wohl aus laderborn - gegen zwei Hamnoveraner, v. Schwichelt und v. Steinberg erwihnt. In seiner Antwort vom 6. Aug. versprach Bęlleïsle alles, ;wenn die Umstäude 's erlauben." Fasc. 2224. 
Von Kuıkölns Beziehungen zu Frankreich u. seiner wirtschaftl. Lage. 99

Österreich verbündeten dentschen Kleinfürsten geräumt hatten, zeigte sich nach dem Siege Ferdinands bei Minden Ende des Jahres 1759. Damals healssichtigten nämlich die Franzosen in deu von ilmen besetzten feindlichen Ländern ${ }^{1}$ ) die Waldungen zu versteigern und umzuhauen, dem Vernehmen nach zam Eutgelt für die Behandlung der sächsischen Gebiele durch die Preussen. Darauflin erliess Ferdinand die Bekanntmachung, er werde sofort das Gleiche in Westfalen tun, wcun man die Absicht durchufuführen wage ${ }^{2}$ ). Eiligst befahl der kürkölnische Grosskanzler dem Gesandten in Paris, auf einen Befehl an die französische Heeresleitung binzawirken, der deren Vorhaben verhindere; den österreichischen Gesandten habe er schon unterrichtet. Werde kein Erfolg erzielt, so sei der Schaden in Westfalen grösser, ${ }_{n}$ als wenu alle Städte, Dörfer und Häuser abgebrannt werden sollten" 3 ). Es gelang, das Unheil abzuwcnden. Belleïsle ordnete die Schonung der Waldungen an. Es war, wic Rheen mitteilte, mit deu Landstäuden der betreffenden. Gebiete eine Knnveution geschlossen worden ${ }^{4}$ ).

\section{Erfolge und Misserfolge Rheens in Paris. - Immer schwierigere Lage Kurkölns und des Kurfürsten. -- Sein Tod und Abschied des Gesandten aus Paris (Febr. 1759).}

Am 1. August 1759 hatte sich Ferdinand durch den Sieg hei Minden wieder den Zugang zu den südwestlich liegenden kurkölnischen Gebieten erschlossen. Schon einige Tage vorher war

1) Raesfeld erwähnte am 27. Nov, die klevischen und hanauischen Gebiete, Rheen an 16. Dez. ausser diesen: Grldern, Mark und Rarenstein. Fasc. 2224. $\quad$ 2) Ferdinand am 18. Nov. 1759. Fasc. 2224.

3) Raesfeld ain 27. Nov, an Rheen. Fase. $222^{4}$.

4) Rheen am 6. und 7. Dez. 1759 nach Bonu. Fase. $222^{4}$.

Am 16. Dez. meldete er die Abreise eines Marquis de Hoensbrock aus Paris wach Bonn und fügte hinzu: „Durch seine Wirksamkeit in Auftrage der Herzogtümer von Kleve und Preussisch-Geldern sowic der Grafschaften Mark und Ravenstein hat er zur Vermeidung der Repressalien beigetragen, mit denen der Prinz Ferdinand von Braunschweig die Waldungen des Herzogtums Westfalen bedroht hatte. 
es ihm gelungen, Osnabrück zu überrumpeln und sich atts neue in den Besitz der fast unversehrten Magazine zu setzen ${ }^{1}$ ). Münster, "dessen Besit $z$ wegen der in den Bistümern zu nehmenden Winter. quartieren durehaus notwendig war" ${ }^{\text {") }}$, wurle erst nach langen, hartnäckigem Widerstand der im Belagerungs und Verteidigungskampf von Festungen geiibten Franzosen, wobei die Stadt selbst sclıwer litt ${ }^{3}$ ), anı 20. November zurüekerobert. Der durch Armentières versnchte Entsatz schlug völlig fehl ${ }^{4}$ ). In bergreiflicher Erregung befalıl der Kurfürst seinem Gesandten жu Paris, sich zu erkundigen, ob die Entschuldigung des französischen Feldherrn, er laabe der Übermacht weichen nuïssen, zutreffe; andernfalls solle er sofort Besclswerde führen ${ }^{5}$ ).

An den Tatsachen selbst änderte dies allerdings nichts. Voll Verzweiflung musste der Kurfürst sehen, wie die Alliierten in seinen Gebieten von neuem die Winterquartiere (1759-1760) berogen. Die von diesen ausgeschriebenen Kontributionsforderungen sie galten vom 1. Februar 1760 ab auf 6 Monate -- hatten eine älnliche Höhe wie die des Winters $1758-1759$. Fïr das weit und breit verwüstete, ansgesogene Land bedenteten sie jedoch eine melir als doppelt so starke Belastung. Zum Vergleich seien die Unkostenberechnungen, die die Alliierten und die Kurköln anf. stellten, nebencinander angefülırt ${ }^{6}$ ).

Allierten Kurköln

$\begin{array}{lrrrr}\text { Münster } & 1502432 & \text { R.tl. } 2400000 & \text { Rtll. } \\ \text { Osnabrück } & 642350 & & 550000 & n \\ \text { Paderborn } & 634523 & n & 800000 & n \\ \text { Westfalen } & 1294680 & n & 2000000 & n \\ \text { Hildesheim } & 1024425 & n & 649000 & \end{array}$

1) Knesebeck a. a. O. Bd. I, S. 423. - Osten-Reden a. A. O. Bd. II, S. 55 f. - Renonard Bd. II, S. 205. 2) Osten Reden a. a. O. Bd. II, S. 89.

3) Huppertz a. a. O. S. $197 \mathrm{f}$ - - Am 9. Sept. beklagte sich der Kurfürst über das Vorgehen der Alliierten bei der Belagerung in Wien mit den Worten, es zeigten "geflissentlichste Brandstiftungen ..... durch eingeworfene Bomben, Karkassen und Fenerkugeln .... viel mehr aul die Vernichtung derer Häusern als derer Vestungswerkerm labei geäußerter Absicht." - T. Krgk, a. a. O. 1760. Bd. II, S. 354.

4) Osten-Reden a. a. O. Bd. II, S. 82, 96 f. - Schaefer a. a. O Bd. II I, S. 383 f. - Huppertz a. a. O. S. $209,236$.

5) Raesfeld an 29. Dez. 1759 an Kheen. Fasc. 2224.

6) Die Berechuungi der Allierten führt Westphalen a. a. O. Bd. IV, 
Zım drittenmale während des gegenwärtigen Krieges mussten die Bewohner alle Leiden der Winterquartiere auf sich nehmen. Und nicht zum geringsten empfand dies sehr bitter der Kölner Kurfürst Clemens Aıgıst. Docb nicht allein die Einkünfte aus seinen Gebieten schmolzen so wiederum inelr zusammen, auch von Paris kamen keine erfrenlichen Nachrichten. Schon in der zweiten Hälfte des Jahres 1759 wurde es dem kurfürstlichen Gesandten Rheen immer schwerer, Subsidienbeträge zu erbalten ${ }^{1}$ ). Als er Anfang September bat, man möge an die Erledigung der drei letzten Monatsraten denken, wies man ihn ab, denn er berichtete nach Bonn, er dürfe jetzt nicht mehr davon reden, bis die Verlialtnisse „une meilleure face“ zeigten ${ }^{2}$ ). Trotzdenr Anfang Oktober davon noch keine Rede sein konnte, drängte Rheen schon wieder. Er erwiderte Choiseul, der sich ablehnend verhielt, die Subsidien seien noch das Wenigste, wichtiger die Hilfe, dic man zu bringen verpflichtet sei, demn der König habe die Staaten vor einem feindlichen Einfall \%u bewahren garantiert, und doch befinde sich dort der Kriegsschauplatz. Das Land bringe nichts ein, auch nicht sofort nach dem Friedensschlluss. Nirgendwo glicke es seinem Herrn, grössere Anlcihen aufzunehmen ${ }^{3}$ ). Am 3. September hatte nämlich der Grosskanzler Raesfeld in Wien 2-300000 Gulden gegen $5 \%$ z leilien versucht, jedoch am 23. September die Antwort erhalten, man sei dazu nicht imstande, wolle aber deu kaiserlichen Minister im Haag beanftragen, in Holland für Kurköln cine Anleihe in die Wege zu leiten ${ }^{4}$ ). Sicherlich wollte Rheen auf

S. 133 an, die Kurkölns Eunen a. a. O. Bd. II, S. 340 und der kurkölnische Gesandte Rheen in einem Mémoire an Belleisle vom 10. Febr. 1760 (Beilage) Fasc. 2225. Dis Angaben der beiden letztgenannten stimmen überein bei Münscer, Westfalen und Hildesheim, nur füg't Rheen bei diesem hinzu "doit fournir d'abord“. Ferner gibt Rheen noch die Leistungen Paderborns an - Ennen nicht - während er die von Osnabrück, die Ennen mitteilt, weglässt und statt dessen schreibt: „Das Bistum Osmabrück hat seine Auflage noch nicht orhalten. Es wird vielieicht, $\dot{x}$ cause de son alternative" glimpflicher behandelt." Es ist damit dio abwechselnde Besetzung des Bischofsstuhles mit einem katholischen und protestantischen Oberhirten gemeint.

1) Am 26. Juli hatte Rheen eine Zahlung in Bonn angemeldet; Fasc. $222^{\text {? }}$

2) Rheen am 13. Sept. 1759 nach Bomn; Fasc. $222^{4}$.

3) Kheen am 4. Okt. 1759 nach Bonn; Fasc. 2224.

4) Raesfeld am 3. Sept. 1759 uach Wien; Aus Wien „23. „ 1759; Fasc. 199. 
diese und ahnliche Versuche des Kurfürsten, Geld $\%$ erhalten, anspielen. Obwobl Choiscul in seiner Entgegnung die schlechte finanziclle Lage des Köniuss betonte, liess er sich bewegen, dem Gesanilten zwei Assignationen zur Einlösung bei dem Hofbankier zu dhergeben. Geld empfing Rheen deshalb doch nicht, denn der Bankier erklärte, ihm sei kein Zahlungsbefehl zigegangen ${ }^{1}$ ). Abgesehen von diesen Schwierigkeiten bei der Erlangung des vertragsmässig zugesicherten Geldes musste der Kurfürst es auch zusehen, wie der bisher in Frankreicl geduldete Absatz von Losen der kurkölnischen Lotterie verboten wurde. Alle Schritte Rheens, das Verbot riickgängig zu machen, waren umsonst ${ }^{2}$ ). Man entgegnete ihm, eine Ausnahme von der allgemeinen Regel - dem Herzog von Zweibrücken lıatte man die Erlaubnis ebcnfalls ent\%ogen könne nicht gemacht werden Zum grössten Verdruss in Bonn wurde eine Simnesänderung in Paris nicht erreicht; dort war man zu sehr darauf angewiesen, alles Geld im Lande zu behalten. Da dem Kurfirsten um diese Zeit weder von Osterreich, noch von Frankreicl, noch aus seinen Gebieten Geld in genügender Menge zufloss, er auf der anderen Seite das reiche, vom Kriegsglück begünstigte England sal, mag sehr wohl in Bonn eine Neigung, mit England Verbindung ru suchen, damals stärker als sonst aufgetreten sein. Solche Stimmungen sind jedoch ebenso wie die erwähnte ${ }^{3}$ ) Annäherung an Ósterreich nicht zu ïberschät\%en ${ }^{4}$ ). Es kann zugegeben werden, dass der Kurfürst eine Füblungnabme gesucht hat; die Gesandtschaftsherichte Rheens zeigen allerdings keine Spur. Praktisch waren derartige Versuche aber noch aussichtsloser als jene vom Jalıre 1758. Wenn Pitt, der englische Premierminister, schon Max. Josef von Bayern, dem Neffen von Clemens August, bei dem sich seit 1758 ebenfalls englandfreund liche Bestrebungen zeigten ${ }^{5}$ ), erklärte: so lange England existiere,

1) Rheen am 15. u. 30. Nov. 1759 nach Boun; Fasc, 2224.

2) Rheen am 15., 21. Nov. 1759, am 6., 13. Jan. 1760 nach Boun; Fase. $222^{4}$ u. ${ }^{5}$. - In einem Schreiben vom 6. Nov. an Choiseul sagte Rheen cmpfehlend: Den Untertanen des Königs seien die meisten hohen Gewinne der Lotteric zugefallen so z. B. an Paris du Montmartel 200000 Livres. Fasc. 2224. Vergl. auch Const. Becker, Die Politik Kurkölns. Diss. a. a. O. S. 19. Anm. 3.

3) Vergl. vorl. Arbeit S. $78 \mathrm{ff}$.

4) Eunen a. a. O. Bd. II, S. $340 \mathrm{f}$.

5) Th. Bitterauf a. a O. S. 111, 117, 136, 138, 142. 
Von Kurkölns Beziehungen zu Frankruich u. seiner wirtschaftl. Lage. 103

sei dort noch kein Subsidientraktat für cin dolce far niente ohne Gegenleistung geschlossen worden ${ }^{1}$ ), so war dies erst recht dent Köhner Kurfürsten gegenüber zu sagen angebracht. Dabei war aber die Lage des Bayern nicht so schlecht, dass er richts mehr bieten konnte, während die Alliierten voln Kölner alles Land bis auf das rheinische Erzstift schon besassen, und dics war gan\% in der Gewalt der Franzosen.

Mit Beginn des Jahres 1760 war der kurkölnische Gesandte von Paris nach Bonn gereist ${ }^{2}$ ). Er hatte die Subsidiengelder, die ihm vom Hofbankier endlich Mitte Januar ausgezahlt worden waren, mitgebracht ${ }^{3}$ ). Am 5. Februar 1760 kehrte er wieder auf seinen Posten zurück. Für Choiseul überbrachte er ein Handschreiben seines Herren. Jener antwortete mit einem sehr höflichen Schreiben und einer Anweisung auf 160000 Livres, \%ablbar am 1. März, dic auch wirklich am 2 März nach Bonu abgingen ${ }^{4}$ ). Der Inlualt des von Rheen überreichten Briefes ${ }^{5}$ ) laisst sich in etwa aus der Tätigkeit des Gesandten schliessen. Mit ungewöhnlichem Eifer drängte er auf die Bezahlung der den französischen Heeren geleisteten Dienste und auf Repressalien in Feindesland. Bellë̈sle erklärte ilım, tout court", beides sei während dieses Krieges ausgeschlossen. Zudem seien mit Kleve, Mark, Geldem und Hanau Verträge eingegangen worden ${ }^{6}$ ), und es miisse in Falle eines Vorgehens mit der Möglichkeit einer noch stärker auftretenden „Vexation" der kurkölṇischen Lande gerechnet werden ${ }^{7}$ ).

1) Bitterauf a. a. O. S. 137.

2) Breteuil, der franz. Gesaudte am Bonner Hote, war an 12. Dez. in Paris eingetroften. Er kehrte nicht mehr nach Bonn zurück, sondern ging nach Petersburg. An seine Stelle kam ein Neffe des Bischofs von Orleans, Marquis de Ballset. Rhen am 14. Dez. 1759 und 2. Jan. 1760 nach Bonn; Fasc. 2224 u. ${ }^{5}$. - Gaz. de Col. vom 8. Febr. 1760; Paris, 2. Fubr.

3) Rheen am 6, 13. Jan. 1760 nach Bonn; Fasc 2225. Dem "Livre rouge" gemäss hatte Frankreich dem Kurfürsten im Jahre 1759 insgesunt 949000 Lirres ausgehändigt. Spittlers Magazin a. a. O. Bd. III, S. 337.

4) Rheen am 20. Febr. und 2. März nach Bonn. Fasc. 2225. Das Geld war an den Finanzdirektor Falkenberg adressicrt.

5) Enmen teilt a. a. O. Bd. II, S. 516 (Nr. 64) Teile eines Briefes des Kurf. an Ludwig XV. mit, der, datiert vom 7 . Febr. 1760, dieselben Gedanken enthält.

6) Es wäre verfehlt anzunehmen, diese Gebiete seien von den Franzosen schonend behaudelt worden.

7) Uber die Ablehnung der R:pressalien, die Choiseul und Belleïsle 
Weit tiefer als dic mit diesen cinleuchtenden Gründen belcgte Ablelınung der kurfiirstlichen Forderungen traf Clemens August die von Rheen am 13. Mär 1760 angekündigte Kürzng seiner Subsidienbeträge. Choiseul wollte statt jührlich 750000 Livres nur melr 600000 Livres bezahlen "). „Mémoires" an Choiseul nnd den König waren umsonst ${ }^{2}$ ), und den Einwand, Main\% erbalte doch fortwälrend Geldsummen, schnitt Belleïsle mit dem Bemerken ab): ,Man hat Sie getäuscht ${ }^{4}{ }^{3}$ ). Die Erregung in Bonn war gross. Sie entlud sich in begreiflicber Weise auf den Gesandten. Er

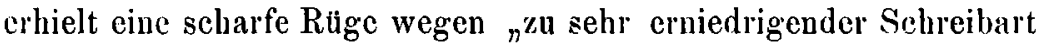
und der unbefugten Beilegung des Titels Minister" in dem Ménoire an den König. Der Grosskan\%ler verlangte, dass nunmehr allc Mémoires zuerst in Bonn zur Durchsicht vorgelegt wiirden ${ }^{4}$ ).

Inündlich zugesagt hatten, schriel, Rheen am 14. Febr. 1760: ,j'ai prevul que sa réponse écrite ne correspondrait point à la réponse verbale, qu'il m'a douné vendredi dernier." Rheen arn 10., 14., 17. Jan. und 2. Mürz 1760 nach Boun; Fase. $222^{5}$.

1) In den verschiedenen Müuzsorten kamn der Widerspruch nit den Angaben Rheens voun 7. Dez 1758 (Vorl. Arbeit S 41) nicht begrüudet sein. Am 11. Aug. 1758 setzte Raesf. 1035000 Reichstlr = 3387272 Liv. $14 \%$ S., sowie $800000 \mathrm{Rt} l \mathrm{r} .=2618181$ L. $16^{4} / 10$ S. (Fase. $222^{2}$ ). Daraus folgt, dass $-1 \mathrm{~L}=20 \mathrm{~S}$. gerechnet $-1 \mathrm{Rtlr}$. $=60,455 \mathrm{~S}$. oder 3,273 $\mathrm{L}$, war. Da allgemein damals der Gulden (Flor.) $4 / 3$ Rtlr. galt, kamen auf 1 Gulden 2,182 L. Demmach entsprächen den 300000 bezw. 210000 Flos. (S. 44 vorl. Arb) 654600 bezw. 523680 L. und nicht 750000 L. Es bleilut wohl nichts andere; als eine Frhöhung der Subsidienheträge während des Jahres 1759 anzunehmen. Merkwürdig ist nun der Nachweis in "Livre rouge" (Vergl. Vorl. Arb. S. 103), dass noch mehr als $750000 \mathrm{~L}$. jährlich, z. B. im Jahre 1759, nach Bonn geflosser sind. Höchstwahrscheinlich solten damit zum Teil die Aufweudungen der kurfürstlichen Untertauen für die franz. Armee, von denen Rheen oft spricht, bezahlt werden.

2) Rheen am 13. März 1760 nach Bonn: Fasc. 2225.

3) " "19, 23., 25. März " ", " $222^{5}$.

Auch Baron v. Grosschlag, der Bevollmächtigte von Kurmainz, stellte es in Abrede, und Starhemberg, Osterreichs Gesandter, hielt es der Geldnot wegen für untnöglich.

4) Rassfeld am 24. Mär\% 1760 an Rheen; Fasc. $222^{5}$ - Schon ror zwei Jahren (im Mai 1758) hatto der Gesandte den Titel Minister vergeblich gewünscht; er sollte sich uur kurfürstlicher Hofrat in kurt. Angelegenheiten nemuen. (Raesf. am 14. Mai 1758) Auch eine Wiederholung der Bitte am 27. April 1759, wobei Rheen versprach, keinen Kreuzer Besoldung mehr zu fordern, fruchtete nichts. 
Das Vertrauen des Kurfürsten auf seinen Gesaudten war stark erschiittert. Weder dessen Erklärung über nle mot simple ministre ${ }^{\text {" }}$ ), noch die Mitteilnng, Choiseul labe ihm eine Anweisung anf 100000 Livres iibermitteln lassen ${ }^{2}$ ), hielten Raesfeld ab, in Auftrage des Kurfïrsten zu Paris Monsieur d'Amillon, Abbé du Gué de Launay ${ }^{3}$ ), um Auskunft zu bitten, ob es "nut/hringender und entsprechender sei, die Vertretung am französischen Hof Sicur de Réen oder dem Minister Sr. Hoheit, des Kardinals von Bayern, Comte van Eick, anzuvertrauen" $\left.{ }^{4}\right)$. Der in Bonn wohl eingetroffene Bescheid wird kaum befriedigt haben, denn nach $21 / z$ Monaten erkundigte man sich nochmals bei Fernande Montrafied, Comtesse de Raymond 5). Sie entgegnete in ihrem Sclureiben: "Der Eifer und die Liebe für seinen Fürsten sind die Richtlinien bei allen, was er im Interesse Sr. kurf. Durchl. unternimmt" 6).

Das Merkw iirdigste bei diesem an sich geringfiigigen Zwischenfall liegt in dem Verhalten des Kurfürsten.

Schon im Februar 1759 berichtete Rheen nach Bonn, van Eyck unterhalte unerlaubten Briefverkehr mit Leuten des Bonner Hofes, und im Mai 1760 schrieb er, er wünsche seine Briefe und Depeschen besonders vor "Abhé Minoray" gehütet. Dieser schreibe stets an van Eyck und berichte ihm alles, was sich Interessantes an Hofe zutrage ${ }^{7}$ ). Und gerade van Eyck sollte durch Clemens August $z u$ seinem Vertreter gemacht werden! Sollte zwischen beiden nicht ein innerer Zusammenhang zu suchen sein ${ }^{8}$ )? Darauf kann auch die Tatsache hinweisen, dass Raesfeld auf die Meldung

1) Rheen schrieb am 3 April 1760, „le mot simple ininistre" heisse in deutscher Sprache Sachwalter und Befehlsaustichter, in französischer Chargè d'Atfaires. Fasc $222^{5}$.

2) In der Mitteilung (27. März) betonte er, er sage niemand, „que V. A S. E soit traité plus favorablement que tous les autres princes." Am 21. April erhielt er das Geld und sandte es am gleichen Tage nach Bonn an Finanzdirektor Falkenberg.

3) Über die Persönlichkeit liess sich nichts Näheres feststellen.

4) Raesfeld ain 2 April 1760 aus Bonn: Fasc. 22:5.

5) Genaneres liess sich über sie nicht finden.

6) Die Comtesse am 29. Juli 1760 aus Paris. Fasc. 2226.

7) Rheen $4 \mathrm{~m}$ 11. Febr. 1759 (Fasc. 22293) und aul 28. Mai 1760 (Fusc 2.25) nach Bonu. - Abbé Franz v. Mineray war Geheimsekretär in Bonn. Kurk. Hofkalender v. J. 1760, S 50. - Ennen a. a. O. Bd. II, S. $3 \mathrm{CO}, 30:$.

8) Vergl vorl. Arbeit S. 76. 
Rheens, van Eyck sei bei seinem Herm in Ungnade gefallen Rheen bezeichnete ihu dabei als ngrossier voleur" ${ }^{1}$ ) - dem Gesaudten den Befehl zukommen liess, im Falle Eyek vorsichtig zu sein und vor allem keinc üble Nachrede zu verbreiten ${ }^{2}$ ).

Die Subsidienfrage fand schliesslich auf einem Mittelwege ihre Erledigung, nicht ohne dass „die Verwendung der guten Dienste der grossmächtigen Frauen den genannten Minister [Choiseul] gezwungen haben, seine Absicht zu ändern". Zwar blieb es bei den 600000 Livres, doch erklärte Choiseul sich bereit, die monat. lich zurückbehaltenen 12500 Livres am Ende des Jahres zusammen mit 150000 Livres auszuzahlen. Rheen schloss seinen Bericht mit den Worten: „Bei der besagten Frau ${ }^{3}$ ) hah ich mich vorgestern auf die höflichste Art bedankt für ilıre gütige bci die erwïhnten 2 Minister ${ }^{4}$ ) geschehene Fursprach." Sie habe sie ilım auch weiterhin zugesichert. Dann sei er zu ibrem Intendanten gegangen und halse ihm dic 200 Louisd'or gegeben. Anf diese Weise lasse nsich oft viel Gutes hier ausrichten wider willen und wollen deren königlichen Ministern" ${ }^{4}$ ).

Man wïrde dem kurkölnischen Gesandten entschieden Unreeht tun, wollte man zuerst bei ihm die Gründe für die Misserfolge der letzten Zeit suchen. Sie lagen vor allem im inneren Zustaud Frankreichs. Seine finanziellen Schwierigkeiten nahmen immer droliendere Formen an, und allgemein zeigte sich eine immer wäcltiger au-

1) Rheen am 16. Nov. 1760 nach Bonn; Fasc. $222^{6}$.

2) Raesf. am 18. Dez. 1769 an Rheen; " $222^{5}$.

Dass Clemens August nach der Art Ludwig's XV. neben seinen offiziellen Vertretern wahrscheinlich noch besondere Geheimagenten hatte, zeigt auch folgendes. Am 1. Mai 1760 (Fasc. 2225) befahl halesfeld dem Gesaudten, einem gewissen le Fèvre, der unter den Vorwand, kurf. Kommissar zu sein, Unterschleife ,in commerciis" begehc, das Handwerk zu legen. Anscheinend ging dieser, von Beruf Kaufmann, in Paris zugleich seinen Geschäften nach. Am 15. Mai antwortete Rheen (Fasc. 22.5), er habe den Mann - le Febure nennt er ihn - zu sich kommen lissen. Dieser besitze zwar liein förmliches Patent als "Commissionaire", dicsen Titel jedoch in den ihn seit 1752 vom Kurfürsten ausgestellten Reisefässen Er versichere, keinen Unterschleif, auch nicht in commerciis gemacht \%u haben, behaupte dies indes von dem Agrenten Girost (Kurk. Hofkalender vom Jahre 1760, S 51) und dessen Vetter Laqueux.

3) Madame de Poinpadour.

4) Es sind Belleïsle und Choiseul gremeint.

5) Rheen am 17. April 1760 nach Bonn; Fasc. $222^{5}$. 
schwellende Sehnsucht nach Frierlen. Der für England gunstige Verlauf des amerikanischen Krieges im Jahre 1759, seine Erfolge gegeniiber Frankreich bei Quebec, Lago und Quibéron wurden durch die Ereignisse in den ersten Monaten des Jahres 1760 vollends gesichert. Choiseul dachte seit Ende 17.59 an deu Frieden ${ }^{1}$.

Bereits an 13. Dezember berichtete Rheen ${ }^{2}$ ), es werde viel von Friedensvorschliaggen gesprochen; er halte sie aber für hinfällig, da Frankreic̀ nicht gesiegt, Österreich Schlesien nicht in Besitz habe und Fricdrich dies Laud niemals hergelen werde. Trotzdem wurde ihm von Raesfeld bedeutet, aufmerksam zu seiu und zu erkunden, ob für Kurköln nichts Nachteiliges dabei im Spiele sci ${ }^{3}$ ). Rhceu hatte schon, bevor er diesen Brief erhielt, Anlehnung an den österreichischen Gesandten Starbemberg gesucht nnd ihn gebeten, an die seinem Herrn versprochenen Indemnisationen in seinen Besprechungen mit den französischen Ministern sowie bei cinem Friedensschlusse zn denken. Dieser hatte ibn jedoch abgewiesen, da er solch nodiose Dinge" nicht zur Sprache bringen könne Er labe genug damit zi schaffen, den französischen ITof in guter Laune zu halten, denn Frankreicb habe sich wegen Sachsen und Österreich ins Verderben gebracht; zudem sähen die französischen Minister es nicht gerı, wenı Höfe mit eigenen Bevollmächtigten sich an fremde Gesandten wendeten ${ }^{4}$ ).

Es ist bekannt, dass es dem Wiener Kabinett gelang, Frankreich von der Idee eines allgemeinen Friedens abzubringen, und dass die Versuche Clıoiseuls, einen Separatfrieden mit England herbeizuführen, fehlschlugen. In Boun verfolgte man diese im stillen gepflogeneu Verlandlungen uit gespauntester Aufmerksinkeit Unablässig tanschten Raesfeld und Rheen gerade über diese Angelegenheit Briefe aus ${ }^{5}$ ). Der Kurfürst wünschte die Wahrnelımung des kurkölnischen Interesses durch die Erzielung von

1) Schaefer a. a. O. Bd. II, 1 ; S. 349 f., $446 \mathrm{f}$.

2) Rheen am 13. Dez 1759 uach Bonn; Fasc. 2224.

3) Raesfold am 23. Dez 1759 an Rheen; $n 2224$.

4) Rheen am 14. Dez. 1759 nach Bonn; Fasc. $222^{4}$.

5) Raesfeld am 4. März 1760 an Rhcen; dieser am 6. Jan., 9. März 1760 an jenen. Fasc. 2225. - In dem Briefe vom 6. Jan. hob Rheen hervor, man dürfe sich viel von dem Einfluss Breteuils in Petersburg, der seine Hülfe zugesagt habe, versprechen. 
Gebietserweiterungen beim Frieden und durch die Wahl Mlinsters als Friedenskongressstad ${ }^{1}$ ). Dort habe der 30jälrige Krieg scin Eude gefunden und könnten die Vertreter der Nationen aufs beste verpflegt werden. So zablreiche Schreiben gingen aus Bonn an Ludwig XV. and seine Minister, dass Rheen am 28. Mai bat, es möchten nicht mehr so vicle Briefe wegen eines Friedens nach Bonn gesandt werden, "der nicht stattfinden werle". Clıoiseul labe ibu gesagt, der Minister des Bonner Hofes glaube alle Zeitungsnachrichten und sogar oft Dinge, die unsinnig" wären; dengemäss werde selbst der Kurfurst beeinflusst ${ }^{2}$ ).

Worin die so erselnten Indeminisationen bestehen sollten, gestaud der kurkölnische Gesandte zu Wien, Leykan, in einem Prowemoria an den Kaiser vom 21. Mai 1760. Demnach begehrte Clenens August :

nDie Graf- und Herrschaften Mörs, Lingen, T'ecklenburg, Stadt Soist mit ilırer Börde, sodann die Ibrer Durchlaucht zu Lehen gehende auch versetzte etliche des Herzogtuns Cleve Städte und Dörfer." So werde der Empörer geschwächt, und es sei sicher, dass $n$ die von denen die Übermacht missbrauchenden Ständen gesetzmässig abnehmende Länder in keine besseren und sicheren Hände zugetcilt und bewahrt werden" könnten ${ }^{3}$ ).

In Wien erwiderte man Leykan, sein Herr möge sich mit seinen Wünschen an den Reichstag wenden ${ }^{4}$ ). Demgegenüber bemerkte Rheen, sich auf eine Zuschrift aus Regensburg stitzend ${ }^{5}$ ), es komme alles auf Wien, Versailles und Petersburg' ${ }^{6}$ ) an. Die

1) Raesfeld am 24. April, 17. Mai 1760 an Rheen; dieser an 7. Mai 1760 wach Bonn. Fasc. 222:. - Clemens August war nicht der einzige, der dic Vorteile einer solchen Tagung zu würdigen wusste. Holland war für Breda, Frankricl für Nancy und Österreich für Augsburg. Dieses gefalle, so schrieb Rheen am 25. Aug., Wien am besten wegen sciner Lage, ,de la parité de la religion", die dort herrsche, und der beabsichtigten Wahl des Eroherzogs zum König von Rom. Fasc. $222^{6}$. Bitterauf a. a. O. S. 171.

2) Rlieen am 28. Mai 1760 nach Bonn. Am 25. Mai hatte er von einer zwischen Belleïsle und Chniseul bestehenden Eifersucht gemeldet. Dieser sei "sehr hitzig, elı- und ruhmsüchtig“ und sehe ungern Schrciben des Kurfürsten an Belleisle "wegen des Friedensgeschäftes". Er bitte deshalb, solche nur noch an den König und Choiseul zu senden. Fasc. 2?25.

3) Fasc. 211. 4) Racesfeld am 28. Juli 1760 an Rheen; Fasc. $222^{5}$.

5) Rheen am 10. Aug. 1760 nach Bonn; Fasc. $222^{6}$.

6) Am 20. Juli 1760 meldete Rheen nach Bonn, er habe sich noch- 
Reichsgarantie sei ${ }_{n}$ ohmehin eine bloss und schwache Formalität, welche ihre Wirkung nach dem geschlossenen Frieden erst erreichen" könnte"). Alles, was Rheen in Versailles erzielte, war die Zusage Choiseuls, fur Münster als Friedenskongressstadt ein $\%$ treten, es mitsse jedoch vom Feinde frei sein $\left.{ }^{2}\right)$. So entgegenkommend diese Antwort wenigstens in einem Punkte $z u$ sein schien, sie war praktisch wertlos. Die Bistiimer befanden sich im umbestrittenen Besitz der Alliierten. Die Eimnahmen des Kur. fiirsten waren bis auf ein Minimum hinabgesunken. Zwar hatten ilm im vergangenen Herbst Vertraute seiner Umgebung ${ }^{3}$ ) ans Minster, von dem er, unbekïmmert um die unglaublich schlechte wirtschaftliche Lage der Stadt, 200000 Rtlr. gefordert hatte ${ }^{4}$ ), Geld iiberbracht; auch war Anfang 1760 nochmals eine Sendung erfolgt ${ }^{5}$ ). Doch was besagten diese gewiss nicht grossen Summen!

mals an Breteuil in Petersburg genand und ihn gebeten, bei der Kàserin lür die Wüısche des Kurfürsten tätig zu sein. Fasc. 2225.

1) Rheen am 250. Aug. 1760 uach Bonn; Fasc. 22.26.

2) $" 14 ., 1760, n \quad " 222^{6}$. - Am 19. Juni 1760 erwähnte Kheen auch den "pretendu comte de St. Germain", der damals in den Kreisen der hohen Diplomatie sein Unwesen trieb (Schaeftr a. a. O. Bd. II, 1, S. 486f.). Dieser vesstehe es vorzüglich, so schriel Rheen, sich bei Frauen einzuschmeichehn, die Leute zu betrügen und sich den Anschein \%u geben, nts wisse er "arcaua“. Er sei augen. blicklich auf der Reise von London durch Holland, Ostfriesland nach Berlin. „Le roi de Prusse pourra de cet homme aprendre bien des closes, mais rien du secret, qui se traite dans le cabinet des ministres le Sa Majesté d'avec ses alliẻs. Fasc. 2:25.

3) Es waren dies die beiden Nagel: zu Ittlingen und zu Loburo.. Huppertz a. a. O. S. 190, 209, 211. - Nach einer Reiseunkostentabelle befand sich Nagel-Loburg, der frühere Kommandeur des kurkölnischen Reichskontingents am 25. Aug. 1759 zu Bonn, am 26. zu Neuss und Wesel, am 1. Sept. zu Düsseldorf, am 5, zu Wesel, an 6. zu Koesfeld. am 13. zu' Wesel, am 21. zu Neuss und Kölı, am 24. zu Bonn. Er hat somit dell Vormarsch des französischen Generals Armentières gegen Münster benutzt, um in die Stadt za kommen. Fasc. 184.

4) Huppertz a. a. O. S. $220 \mathrm{f}$.

5) Am 28 März 1760 schrieb Ferdinand an Ammon in Münster, er wünsche interrichtet zu werden „sur l'évidence de la remise des 120 mille Ecus que la Régence de Münster a fait à l'Electeur de CoJogne". Ammon erwiderte am 2. April, die münstersche Regierung stelle die Übrrsendung von Geld nicht in Abrede, doch, ,Ia somme n'étoit pas si grande". Westphalen a. a. O. Bd. IV, S. $265 \mathrm{f}$. 
Gehälter wurden $z u$ Bonn nicht mehr gezahlt, und meist mit schlechter Minze die dringendsten Fordermgen befriedigt ${ }^{1}$ ). Mit bitterer Resignation fïgte man sich in Boun jetzt bald den Schicksalsschlägen, nahm gern das Geld, das noch ans Paris kam²), klagte aucl ab und zu, wenn man sich gar zu sehr vernachlaissigt oder gekränkt saht' ${ }^{3}$ ) und liess im uibrigen den Dingen ihren Lauf. Mit Mïhe gelang es Rheen, den wahrscheinlich aus Unwillen verweigerten Empfang des nenen französischen Gesandten am Bonuer Hofe, Bausset, Ende Juli durchzusetzen. Schon sollte er yon Choisenl zuriuckberufen werden, als Rheen mahute, eine solche Massuahme der Missstimmung miisse unbedingt vermieden werden, da man "vonnöten habe, Ihn [Choiseul] als einen Abgott wobl zu feiern". Der Kurfürst wisse doch, "wie sehr es in seinem Interesse liege, diesen allmächtigen Minister vor allem nach jeder Richtung lin in günstiger Stimnung zu erhalten und sorgfältig alles $z u$ vermeiden, was ihn im geringsten verstimmen und unzufrieden machen könne" $\left.{ }^{4}\right)$. Die ernste, den Tatsachen entsprecheude Mahnung wirkte; der Kurfürst empfing den Gesandten. Welch bittere Stimmungen er in seinem Innern dabei unterdrückt haben wird, mag ein kurzer Hinweis auf die Lage seiner Bistümer um diese Zeit zeigen.

Ferdinand von Braunschweig verstand es im Kriegsjabr 1760 abgesehen von kleinen Schwankungen im Kriegsglück die Linie

1) Ennen a a. O. Bd. II, S. 350.

2) Rheen waren für den letzten Juli 1760100000 L. zugesagt. Choiseul gab ihm aber schon am 1. Juli eine Zahlungsauweisung. Einen Teil der Sunme in Gold brachte der neue franz. Gesandte Bausset, der an 6. Juli über Lüttich und Köhı nach Bonn reiste, mit. Rhcen am 26. Juni und 3. Juli nach Bonn; Fasc. $222^{5}$.

3) So im August und Sept. als Broglio und Ferdinand sich an der Diemel gegenüberstanden. Jener fouragierte wieder in Hessen und "wir", so schreibt Osten-Reden a. a. O. II, S. 204, "machten es im Bistume Paderboru nicht besser." Raesfeld befahl am 3. Sept. dem Gesandten, sich darübcr zu beschweren. Es war diesem sogar ein Bericht des Paderborner Rates zugegangen, der bittere Klage über das schamlose Benehmen der hannoverschen Truppen in der Kirche und dem Pfarrbaus des Dorfes Dösel führte. Sellsst die Hostien waren nicht geschont worden. Rheen am 14. Sept. $17 b^{\circ}$ nach Bonn; Fasc. 2225. Vergl. Stoffers in Ztschrft. für vaterl. Gesch. u. Altertumskd. Bd. 70, Abt. 2, S. 81.

4) Rheen am 23. Juli 1760 nach Bonn; Fasc. $222^{5}$. 
der Dicmel, eines linken Nebenflusses der Weser, und danit die kurkülnischeu Gebiete, die sogar in richtiger Einschätzung ihres Wertes im Fruihjahr 1760 der nene Landgraf von Hessen bei den VerLandlungen über einen ueuen Sulssiclienvertrag mit Euggland als Kontributiousgebiete beansprucht hatte ${ }^{1}$ ), zu behaupten. Selbst ins rheinische Erzstift kamen die Alliierten Eude des Jahres, als Ferdinand unter seinem Neffen, dem Erbprinzen von Braunsehweig, zur Ablenkung des von Hessen ans andrängenden Marschalls Broglio einen Vorstoss dorthin machen liess ${ }^{2}$ ). Das Ende des Feldzuges sah die Alliierten wieder in den Bistümern ihre Winterquartiere beziehen. Anscheinend sind die gestellten Fordederungen für die Truppen so hoch wie im Winter 1758-59 gewesen. Es ist dies aus der Angabe ron Huppertz zu schliessen, Münster habe 3514500 Rationen und 5969760 Portionen liefern milssen $\left.{ }^{3}\right)$. Nimmt man dem Brauch entsprechend als Lieferungszeit 6 Monate zu je 30 Tagen, so macht dies täglich 1758-59 an Rationen 19525, an Portionen 33165. Dis Hochstift Paderborn musste zur Winterquartierverpflegung 1081800 Rationen und 1883880 Portionen beschaffen ${ }^{4}$ ). Äbnliches wird wohl auch für die anderen Stifter gegolten haben. Ob das Land diese Mengen aufbringen konnte, darnach wurde nicht gefragt. Unnachgiebig wurden Naturalien oder das Entsprechende in Geld eingetrieben. Am 4. April 1761 befahl Ferdinand dem Kammerpräsidenten von Massow die Beitreibung der noch in den Stiftern und dem Herzogtum Westfalen ausstehenden Gelder und Naturalien unverziiglich in Angriff zu nehmen. Er gebot: „Wenn die militärische Exekution nicht fruchtet, so müssen die Herren Capitularen und die von der Regierung in eugen Arrest und bey Wasser und

1) „Die Absichten des Hofes von Kassel waren vorzugsweise auf (lie vier Bistümer und die dem Churfürsten von Cöln gebörigen Gebiete gerichtet. Da man jedoch für die Armee Winterquartiere und für die Truppen Gratifikationen bedurfte und andererseits diese Winterquartiere der Krone cine Ausgabo von mehreren Millionen Talern ersparen, so habe ich die Vorschlïge immer zurückgewiesen." Ferdinand am 5. Febr. 1760 an Holdernesse. - Knesebeck a. a O. Bd. II, S. 30.

2) Osten-Reden a. a. O. Bd. II, S. 215 f. - Westphalen Bd. IV, S. $496 \mathrm{f}$. Renouard, Bd.II, S. 634. - Schaefer 4. a. O. Bd. II, 2, S. $136 \mathrm{f}$.

3) Huppertz a. a. O. S. 267.

4) Stoffers in Zt. f. vat. Gesch. u. Altert. Bd. 70 Abt. 2, S. 82. 
Brodt gesetzet werden. Das Stift Osnabrück soll zwar nach des Königs von Engelland erfolgten Deklaration freundschaftlich und nicht als die übrigen Stifter behandelt werden", doch müsse es die auferlegte Menge an Mehl und Fourage liefern ${ }^{1}$ ). „Die vier Bistüner sind vollständig ersehöpft und das Herzogtum befindet sich im bejammernswertesten Zustande", mit diesen Worten be. gleitete die Gazette de Cologne an 29. Mai 1761 ihre Meldung aus Regensburg (24.), dort habe der kurkölnische Gesandte deu Reichstag ein Mémoire vorgelegt, das die Notlage des Kurfürsten von Köln und seiner Länder schildere. Ein ähnliches, vor allem allerdings die Stellung Kurkölus zu Frankreich behandelndes Schriftstück fertigte um diese Zeit die kurfurstliche Kanzlei zu Bonin aus ${ }^{2}$ ). Es beginnt mit einer Schilderung der Lage Clemens Augusts. Dann wird um Zusendung der 4 Monatsraten, die auf Grund des Vertrages nach der Höhe von $750000 \mathrm{~L}$. noch rückständig seien, sowie um die monatlich von den Jahressubsidien des Königs zurückgehaltenen $12500 \mathrm{~L}$." gebeten. Inden dann das Sclureiben an die Zuwendung guter Indennisationen beim Friedensschlusse erinnert, fälırt es fort: „Bezïglich dieses Punktes, der mir viel Sorge macht, bitte ich Sic, Monseigueur, den Herren meiner Kapitel and Regierungen eine ostensible Antwort zugehen zu lassen, weil sie abermals diese Zusicherung vou mir fordern". Zu Beginn des Krieges habe er Geld und Kredit gehabt, jet\%t bilde die königliche Unterstiitzung die einzige Quelle $z u$ seinem Unterlialt. "Vor diesem Kriege", so heisst's weiter, nwar ich nach den Kurfürsten von Sachsen, Brandenburg und Hannover der reichste Reichsfürst. Das in meinen Gebieten permanente Kriegstheater hat nich zuletzt dalin gebracht, dass ich nur noch von Könige Hüilfe erwarten kann". Mit der Versicherung, das Land werde sich erst nach fünzig Jahren von seinen Verlusten erbolen, schliesst der Brief. Sein Inhalt gibt ein getreues Spiegelbild der Lage des Kurfursten in der letzten Zeit seines Lebens ${ }^{3}$ ).

1) Westphalen a. a. O. bd. V, S. 269.

2) Der Brief ist weder datiert, noch adressiert, noch unterschrieben. Höchstwahrscheinlich war er an Choiseul gerichtet und sollte von Clemens August unterzeichuet werden, wurde aber im letzten Augenblick, als er in Reinschrift zur Unterschrift und Absendung bereit lag, zurück behalteu. Fase. 2226.

3) Aus Paris hat Clemens August nach dem "Livre rouge" in Spittlers Magazin Bd III, S. 337 im Jahre 1760 nur 500000 L. erhalten. 
Der finanzielle Zusammenbruch war in unmittelbare Nähe gerückt, und nur eine Summe, die er Ende Januar 1761 in Holland aufnelımen konnte ${ }^{1}$ ), beschwor die nächste Gefahr. Nicht lange mebr sollte der Kurfürst unter den Lebenden weilen.

Auf einer Reise nach Munchen zur Taufe eines Kindes der Kronprinzessin von Polen, seiner Nichte, wurde Clemens August am 6. Februar 1761 abends $5 \mathrm{Uhr}$ in Elrenbreitstein vom Tode uberrascht. Er war tags zuvor nachmittags 4 Uhr dort angekommen und hatte sich mit dem Kurfürsten von Trier zu Tisch gesetzt. Bein Nachtisch fühlte er sich unwohl. Die Brust war ihm beklommen, und sein Atem ging schwer. Er legte sich zu Bett und verbrachte eine äusserst unruhige Nacht. Sein Zustand wurde am Morgen des 6. noch bedenklicher, und als man ihm erklärte, es sei Gefahr vorbanden, empfing er die hl. Wegrebrung und Letzte Ölung. Gegen Abend verschied er, nachdem er noch die Anwesenden reichlich beschenkt hatte ${ }^{2}$ ). Ein langjäbriges, organisches Herzleiden batte seinem Leben eir Ziel gesetzt ${ }^{3}$ ).

${ }_{n}$ Malis suorum ingemiscens occubuit ${ }^{\mu}$,

sagt die Inschrift unter dem Bildnis des Kurfürsten iu dem alten Kapitelhause der Stadt Hildesheim ${ }^{4}$ ). Der Tod war für Clemens August wohl eine willkommene Erlösung von unsagbar trostlosen Verbältnissen.

Nur kurze Zeit nach dem Tode des Kurfursten verliess auch der kurkölnische Gesandte zu Paris, Rheen, auf immer seinen Posten. Er war Ende September 1760 noch einmal nach Boum gereist $^{5}$ ) und Anfang November wieder nach Paris ruriickgekelırt. Gleich nach seiner Rückkehr hatte er den heftig zufabrendeu Choiseul mit seinen ungestümen Geldforderungen so gereizt, dass dieser ihm nfurieusement ${ }^{4}$ grollte, zumal er zur Erreichung seiner

1) Ennen a. a. O. Bd. II, S. 351.

2) Gaz. de Cologne vom 13. Febr. 1761; Ehrenbreitstein 8. Febr. " " $" 6 . \quad$ " 1751; Bonn, 5. Febr.

3) Ennen a. a. O. Bd. II, S. 352. - Allg. Dtsche. Biogr. Bd. IV, S. 302 ff.

4) Spruch und Bilduis befanden sich dort auf einer Tafel sämtlicher Bischöfe von Hildesheim. Archiv des hist. Vereins für Niedersachsen; Hannover 1815 , S. 165.

5) An 24. Sept. 1760 erklarte Rheen, der Feldzug sei wieder ergebnislos. Morgen werde er persönlich die einkassierten Gelder überbringeu. Fasc. $222^{6}$. 
Ziele wiederum die Hülfe dritter Personen in Anspruch genommen liatte ${ }^{1}$ ). Dieser Grimm scheint nicht mehr geschwunden $z u$ sein. Nachdem Rheen voch zweimal Geldsummen im Gesamtbetrage ron etwa $150000 \mathrm{~L}$. in der ersten Hälfte des Monats Februar 1761 durch den Bankier Mcinertzhagen nach Bonn hatte übermitteln lassen ${ }^{2}$ ) - Clenens August wird sich des Geldes nicht mehr haben crfreuen können - verliess er wahrschcinlich Ende Februar 1761 Paris. Die Mitteilung des Riiektritts an den König und Choiseul besagte ${ }^{3}$ ), Herr von Rheen bedaure es tief, den Unwillen Choiseuls wachgerufen zu baben. Auch weil dem Gesandten, dessen Gesundlheit stark gelitten habe, die weitere Be schäftigung mit der Politik verleidet sei, habe man seine Abberufung beschlossen. Der Gesandte stehe im Begriffe „den Degen und die Feder mit dem geistlichen Gewand und dem Brevier zu vertanschen". Indem um pünktliche Zusendung der ihm von Ludwig XV. verliehenen Pension, „die gegenwärtig sein einziges Hab und Gut ausmache", gebeten wurde, endigt das für Rheen keineswegs unrühmliche Schriftstiick.

Sollte man über Rhcen und seine Tätigkeit am Pariser Hofe im Dienste Clenens August ein Urteil fällen, so dürfte man dem Gesandten wohl eine ziemlich scharfe Beobachtungsgabe and ein nicht geringes diplomatisches Geschick zusprechen. Wenn seine aufreibende Wirksamkeit nicht nach jeder Richtung bin den von seinem Hern vor allem erwarteten Erfolg hatte, so lag dies nicht

1) Diesmal war es der bayrische Kardinal Johaun Theodor gewesen, der sich in Zwist mit seinem Neffen Max. Joseph damals von München nach Paris begoben hatte und sich dort unter dem Namen cines Comte de Franchimont aufhielt; durch inn hatte Rheen eine unmittelbare Verbindung init Ludwig XV. gesteht. Rheen am 24. April und 20. Nov. 1760 nach Bonı; Fasc. 2:25,6. - Bitterauf a. a. O. S. 165.

2) Rhcen an 8. Febr 1761 nach Bonn; Fasc. 2226. - Die Mit. trilungen Rheens lassen auf eine Gesautsumme in der Höhe von 170740 L. schliessen Nach dem Auszug in Spittlers Magazin Bd III, S. 337 waren es 150000 L. -- Am 29. Jan. 1761 teilte Rheen den Tod des fran\%. Kriegsministers Marschall Belleisle mit, von dem er am 12. Mai 1758 iu ehrenvollem Vergleich gesagt hatte: "dormant aussi peu que le roi de Prusse et travallant de sa tête pour le moins que lui." Fase 2221.

3) Unter dem 16. Mai 1761 von Bom an den König und Choiseul bestimmt. Fase, $222^{6}$. 
Von Kurkölns Beziehungen zu Frankreich u. seiner wirtschaftl. Lage. 115

so sehr an ihm selbst, als vielmehr an seiner undankbaren und von vornherein wenig aussichtsvollen Aufgabe. Er selbst hat damals, als ihm im Jahre 1760 das kurfïrstliche Vertrauen zn schwinden drohte, treffend mit den gegen üble Deuter gerichteten Worten seine Lage gekennzeichnet ${ }^{1}$ ): ${ }_{n}$ tadeln kan jedermänniglich, aber nicht besser tun und dienen. mein Amt ist auf keine weiße zu beneiden bei einem Hofe wo die ministri den Herm spielen, wo die umstände sehr fatal sind und wo ich nur odiose Klagen wider Freunds- und Feindstruppen vormstellen und geldsummen mit Ungestümmigkeit zu sollicitieren habe".

\section{Nene Männer, neue Wege - Schluss.}

Nach dem Tode des Kurfürsten gewannen die Verhältuisse in Köln bald ein anderes Aussehen. Kaum einen Monat später -.- es war an 3. März 1761 - liessen die Franzosen den noch in Bonn stehenden Rest der kurfürstlichen Truppen, soweit sie nicht dem französischen König den Eid der Trene leisten wollten, entwaffnen und wegfuhren. Nur das kurfürstliche Schloss blieb vou Teilen des Leibregiments besetzt; sonst erhielt Bonn französische Besatzung ${ }^{2}$ ).

Von den erledigten Bistiimern erhielt Köln zuerst am 6. April in Maximilian Friedrich von Königsegg eimen neuen Oberhirten. Zuın erstennale seit 177 Jahren war damit der Kölner Kurfiurst

1) Rheen am 3. April 1760 nach Bonu; Fasc. 2225.

2) Spen. Zeity rom 21. Mär» 1761; Bonn, b. März. - Huppertz a. a. O. S. S. 276 - Schaefer a. a. O. Bd. Il, 2; S. 201. - Waddington Bd. IV, S. 310. - Die Stäke rines Teiles der noch in Bonn im Monat Juni 1760 vorhandenen Truppen geben folgende Staudestabellen an (Fisc. 214):

$\begin{array}{lcccc}\quad \text { Regiment } & \text { Bestand } & \text { Marschbereit } & \text { Weiber } & \text { Kinder } \\ \text { Schorlemer } & 287 & 110 & - & - \\ \text { Ludwig Ernst } & 162 & 118 & 37 & 31 \\ \text { Wenge } & 167 & 70 & 93 & 117 \\ \text { Bönnighausen } & 192 & 124 & 26 & 27\end{array}$

Hs fohlen in dieser Uhersicht ein münstersches Infanterie- und zwei münst. Kav-Regg, sowie die wenigen erzstiftischen Soldaten. Trotzden werden es insgesamt kaum urehr als 800 Marschbereite gewesen sein. 
nicht aus dem Hause Wittelshach. Am 16. September des folgenden Jabres wurde Königsegg zur Überraschung Friedrichs II. und Ferdinands auch zum Bischof von Münster gewählt ${ }^{1}$ ), wodurch Säkularisationspläne, die Englands und Preussens Herrscher wälurend des Krieges nie, ganz aus den Auge gelassen latten ${ }^{2}$ ), wieder in weitere Ferne gerückt waren. Zuletzt erhielten Paderborn in Wilhelm Anton von Asseburg an 25. Januar 1763 und Hildesheim in Friedrich Wilhelm von Westphalen am 7. Febr. 1763 nene Oberbirten.

Das Fehlschlagen der Säkularisationspläne hing zusammen mit der gegen Ende des Krieges dureh die zweideutige Politik des neuen englisehen Ministers Bute beginnenden Eutfremdung zwischen Preussen und England. Da Königsegg sich im Gegensatz zu seinem Vorgänger der englischen Politik anschloss, ist sowohl seine Wahl zum Bischof von Münster ohne Rücksichtnahme auf Preussen verständlich, wie anch seine Anfang 1763 an Eng. land gerichtete Bitte, es möclten bis zum Friedensschluss hannoversche Truppen in Münster bleiben ${ }^{3}$ ).

Die westfälischen Bistümer blieben sämtlich bis zum Schluss des Feldzuges auf dem westlichen Kriegsschauplat\% in der Hand Ferdinands. Zwar gewannen dic Franzosen im Herbst 1761 einige Erfolge. Gauz barbarisch hausten sie im Bistum Osnabrück nud bedrohteu von Göttingen und Eimbeck aus Braunsehweig, Ilildesheim und Hannover ${ }^{4}$ ). Ferdinand befahl schon die Festungswerke von Hannover und Hildesheim zu schleifen, um eine Festsetznng der Franzosen in den Städten zu verhindern ${ }^{5}$ ). Am Ende des Jabres war er indessen wieder im unbestrittenen Besit\% der Gebiete und zwang für den Winter den sich heftig sträubenden lewohnern wieder die üblichen Kontributionen auf $\left.{ }^{6}\right)$. Noch ein

1) Westphalen a. a. O. Bd. VI, S. 61, 66. - Faber a. a. O. Neue Folge 5. Teil, S. 227f. -- Pol. Corr. Bd. XXI, Nr. 1368j, 1368 b.

2) Pol. Corr. XIV, Nr 8506, 8590; Bd. XX, Nr. 12735, 12834. - Nit. Papers Bd. I, S. 473; Bd II, S. 33, 35. -. Koser a. a. O. Bd. II, 1; S. 59, $88,167,169,243,334 . \quad 3)$ I'ol. Corr. Bd. XXII Nr. 14369, 14387.

4) Danz-Beiträge Bd XIV, S. 178 . - Schaefer a. a. O. Bd. II, 2, S. $318 f$.

5) Kuesebeck a. a. O. Bd. II, S. 284.

b) Ga\% de Col. vom 22. Dez 1761; Hannover, 10. Dez. " " "29. Jan. 1762; Wien, 20 Jau.

Ferdiuand machte auch jetzt wie in den Jahren zuvor der Bevölkerung viel \%u schaften. Knesebeck a. a. O. Bıl. II, S. 306, 309. 
Kriegsjahr musste die unglïckliche Bevölkerung uber sich ergehen lassen. Endlich wurde am 15. November 1762 des kurz bevorstebenden Friedens wegen auf Grund einer Konvention durch eine von Koesfeld über Dortmund, Marburg und Fulda laufende Demarkationslinie den feindlichen Heeren ein bestimmtes Gebiet zugewiesen ${ }^{1}$. Sehon Ende Dezember - Ferdinand hatte am 23. Dezember seinen Oberbefehl niedergelegt - räumten die meisten der englischen, hannoverschen, braunsehweigischen und hessischen Truppen dic Bistümer.

Diese befanden sich beim Abschlusse des Hubertusburger Friedens am 15. Februar 1763 im Zustande äusserster Erschöpfung und schrecklicbster Verwüstung. Seit den Zeiten des 30jährigen Krieges hatte das Land vicht melır so viel Elend gesehen.

Obwohl die von den Franzosen und besonders von den Alliierten eingetriebenen Naturalien und Geldsunmen allein schou Werte von vielen Millionen Reichstalern ausmachten, so waren die materiellen Verluste der kurköluischen Gebiete während der 6 Kriegsjahre nicht das Schlimmste. Was besagte das alles im Vergleich zu den weit und breit brach liegenden Fluren, der Lahmlegung von Handel und Gewerbe, der Verwüstung von Dörfern und Städten, den Verlusten an Einwohnern nud endlich der ungünstigen Einwirkung auf Sitte und Denkungsart der Bewolner. Auf Jahrzelınte hinaus war das Land geschädigt. Es bedurfte emsigster, ausdanerndster Arbeit, um die Wunden des Krieges zu heilen.

Ob nicht mancher Untertan, wenn auch nur still und verschwiegen, all den erlebten Jammer nit der Person des Landesfiursten in Beyiebung brachte! Man wusste von Clensens August, er war gutmititig und hatte manchmal cine offene Hand; er war aber auch - das Traurigste für ein Volk in schwerer Zeit ungemein vergnägungssüchtig, der Schmeichelei leicht zugänglich, unselbständig und kurzsichtig in der Politik, ein willenloser Bundesgenosse Frankreichs und Österreichs. Finan\%iell an Frankreich gebunden, erscheint bei ihm das in seinem Ursprung bis in den Aufang des 15. Jahrhunderts zuriickgehende Unwesen ${ }^{2}$ ),

1) Westphaten a. a. O. Bd VI, S. 1055f. - Knesebeck a. a.' O. Bd. II, S. 557.

2) v. Bezold, Das Bündnisrecht der deutschen Fürsten. Rektoratsrede, Bonn 1904, S. $13 \mathrm{f}$. 
gegen bestimmte Geldsummen gewisse Verpflichtungen fremden Staaten gegentiber zu ubernebmen, in eigenartiger, ahstossender Waudlung. Obne für die empfangenen Geldbeträge ummittelbar Dienste zu leisten, öffnete er seine Lande den Franzosen und strich, ohne Unterlass fordernd, Geldsummen ein, die in vielfacher Höhe auf Kosten von Hab und Gut, Glück und Leben sciner Untertanen durch die Franzosen wieder eingetrieben wurden. Dic Entschuldigung, Clemens August sei von Frankrcich, das sich zum Beschützer aufwarf, hintergangen worden, ist wenig triftig ${ }^{1}$ ). But die Vergangenheit nicht Beispiele genug, dass die Beschützung der deutschen Fürsten, welche dic Franzosen allenthalbeu zur Schau trugen, nur ein nichtiger Vorwand war. Die Franzosen bielten es "im Gegentheile für unsinnig auch nur einen einzigen Grenadier zи opfern, um den mit ihnen verbündeten deutschcu Fürsten Hülfe zu leisten, selbst wenn die letzteren dies noch so vötig hätten"z). Ebensowenig wird man betonen dürfen, dass eine andere Haltung des Kurfürsten die Schicksale seiner Lande nicht geäıdert hätte. Sie wäre indes auf jeden Fall ehrenhafter gewesen. Wenn er nun aber nach Lage der Verbältnisse einer uiberlegeneren Macht gegenüber Not und Elend von seinen Landeskindern nicht fernbalten konnte, was hatte er zu deren Linderung. getan? War er nachsichtig bei der Zahlung der Abgaben gewesen? Hatte er die eigenen Ansprüche und Bedürfnisse gebührend eingeschränkt? War er in erster Linie für seine Untertanen an fremden Höfen eingetreten? Hatte or in landesväterlicher Neigung mit seinen Untertanen derselben Gefahr mutig ins Auge geschant und dasselbe Los geteilt, wie es Friedrich der Grosse, von allen bewundert, getan hatte? Musste nicht jede dieser Fragen verneint werden? Auch die Kurkölner hatte ein Band umstrickt, „das der Müßiggang und der Eigemnuty in der Hand hielt." Vielleicht war es bekannter, als man heute aminumt, dass nur vor dem Widerspruch der Stände ${ }^{3}$ ), die die ganze Schwerc

1) Hier sei darauf hingewiesen, dass an vielen Stellen vorliegender Arbeit sich aufdrängende Vergleiche mit kreignissen der grossen Gegen wart absichtlich vermieden worden sind.

2) Ferdinand am 29. Scpt. 1759 an Lord Holdernesse. - Ruesebcek a. a. O, Bd. I, S. 462.

3) C. Becker in den Annal $n$ d. hist. Ver.f. d. Niederrh. Heft 92, S $87 \mathrm{f}$. 
Von Kurkölns Beziełıngen zu Frankreich n. seiner wirtschaftl.Lage. 119

des Krieges mit dem Volke trugen, die unablässigen Geldforderungen des Kurfürsten Halt machten.

So wird auch Clemens August dazu beigetragen liaben, dass das Ansehen und die Anffassung von der Stellung and Wiirde des Landesherrn untergraben wurde. Die beiden letzten Kölner Kurfürsten, die für ihr Land besser sorgten, änderten daran kanm etwas. Inmer mebr griff der Gedanke un sich, der, in Frankreich an lebhaftesten, damals allgemein in der Iuft lag: diese Fürsten zehren vom Volk, sie lieben es nicht und geben ihm wenig. Wie in Frankreich so hat auch im westlichen Deutschland der 7 jährige Krieg dazu beigetragen, den Boden zur Auf. nahue der revolutionären Gedanken um ein Bedentendes fruchtbarer wu machen. Und so blickte man auch von hier aus begeistert nach Westen:

${ }_{n}$ Als sich der erste Glauz der neuen Sonne heranbob, Als wan hörte vom Rechte der Menschen, das allen ge. mein sei,

Von der begeisternden Freilıeit und von der löblichen Gleichlueit". 